\title{
TEC-0108
}

\section{A Line-of-Sight Software Reusability Assessment Project}

Robert Atkins

Joni Jarrett

Michael Collins

Gerald Wakefield

August 1999

Approved for public release; distribution is unlimited.

\section{9}

U.S. Army Corps of Engineers

Topographic Engineering Center

7701 Telegraph Road

Alexandria, Virginia 22315-3864

US Army Corps of Engineers

Topographic

Engineering Center
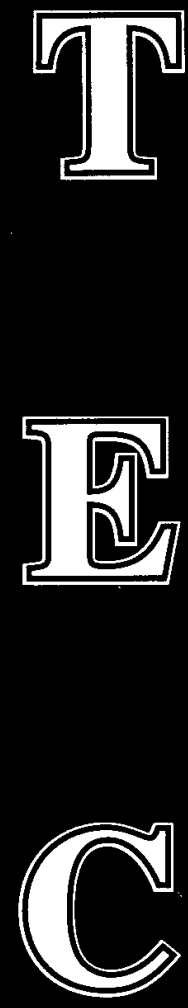
DTIC QUALTIY INGPECTED 4 
Destroy this report when no longer needed.

Do not return it to the originator.

The findings in this report are not to be construed as an official Department of the Army position unless so designated by other authorized documents.

The citation in this report of trade names of commercially available products does not constitute official endorsement or approval of the use of such products. 


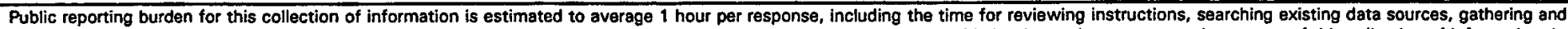

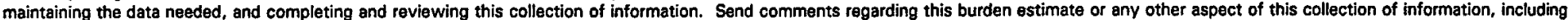

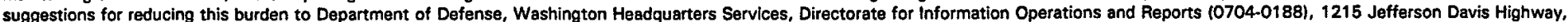

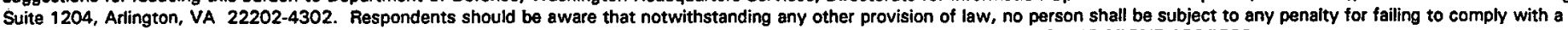
collection of information if it does not display a currently valid OMB control number. PLEASE DO NOT RETURN YOUR FORM TO THE ABOVE ADDRESS.

\begin{tabular}{l|l|l} 
1. REPORT DATE (DD-MM-YYYY) & 2. REPORT TYPE & 3. DATES COVERED (FrOm - TO)
\end{tabular}

\begin{tabular}{l|l} 
August 1999 & Technical
\end{tabular}

\section{TITLE AND SUBTITLE} October 1996 - December 1997

A Line-of-Sight Software Reusability Assessment Project 5a. CONTRACT NUMBER

5b. GRANT NUMBER

5c. PROGRAM ELEMENT NUMBER

6. AUTHOR(S)

5d. PROJECT NUMBER

DA 40162784A855

Robert Atkins, Joni Jarrett, Michael Collins, Gerald Wakefield

5e. TASK NUMBER

7. PERFORMING ORGANIZATION NAME(S) AND ADDRESS(ES)

5f. WORK UNIT NUMBER

A855-GO-802

8. PERFORMING ORGANIZATION REPORT NUMBER

U.S. Army Topographic Engineering Center

7701 Telegraph Road

TEC-0108

Alexandria, VA 22315-3864

9. SPONSORING / MONITORING AGENCY NAME(S) AND ADDRESS(ES)

10. SPONSOR/MONITOR'S ACRONYM(S)

11. SPONSOR/MONITOR'S REPORT NUMBER(S)

\section{DISTRIBUTION/AVAILABILITY STATEMENT}

Approved for public release; distribution is unlimited.

\section{SUPPLEMENTARY NOTES}

\section{ABSTRACT}

The U.S. Army Topographic Engineering Center evaluated the results of a widely used Line-of-Sight (LOS) software model to provide a standard, verified, and validated algorithm for the Mapping, Charting, and Geodesy (MC\&G) community. The LOS software evaluated in this report was derived from a legacy code that was subsequently put through white box testing, black box testing, and entered into the $\mathrm{McCabe}$ software testing tools to manage the codes' efficiency and maintainability. The Digital Elevation Models (DEMs) used to test the algorithm were tightly controlled and the output was statistically compared to existing Commercial-Off-the-Shelf (COTS) LOS routines and field collected LOS profiles. Six different data sites were used to evaluate the results over various terrain types. Each of the data sets

- used in the analysis is fully described by metadata. The result of the evaluation is an Ada version of the LOS model that is usable and transportable. The code has been submitted to the Army Reuse Center (ARC) at a designation of level 4 . Level 4 satisfies the criteria for reliability, testing, and documentation for the ARC. The LOS reusable software component comes with a user/programmer guide and a

- reuse manual that aids in integrating the component into a software system.

\section{SUBJECT TERMS}

High Resolution Elevation Data Software Verification Reuse Software Line-of-Sight Intervisibility Model

\begin{tabular}{|c|c|c|c|c|c|}
\hline \multicolumn{3}{|c|}{$\begin{array}{l}\text { 16. SECURITY CLASSIFICATION OF: } \\
\text { Unclassified }\end{array}$} & \multirow{2}{*}{$\begin{array}{l}\text { 17. LIMITATION } \\
\text { OF ABSTRACT } \\
\text { UNLIMITED }\end{array}$} & \multirow{2}{*}{$\begin{array}{l}\text { 18. NUMBER } \\
\text { OF PAGES } \\
117\end{array}$} & \multirow{2}{*}{$\begin{array}{l}\text { 19a. NAME OF RESPONSIBLE PERSON } \\
\text { Jean Diaz } \\
\text { 19b. TELEPHONE NUMBER (include area } \\
\text { code) } \\
\text { (703) } 428-6022\end{array}$} \\
\hline a. REPORT & $\begin{array}{l}\text { b. ABSTRACT } \\
\text { UNCLASSIFIED }\end{array}$ & UNCLASSIFIED & & & \\
\hline
\end{tabular}




\section{TABLE OF CONTENTS}

\section{TITLE}

PAGE

List of Figures $\ldots \ldots \ldots \ldots \ldots \ldots \ldots \ldots \ldots \ldots \ldots \ldots \ldots \ldots \ldots \ldots \ldots \ldots \ldots$

List of Tables .............................. vi

Preface .................................. vii

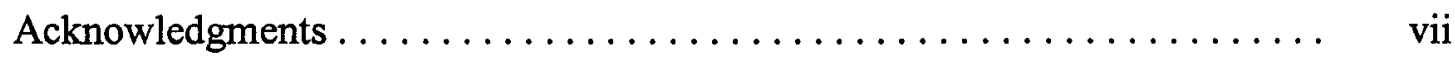

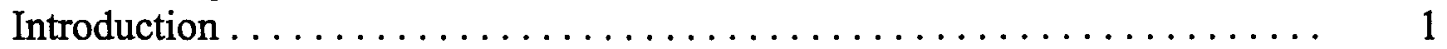

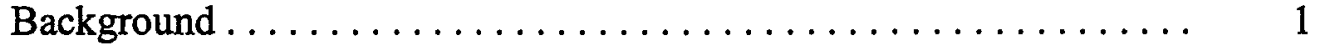

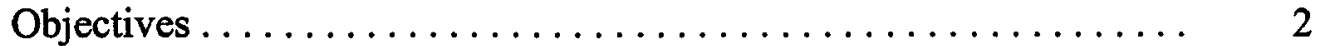

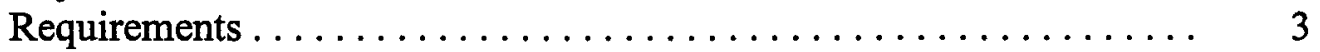

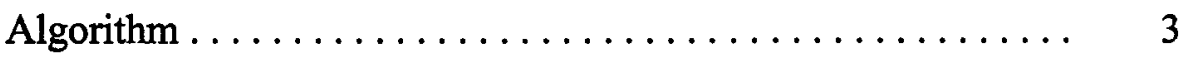

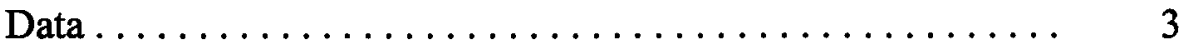

Data Analysis ........................... 4

Documentation ...................... 4

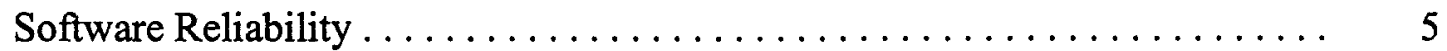

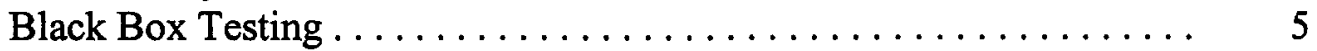

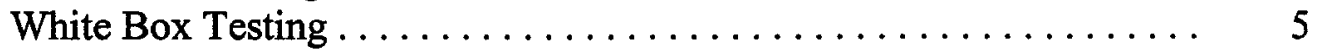

LOS Sources for Error . ............................ 5

Interpolation Methods . ................... 7

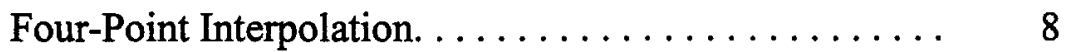

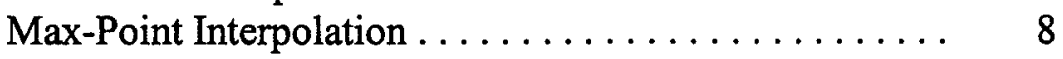

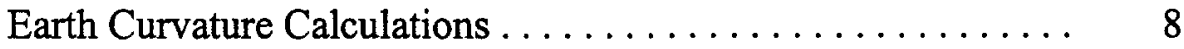

Redundant LOS Sampling . . . . . . . . . . . . . . . . . 13

User-Entered Elevation Value . . . . . . . . . . . . . . . 14

Algorithm Design ........................... 15

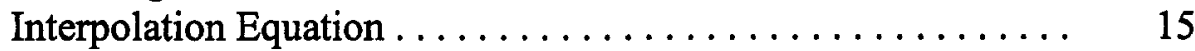

Terrain Profile . . . . . . . . . . . . . . . 16

Translation Errors . . . . . . . . . . . . . . . . . . . 17

Unused Code . . . . . . . . . . . . . . . . . . . . . . . . . . 17

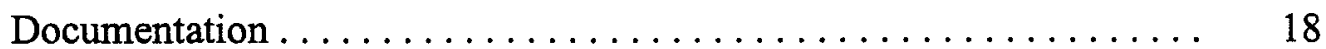

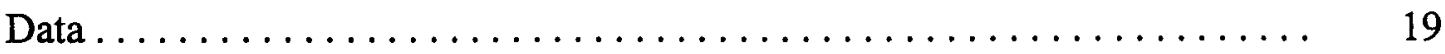

Gridded Data Sets . . . . . . . . . . . . . . . . . . . 19

Field Reference Data . . . . . . . . . . . . . . . . . . . . . . . . 21

Metadata Information . . . . . . . . . . . . . . . . . . . . . 21

Metadata Files and the Master Environmental Library (MEL) . . 22

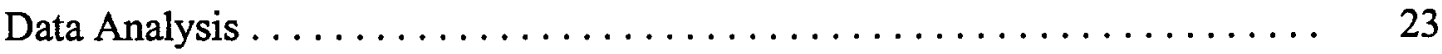

ARC/Info . . . . . . . . . . . . . .

Import Gridded Elevation Data Files and Manipulate and

Resample Excel Field Data Files. . . . . . . . . . . 23

Compare Field Data with Results from LOS

Algorithm/Interpolation Methods . . . . . . . . . . . 24 


\section{TABLE OF CONTENTS}

\section{TITLE}

Statistics

PAGE

Specific Tes

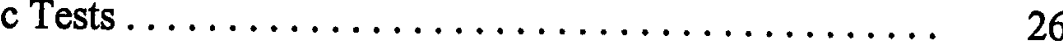

Overall Agreement ................... 27

Phi and Pearson Chi-Square ............... 27

Kappa Test of Reliability ................ 27

Ancillary Parameters ................... 29

$\begin{array}{ll}\text { Sigma-T } \ldots \ldots \ldots \ldots \ldots \ldots \ldots \ldots \ldots \ldots & 29 \\ \text { Total Number of Samples and Transitions ..... } & 30\end{array}$

Statistical Results

Analyzing Algorithm/Interpolation Method and Level of Agreement for Individual Data Sites within a Data

Set and Cumulative for each Data Set ............

Analyzing Algorithm/Interpolation Method and Level of Agreement for Range Band Trends from Site Origin for Data Sites

Analyzing Kappa's Conditional Agreement for

Individual Map Classes

Analyzing Original DTSS Algorithm vs. Revised DTSS

Algorithm using Multiple Resolutions of Data . . . . .

Analyzing Timing vs. Data Density vs. Solution

Recommendations Accuracy...................... 36

39

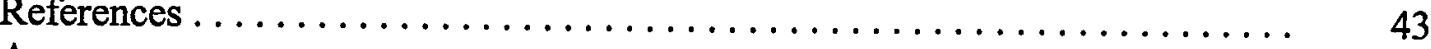

Acronyms . . . . . . . . . . . . . . . . . . . . . . . . . 47

Appendix A - Reuse Methodology for LOS Applications . . . . . . . . . . . 49

Appendix B - Statistical Results for All Locations at 5-m Resolution . . . . . . . 55

Appendix C - Yuma Range Band Analysis . . . . . . . . . . . . . . . 69

Appendix D - Example Metadata Information Yuma DEM . . . . . . . . . . . 81

Appendix E - Example Metadata Information Yuma Fieldwork . . . . . . . . 87

Appendix F - Earth Curvature Error Analysis . . . . . . . . . . . . . . 95

Appendix G - Sample Survey Form. . . . . . . . . . . . . . . . 107 
LIST OF FIGURES

FIGURE TITLE

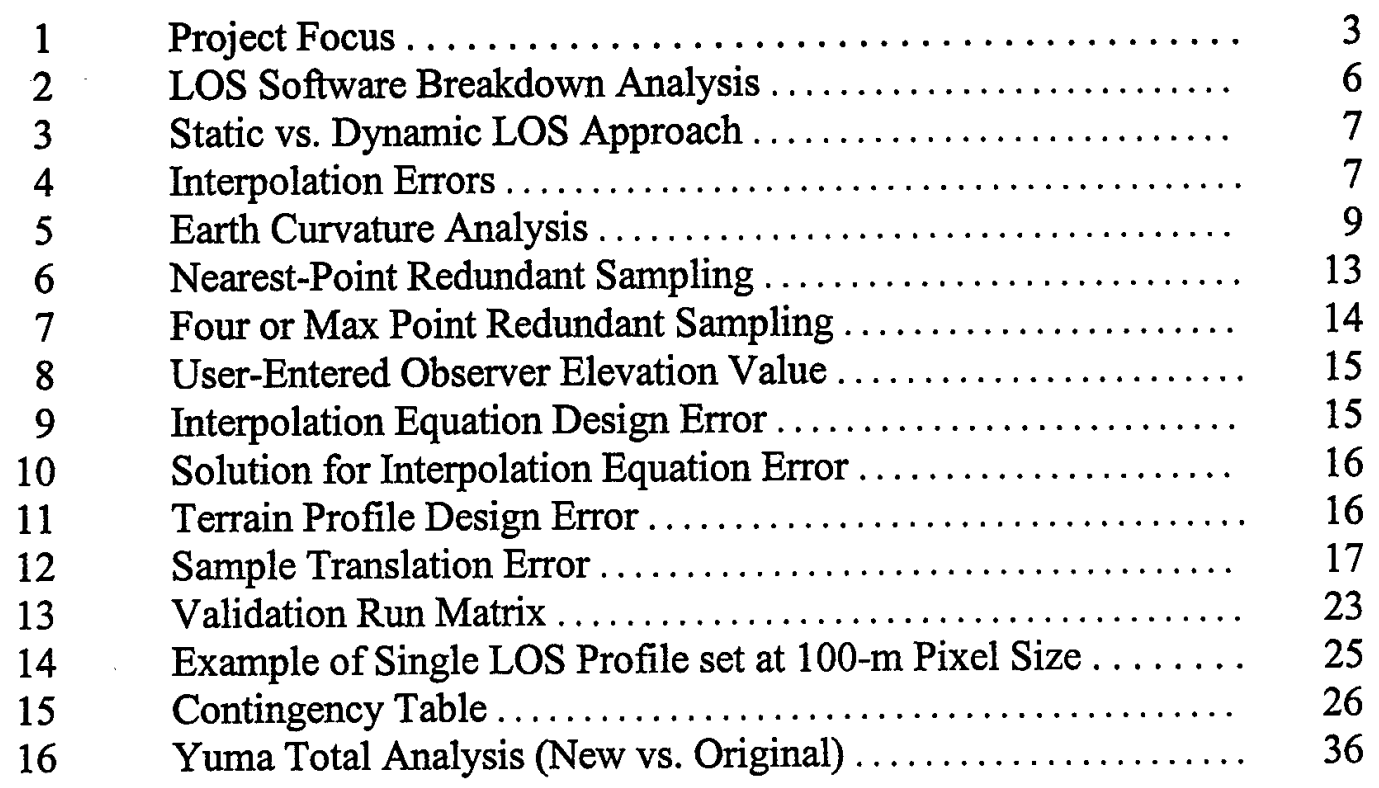

v 


\section{LIST OF TABLES}

\section{TABLE TITLE}

PAGE

$1 \quad$ Percent LOS Savings . . . . . . . . . . . . . . . . . . . . 14

2 . Data Set Sigma-T's ............................... 29

3 Total Samples and Transitions .......................... 30

$4 \quad$ Total Kappa - All Sites - 5-m Results ................ 32

$5 \quad$ Kappa Analysis for All Sites ............................ 34

$6 \quad$ Yuma Site Kappa's ................................ $\quad 35$

$7 \quad$ Kappa vs. Data Density ............................ $\quad 36$

8 Density/Solution Accuracy/Time/Storage Analysis ............ $\quad 37$ 


\section{PREFACE}

This work was done under DA Project 40162784A855, Work Unit A855-GO802, "Software Reuse STO."

The work was performed under the supervision of Messrs. John Hale, Project Leader and Chief, Standards Branch; and Regis Orsinger, Director, Digital Concepts and Analysis Center.

The final production sequence was performed with the help of Messrs. Robert Atkins, Michael Collins, Gery Wakefield, and Ms. Joni Jarrett, Project Team; and Mr. John Hale, Chief, Standards Branch.

Dr. William E. Roper was the Director, and COL Gary Thomas was Commander and Deputy Director of the U.S. Army Topographic Engineering Center at the time of publication of this report.

\section{ACKNOWLEDGMENTS}

The project team would like to thank the following individuals for their support on this project:

U.S. Army Topographic Engineering Center: Ms. Linda Graff, Ms. Jennifer Hansen, Ms. Janice Johnson, Messrs. James Ackeret, Doug Caldwell, Louis Fatale, Chris Gard, Tom Jorgenson, Raye Norvelle, Dan Oimen, Max Roos, Dan Specht, Dan Visone, Joe Watts, Mark Weipert, and Dr. Paul Krause.

U.S. Army TRADOC Analysis Command: Mr. Danny Champion and SSG James Nicholson.

Lockheed Martin (DTSS Contractor): Mr. Alan Spurr.

EarthData Technologies: Mr. Jeff Walker. 


\section{A LINE-OF-SIGHT SOFTWARE REUSABILITY ASSESSMENT PROJECT}

\section{INTRODUCTION}

Background. Today, many basic Mapping, Charting, and Geodesy (MC\&G) algorithms (e.g., Line-of-Sight (LOS) and Mobility) are being incorporated into fielded systems that play key roles in the training of U.S. soldiers. Although a majority of these algorithms have been in use since the 1960's and 1970's, many of them have never gone through a formal testing process. Therein lies the requirement for a program to fill this void to ensure that all $M C \& G$ algorithms used by our soldiers and allies are reliable and are used correctly. The U.S. Army Topographic Engineering Center (TEC) has started such a program to increase the reliability and robustness of several MC\&G algorithms (LOS and Mobility), and to make these algorithms accessible to Army developers.

This is being accomplished through the use of at least two REUSE repositories within the U.S. Army and the Department of Defense (DOD). Within the past few years, the Army established the Army Reuse Center (ARC), in which TEC is the MC\&G domain coordinator. In addition to the Army's effort, DOD has established a Master Environmental Library (MEL) to hold metadata on all DOD environmental data for the modeling and simulation (M\&S) community. These repositories are long-term investments. Algorithms, models, and data that have gone through a rigorous testing and certification process, and have documentation of this process, provide an invaluable resource for the Government. With this greater assurance of reliability, increased productivity can be attained.

The integration of these modules, which have been thoroughly tested and understood, will decrease the likelihood for catastrophic failures of tactical missions. Today, the typical business software package contains approximately 3,000 errors per one million lines of code. The National Aeronautics and Space Administration (NASA), at the time of this report's publication, acknowledges that for every one million lines of code, there are approximately 70 errors; Fujitsu has approximately 10 errors per one million lines of code; and Motorola is expending significant resources to reduce their error rate to 3.4 errors per one million lines of code. It would be wise to take advantage of the efforts of those who develop software with reuse in mind.

Currently there is a need to have many stand-alone topographic MC\&G software products (i.e., importers, exporters, transformers, etc.,) as reusable software packages that could be incorporated into new and existing systems (plug-ins). Private industry is quickly moving into this arena; the Government, as well, should continue to increase its productivity by following the same path. 
This report summarizes the development of a methodology suitable for ensuring the reliability of a fielded LOS package, -- the Digital Topographic Support System's (DTSS) Masked Area LOS Module. This report provides details on the development of this reusable methodology for testing LOS applications. The first section analyzes the specific objectives, requirements, and focus of the project. The second section examines the specific quality assurance tests conducted on the code during the past year. The third section examines the issues of standardizing benchmark data sets, and the different sensitivity analyses conducted. This report also identifies what type and quantity of documentation is required for reusable software components.

This research provides a good framework to conduct quality assurance testing of MC\&G software, and current plans are to continue this work in order to provide more reusable modules to the ARC. It is hoped that the information presented in this report (an after action review) could be used by others performing similar work.

Objectives. The primary goal of this project, from its inception, was to establish a methodology that could be reused by other programs within the agency to further the cause of software REUSE. Though these guidelines would be specific to the testing of LOS applications, they should be easily adaptable for other MC\&G applications. Listed below are some of the major milestones for this project:

- Re-engineer at least one optical LOS module to meet ARC requirements,

- Conduct standard quality assurance procedures on the selected algorithm(s),

- Ensure documentation is produced to meet ARC guidelines for level-4 software certification,

- Establish a database of benchmark data sets to test the current algorithm(s), as well as future MC\&G applications,

- Gather metadata information on all benchmark data,

- Deliver software packages for Sun/Unix and Windows NT/95 platforms to the ARC, and

- Deliver metadata files on all of the benchmark data sets to the MEL.

Since the primary goal of this project is to develop an in-house methodology, the project team focused the effort on a very specific area of the LOS spectrum of models (see Figure 1).

In order to maximize the benefits of this work, the team chose an in-house development program that had a LOS application, the DTSS Masked-Area LOS Module. DTSS is a fielded system that is currently going through a Block 3+ improvement. The Block 3+ improvements, along with the improvements recommended from this project, are contained in the February 1998 release of the software. 


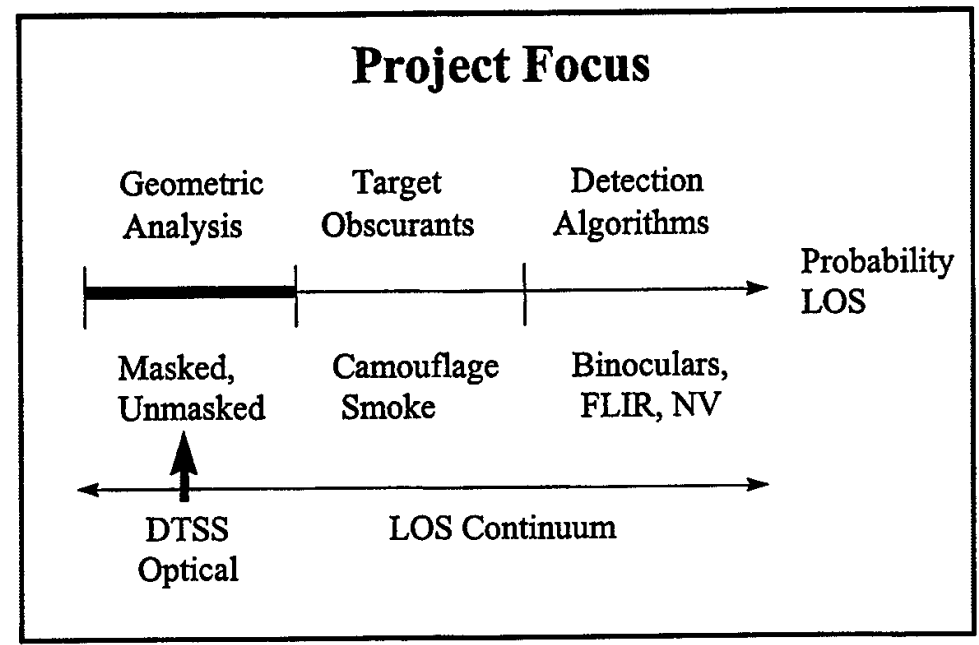

Figure 1. Project Focus

Requirements. Given the above breakdown of objectives, the project focused on several specific areas to meet these requirements. These areas centered on the algorithm (reengineering, verification), the data used to validate the algorithm(s), the types of statistical analyses to be conducted, and most importantly, the documentation of the software package. The following provides more detail on each of these areas:

Algorithm. With the selection of an algorithm integral to a currently fielded system came the task of making the code a stand-alone plug-in module (reengineer) that many users could exploit. Since the fielded system is entirely coded in the Ada programming language, the team's programmer had to become familiar with that language. All Graphical User Interface (GUI) code was removed. Only core LOS modules were maintained. The goal was to deliver a package to the ARC that could be used by many, with GUIs that are unique to the requirements of the system under development. The selection of an Ada compiler was important to ensure that the code also was Ada95 compliant. Formal software verification tools were identified and selected to improve the teams' understanding of the complexity of the code and to identify where the software needed improvement.

Data. Critical to the success of this project was the use of highly reliable data sets in order to conduct the necessary validation tests. This project selected six different areas around the U.S. that had detailed information on the resolution and accuracies associated with the data. During the last 6 years, TEC has generated several high-density digital elevation models (DEMs) over Twentynine Palms, CA; Fort Irwin, CA; Yakima Firing Center, WA; Yuma Proving Grounds, AZ; and Fort Benning, GA; however, just having the DEMs was not enough to allow this project to proceed. LOS Field Survey work also was required over each of these areas. Combining these data sets (DEMs and fieldwork) provided the necessary information to conduct the analysis. To assure this type of work could be repeated, metadata 
conduct the analysis. To assure this type of work could be repeated, metadata information also was compiled on each of these 12 data sets. More detail on these files is provided in Appendices D and $\mathrm{E}$.

Data Analysis. In order to validate the results of the algorithm, specific statistical methods had to be selected to analyze the results. Comparison of the algorithm(s) computed results with the fieldwork provided the necessary data to ascertain the level of agreement between the two results. The closer the results were to 100 percent correlation, the stronger the match to the fieldwork (i.e., real world). Several statistical methods were used, as shown later in this report, and in Appendices B, C, and F.

Documentation. The last major requirement of this project was to ensure that a certain level of documentation was generated to meet the level-4 software certification of the reuse library. A brief description of the 4 levels of software certification is provided below.

- Level 1. The component has been approved for installation based on customer demand. Software accepted as is.

- Level 2. The software satisfies the reusability standards set by the ARC, or the developers own standards, and have been evaluated and approved by the ARC. The software can be compiled at this level.

- Level 3. The software satisfies the criteria for reusability and testing for the ARC, has been tested by the ARC, and comes with test materials that have been evaluated and approved by the ARC.

- Level 4. The software satisfies the criteria for reliability, testing, and documentation for the $\mathrm{ARC}$. The package comes with test materials, Reuse Manual, and User Guide, that aid in the integration of the software into a software system. 


\section{SOFTWARE RELIABILITY}

Much time and effort was spent on this project to ensure software reliability and maintainability was improved over its previous state. The software selected for this project, in use since the late 1970's, had never gone through a formal testing procedure. The software had been translated from Fortran to $\mathrm{C}$, and then to Ada, without any rigorous testing to see if and how the results changed across multiple languages and multiple platforms. In software verification, the question is -- are we building the product right? The following list is a summary of steps taken to verify that the code performed correctly:

- Black Box Testing,

- White Box Testing,

- LOS Sources for Error,

- Algorithm Design,

- Translation Errors,

- Unused Code, and

- Software Documentation.

Black Box Testing. This step in the software verification process looks strictly at the ranges of the input parameters and what error conditions are being checked. In this phase the requirement specification for the software is used to ensure that the software meets the basic requirements of the statement of work; however, since this project did not have this document, testing focused on understanding the inputs and software user requirements. Black Box testing, in conjunction with a thorough code walk-through (White Box Testing), produced simple tests to check for errors in the code. Several errors were identified with this approach and changes were made to the software.

White Box Testing. These verification steps also require a thorough walk-through of the code along with a formal software-testing tool, the $\mathrm{M}^{\mathrm{c}} \mathrm{Cabe}$ Software testing package for Ada. This software identified many areas where the code was unnecessarily complex and where code segments were unused. This software-testing tool was not helpful in identifying flaws in the basic design of the software; therefore, a combination of formal tools and analysis work was required to complete the white box testing. White box testing, with the complete walk-through of the code, allows the evaluators to understand where possible errors in the code might occur. Tests can then be generated to evaluate those conditions. This was a major aspect of the project and is explained in more detail in the following paragraphs.

LOS Sources for Error. The most critical part of the project was to understand where software errors are likely to occur when developing LOS applications, and how to design tests to facilitate the reusability criteria. This project identified several areas within the code that are highly likely to cause errors in the results. In addition, this project identified several sections of the software that although were correctly 
implemented, were incorrectly designed. A list of the areas that are likely to cause errors is provided below:

- Interpolation Methods

Floating Point Precision

Translation Errors

Cut and Paste Errors

- Earth Curvature Calculations

- Redundant LOS Sampling

Design Flaws

- User-Entered Observer Elevation Value

Misunderstanding Errors

The authors' first step in the process of understanding LOS algorithms was to look at how many different ways an optical LOS algorithm could be developed. Figure 2 shows how the LOS process was broken down and depicts the placement of the DTSS Masked Area LOS module and the reusable plug-in module. It is interesting to note that this figure depicts an error in the original design of the DTSS software that was not caught earlier, since the original requirements specification for the software was not available. The DTSS Masked-Area Module was supposed to be able to handle floating-point elevation data; however, when the team received the software, the DTSS package could only handle integer data. Once this observation was noted, the fielded software was changed to handle both floating-point and integer topographic data.

\section{Along Profile}

Static: Constant Step Size

Dynamic: Interpolation at every Grid Intersection

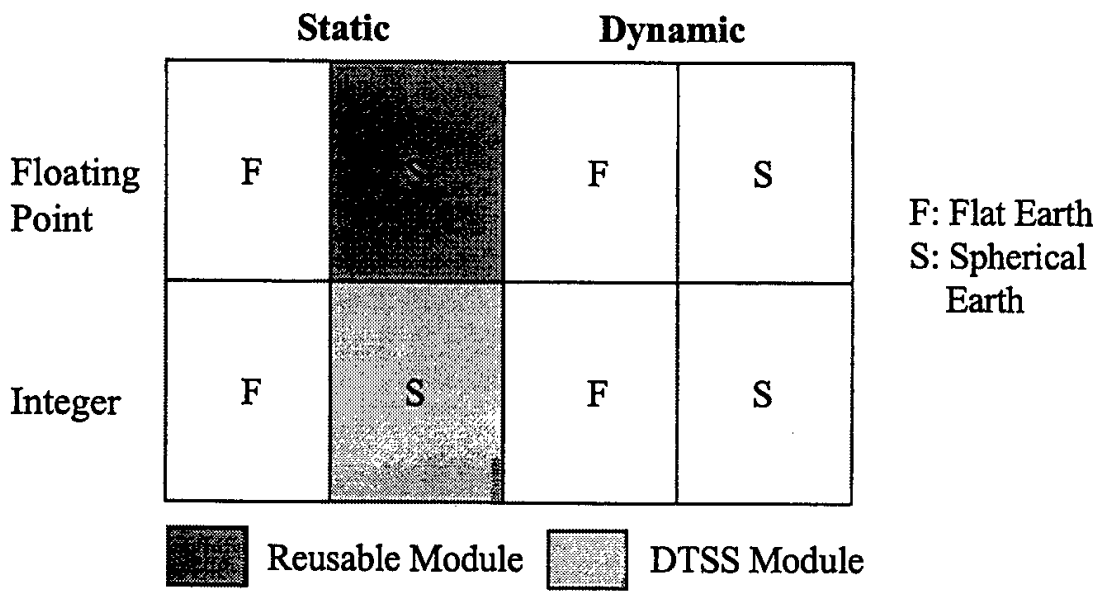

Figure 2. LOS Software Breakdown Analysis

Figure 3 is provided to clarify the difference between a dynamic step along a profile and that of a static step approach. A static approach is used to determine path losses 
and gains along the profile. For quick LOS determinations, a dynamic step approach can be used. The dynamic approach gives a binary solution (once masked, always masked) from observer to target.

\section{Static step size along profile}

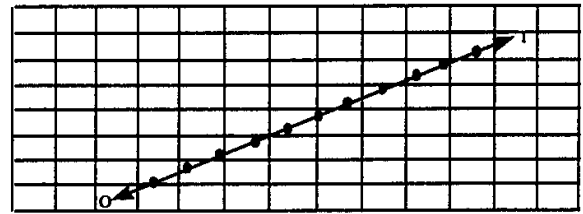

Dynamic step size along profile

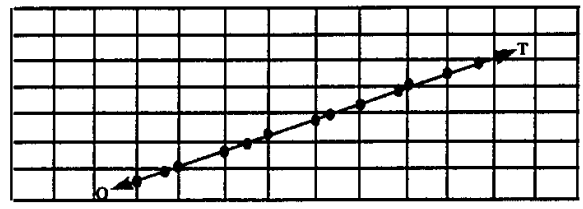

Figure 3. Static vs. Dynamic LOS Approach

Interpolation Methods. The DTSS Masked Area LOS Module allows the user to select one of three different interpolation methods. These methods are 4-point, Max-point, and Nearest-point interpolation. Given that a LOS result can vary greatly depending on the particular interpolation method used, this section of the code was immediately suspect and put under review. Simple tests were designed and Figure 4 shows a synopsis of the errors uncovered.

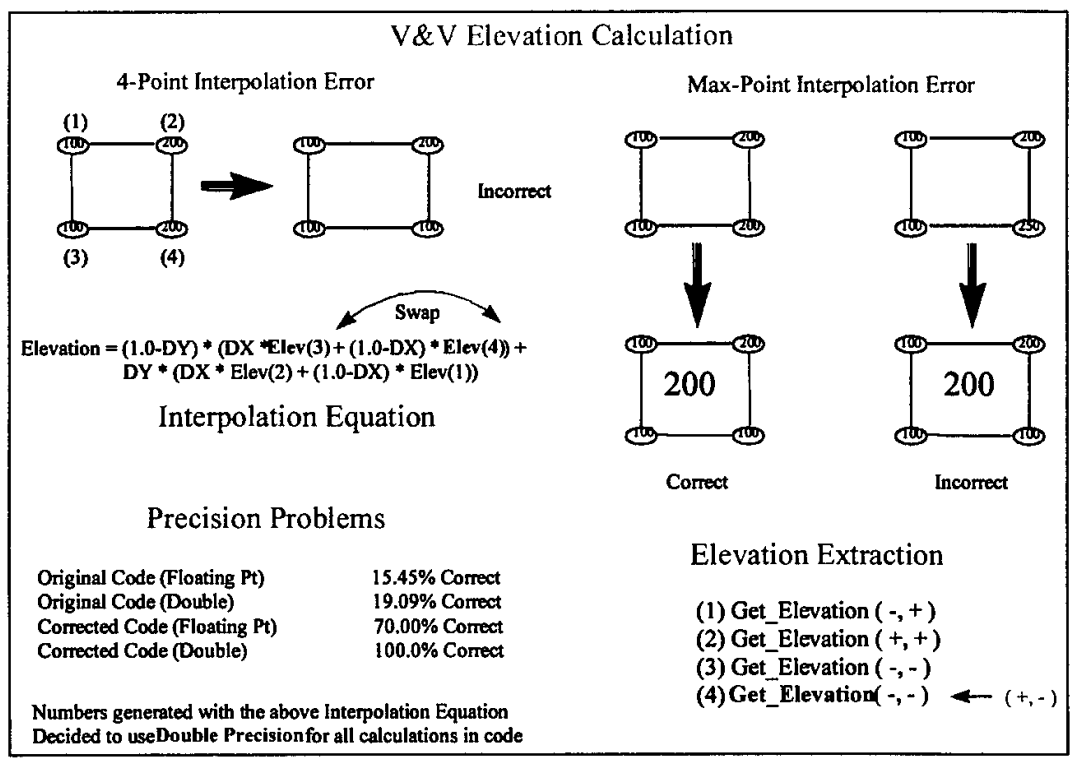

Figure 4. Interpolation Errors 
Of the three methods available, only the method that uses the topologically closest elevation value, the nearest-point interpolation method, produced the correct answer when tested with 4 elevation points. Explanations of the errors that occurred for the 4-point and max-point approaches are provided below.

Four-point Interpolation. In the case of the 4-point approach there was a combination of three errors that produced the wrong answer. These errors were: (1) sampling the southwest corner twice; (2) the elevation values being swapped in the interpolation equation; and (3) the precision of the Institute of Electrical and Electronic Engineers (IEEE) floating-point standard. Each of these errors had to be fixed. The IEEE error could be fixed in one of two ways. First, all floatingpoint numbers could be changed to double precision (the solution used), or second, the magnitude of difference between the numbers in question could be reduced before the floating-point calculation is undertaken. To put things in perspective, the IEEE floating-point error caused errors at the centimeter level in this application. This error could be ignored if it was determined that the error would be contained within the noise of the elevation data being used; however, since three of the six test data sets had accuracies at the decimeter level, the centimeter level errors were considered too large and a solution had to be found.

Max-point Interpolation. In the case of the Max-point approach, only one error caused a wrong answer. As shown in Figure 4, the max point approach sampled twice from the southwest corner, therefore in some cases this redundant sampling will cause errors.

Earth Curvature Calculations. The LOS algorithm used in this study determines the visibility of a target by calculating the elevation angle of the ray from the observer to the target, and compares it to the greatest elevation angle of intermediate terrain obstructions along the profile derived from a DEM. Because most DEMs are orthorectified to some datum, LOS calculations greater than a significant distance should take Earth curvature into account rather than assuming a flat Earth through the study region. This is done by subtracting the amount of vertical Earth curvature for each sample point along a profile from the observer position.

Thorough examination of the software revealed that even though the WGS84 ellipsoid was the defined datum for the input data and resultant products, the Earth curvature elevation compensation was based on a spherical Earth model of unknown origin. The Earth radius constant for the curvature computation is given as $6,371,392.9 \mathrm{~m}$, yet the semi-major axis of the WGS84 ellipsoid is $6,378,137 \mathrm{~m}$, and the semi-minor axis is given as $6,356,752.3 \mathrm{~m}$. Questions arose from this discrepancy, such as: how much does Earth curvature affect LOS calculations?; how was the spherical Earth 
radius derived?; and, what is the magnitude of error introduced by basing Earth curvature compensation on a different datum than that used for the DEM and other LOS spatial inputs?

The easiest (but least accurate) method to compute LOS would be to assume no Earth curvature. This method is commonly referred to as a "flat Earth" model, and may be satisfactory for very local scenarios when accuracy is less of a concern. Generating a flat Earth elevation profile is the digital equivalent to lining up blocks of varying height along a board. LOS would be determined by looking down the line of blocks from the "observer" position and determining which of them were not hidden behind other blocks. Not accounting for Earth curvature can produce a vertical error of about $2 \mathrm{~m}$ over a 5-km elevation profile. This error increases disproportionately as the profile distance increases: $\sim 8 \mathrm{~m}$ at $10 \mathrm{~km}, \sim 20 \mathrm{~m}$ at $16 \mathrm{~km}$, more than $195 \mathrm{~m}$ at $50 \mathrm{~km}$, and more than $780 \mathrm{~m}$ at $100 \mathrm{~km}$.

Because there are significant errors being introduced at distances the LOS model should reasonably encompass, it is necessary to model for Earth curvature. This is done by subtracting the amount of vertical curvature the Earth makes from each elevation point along the LOS profile based on its distance from the observer position. The Pythagorean Theorem is used to calculate the amount of Earth curvature over a given horizontal distance. Solving for the length of the hypotenuse, then subtracting the Earth's radius, $R$, yields the amount of vertical drop due to curvature.

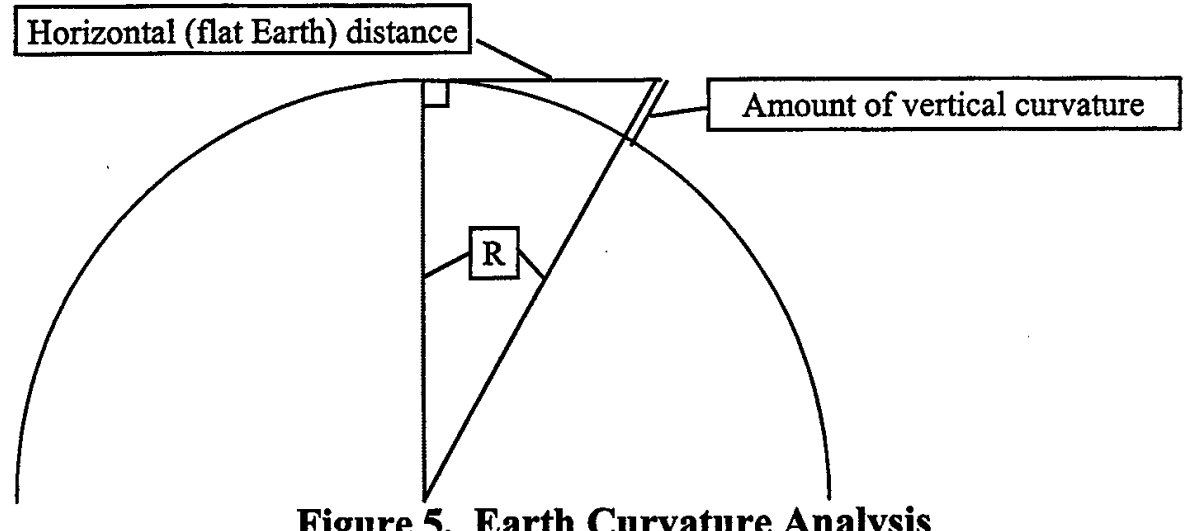

The easiest Earth curvature model to use for this compensation is the "spherical Earth," where a constant Earth radius is assumed. The LOS algorithm used in this effort assumed an Earth radius constant of $6,371,392.9 \mathrm{~m}$.

Historically, the LOS algorithm was derived from legacy software code. No documentation regarding the origin of this radius constant was found. Being expressed to the tenth of a meter implies that it was calculated from related 
values, but how this particular quantity was derived is still a matter of speculation. It is readily apparent that averaging the semi-major and semiminor axes from combinations of familiar geodetic reference data did not produce the constant. It was then hypothesized that the constant represented a spheroid whose surface area or volume equaled that of a known ellipsoidal datum. When the axis values for several geodetic data were applied to the formulae to test this hypothesis, none produced a match for the 6,371,392.9$m$ radius constant. The axis values for WGS 1960, 1966, 1972 and 1984, GRS 1967 and 1980, Clarke 1866 and 1880, the International Ellipsoid, and Bessel's global datum of 1841 , all were considered, yet the derivation of the radius constant remains a mystery.

Despite the radius' unknown origin, it proved itself to be a reasonable approximation of the Earth's surface as compared to the WGS 84 ellipsoid for the purpose of modeling LOS. Test cases were made for various latitudes, profile azimuths, and target distances. The resultant error was relatively small when compared to that of the flat Earth model. The vertical error for the spherical Earth was at most $1.1 \mathrm{~cm}$ at $5 \mathrm{~km}$, between 1 and $4 \mathrm{~cm}$ at $10 \mathrm{~km}$, from 1 to $11 \mathrm{~cm}$ at $16 \mathrm{~km}$, between $9 \mathrm{~cm}$ and $1.11 \mathrm{~m}$ at $50 \mathrm{~km}$, and between $37 \mathrm{~cm}$ and $4.45 \mathrm{~m}$ at $100 \mathrm{~km}$. This represents a 99 percent improvement over flat Earth calculations based on the average error of all test cases.

Having established the importance of Earth curvature computation for LOS modeling, we are left to consider the amount of error introduced by using the spherical model to calculate elevation compensation rather than modeling to the actual datum being used, WGS84 in this case. This becomes a complex problem because a spheroid's radius of curvature is variable depending on latitude and profile azimuth. This research consulted Jordan's Handbook of Geodesy (Jordan-Eggert: Handbuch der Vermessungskunde), Vol. 3 translated into English by Martha Carta, and published by the U.S. Army Map Service in 1962. Citing Euler's theorem, the radius of curvature $(R)$ is computed for a given azimuth ${ }^{*}(\alpha)$ at latitude ${ }^{*}(\varphi)$ as $\frac{1}{R}=\frac{\cos ^{2} \alpha}{M}+\frac{\sin ^{2} \alpha}{N}$ or $R=\frac{N}{1+\varepsilon^{\prime 2} \cos ^{2} \varphi \cos ^{2} \alpha}$ which exploits the radius of curvature in the meridian defined as $M=\frac{a^{2} b^{2}}{\sqrt{\left(a^{2} \cos ^{2} \varphi+b^{2} \sin ^{2} \varphi\right)^{3}}}$, and the radius of curvature in the prime vertical $N=\frac{a}{\sqrt{1-\varepsilon^{2} \sin ^{2} \varphi}}$. The term $\varepsilon^{\prime}$ refers to

1* The angular parameters used for all trigonometric functions used in this effort were expressed in radians. 
ellipsoidal eccentricity to the semi-minor axis and is defined $\varepsilon^{\prime}=\sqrt{\frac{a^{2}-b^{2}}{b^{2}}}$.

By substituting and reducing, a final expression was derived in terms of $a, b$, the semi-major and semi-minor constants of the WGS84 ellipsoid, the look azimuth $\alpha$ and the latitude $\varphi$. This new expression reads

$$
R=\frac{\frac{a}{\sqrt{1-\left(\frac{a^{2}-b^{2}}{a^{2}}\right) \cdot \sin ^{2} \varphi}}}{1+\left(\frac{a^{2}-b^{2}}{b^{2}}\right) \cdot \cos ^{2} \varphi \cos ^{2} \alpha} .
$$

The astute will realize that for all azimuths except those on the equator, each point's latitude along an azimuth will differ from the others. To be absolutely true to the WGS 84, or any other ellipsoidal datum, would require a radius of curvature to be calculated for each sample point along a LOS profile before its Earth curvature compensation value could be computed. For discussion purposes, this method for Earth curvature compensation is identified as "dynamic." It is not hard to imagine the increased computational overhead required to calculate a dynamic compensation as opposed to the simpler fixed radius method where only one value for the radius is used regardless of where the observer is located on the Earth. Thanks to the continual improvements in data processing equipment, the extra computational requirements are less of a concern today than when this algorithm was first introduced.

A realistic look at the problem forces the realization that the amount of change in the radius of curvature is miniscule, even for distances in the hundreds of kilometers, when compared to the Earth's radius for that area. It is reasonable to expect that a single local radius calculation for each azimuth from an observer location would be sufficient for very precise estimations for Earth curvature compensation of an ellipsoid. Sample calculations using only the observer's latitude and the LOS azimuth were performed over the same latitudes, azimuths, and distances as before. The results showed a dramatic improvement over the fixed radius compensation method. Vertical errors that ranged from 0.3 to $4.5 \mathrm{~m}$ introduced by the fixed radius method at a distance of $100 \mathrm{~km}$ are reduced to a range between $4 \mathrm{~mm}$ and $7.1 \mathrm{~cm}$. The largest error produced by the local ellipsoidal radius calculation method at a distance of $10 \mathrm{~km}$ was $0.3 \mathrm{~mm}$, compared to a $4.4 \mathrm{~cm}$ error for the fixed radius method. The average vertical error for the sample points used in this study for a flat Earth representation is $202.09641 \mathrm{~m}$. Using the fixed radius method to compensate for the Earth's curvature produces an average error of $0.57159 \mathrm{~m}$. By calculating a local radius of curvature for the ellipsoidal datum, the average error is reduced to $0.00496 \mathrm{~m}$. This eliminates more than 
99 percent of the vertical error introduced by the spherical Earth elevation compensation method.

The nagging question of computational overhead for this method still looms. A test was derived to calculate a 360 degree sweep of $5-\mathrm{km}$ LOS profiles with a profile interval of 5 degrees, each profile sampled every $100 \mathrm{~m}$. In other words, there were 72 profiles with 50 points sampled along each. Using a $60 \mathrm{MHz}$ Sparc20 with $32 \mathrm{MBytes}$ of memory on the Solaris $2.5 \mathrm{OS}$, $0.000000287 \mathrm{CPU}$ seconds were required for calculations using the "fixed radius" spherical Earth method. The local ellipsoidal compensation method, "new radius for each azimuth and dependent on latitude," required $0.003220632 \mathrm{CPU}$ seconds. From a practical standpoint this number still represents a nearly immeasurable amount of time. Mathematically speaking, though, it takes more than 11,000 times longer than the spherical Earth compensation method. The debate is whether the increased complexity of the calculation is worth eradicating approximately $57 \mathrm{~cm}$ of vertical error on average.

The valid argument against the increased computational complexity is based less on the processing time required, but rather on the accuracy of the reference DEMs available over which to make LOS predictions. The National Imagery and Mapping Agency (NIMA) produced DEMs that have a reported absolute vertical accuracy of $30 \mathrm{~m}$ (at 90 percent linear error). This pushes a $57-\mathrm{cm}$ error close to the noise level in terms of an error budget. The counter argument would be to eliminate as much error as possible in the algorithm in order not to compound errors resident in the data. The issue also is one of error propagation, where a $2-\mathrm{m}$ error at $5 \mathrm{~km}$ can mask an $8-\mathrm{m}$ object at $20 \mathrm{~km}$. From a military perspective there are many interesting and potentially lethal entities that are less than $8 \mathrm{~m}$ in height. Looking toward the future, there are new data collection methods being developed that show promise for the generation of high accuracy and high resolution DEMs. It does not make sense to predict LOS over a high resolution data set whose vertical error is measured in centimeters, when the algorithm will begin introducing a similar measure of error at distances less than $10 \mathrm{~km}$. Because a goal of this project is to provide a documented LOS algorithm for reuse by the DOD MC\&G community, the local ellipsoidal curvature compensation method was implemented.

Without doubt, LOS calculations more than $2,000 \mathrm{~m}$ should not be made without compensating for Earth curvature. As the accuracy of DEMs improve, and the need to model/visualize terrain over even longer distances arises, modeling and simulation developers may have to consider the incorporation of a more rigorous computation for Earth curvature compensation than the spherical model. For current LOS and visualization applications, the errors associated with spherical computations for Earth 
Without doubt, LOS calculations more than 2,000 m should not be made without compensating for Earth curvature. As the accuracy of DEMs improve, and the need to model/visualize terrain over even longer distances arises, modeling and simulation developers may have to consider the incorporation of a more rigorous computation for Earth curvature compensation than the spherical model. For current LOS and visualization applications, the errors associated with spherical computations for Earth curvature compensation, when compared to the inherent vertical errors of available DEMs, are acceptable.

Redundant LOS Sampling. Most LOS routines are extremely expensive in the amount of computation required to do LOS. The DTSS Masked Area Module attempts to reduce the number of LOS calculations by looking at the sample spacing of the data and the angle between adjacent profiles to determine which points nearest the origin not to recalculate. At first glance this seems to be a valid approach in which to reduce the number of calculations and save time; however, this approach only works if you are using a nearest-point interpolation approach. If the user selects either one of the other two methods, then the algorithm must use those first few points along the profile in the LOS calculations. For 4-point interpolation, the elevation values are dependent on the distance away from the other four elevation values and, with max point, one needs to look at all four elevation values to determine which one is the maximum. Figures 6 and 7 show in more detail what happens with this part of the code.

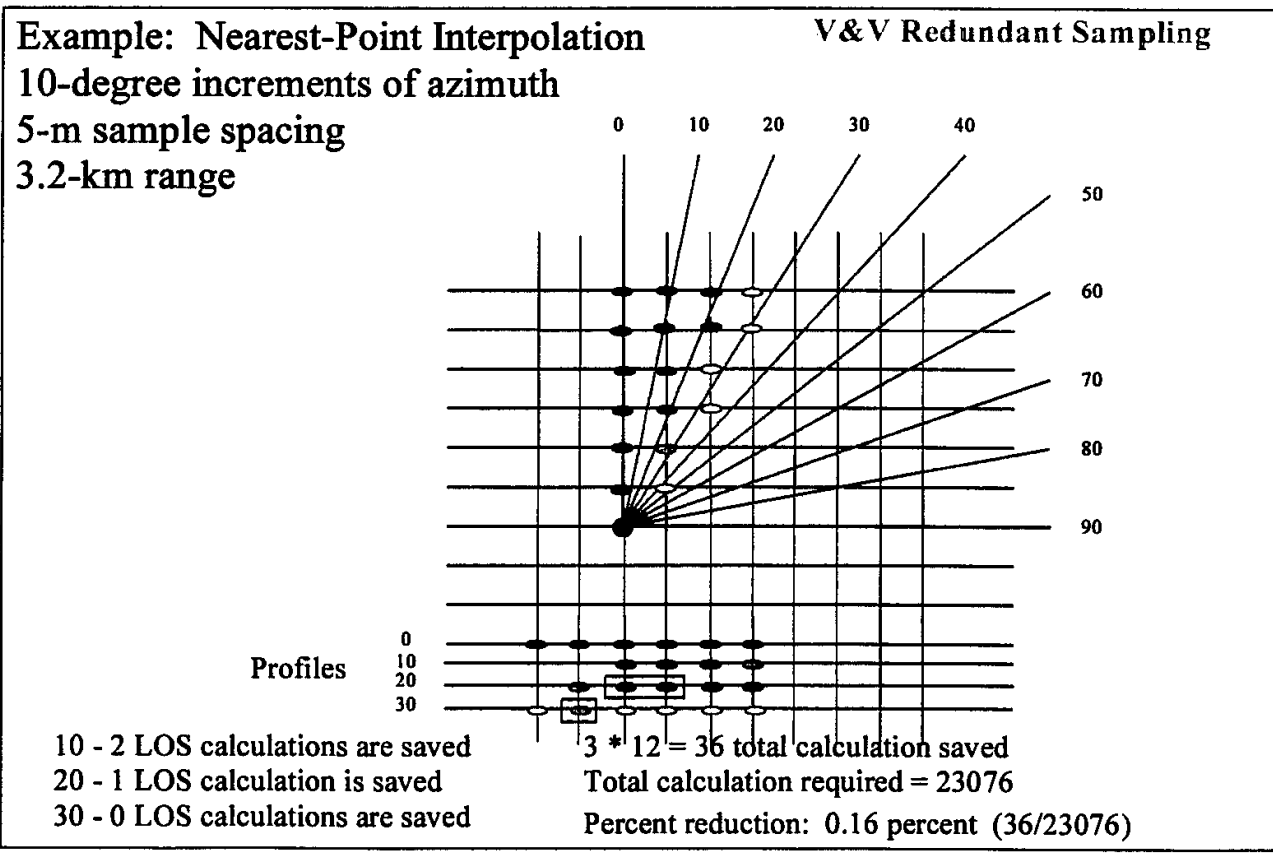

Figure 6. Nearest-point Redundant Sampling 
Table 1. Percent LOS Savings

\begin{tabular}{|c|c|}
\hline Ażimuth Sample & \% Savings \\
\hline Every $5^{\circ}$ & $.39 \%$ \\
\hline $1^{\circ}$ & $2.26 \%$ \\
\hline $.5^{\circ}$ & $4.60 \%$ \\
\hline $.25^{\circ}$ & $10.90 \%$ \\
\hline
\end{tabular}

After determining this section of the code did not work for 4-point and Maxpoint interpolation, and the savings in time were insignificant, this code was removed to simplify and improve software maintenance.

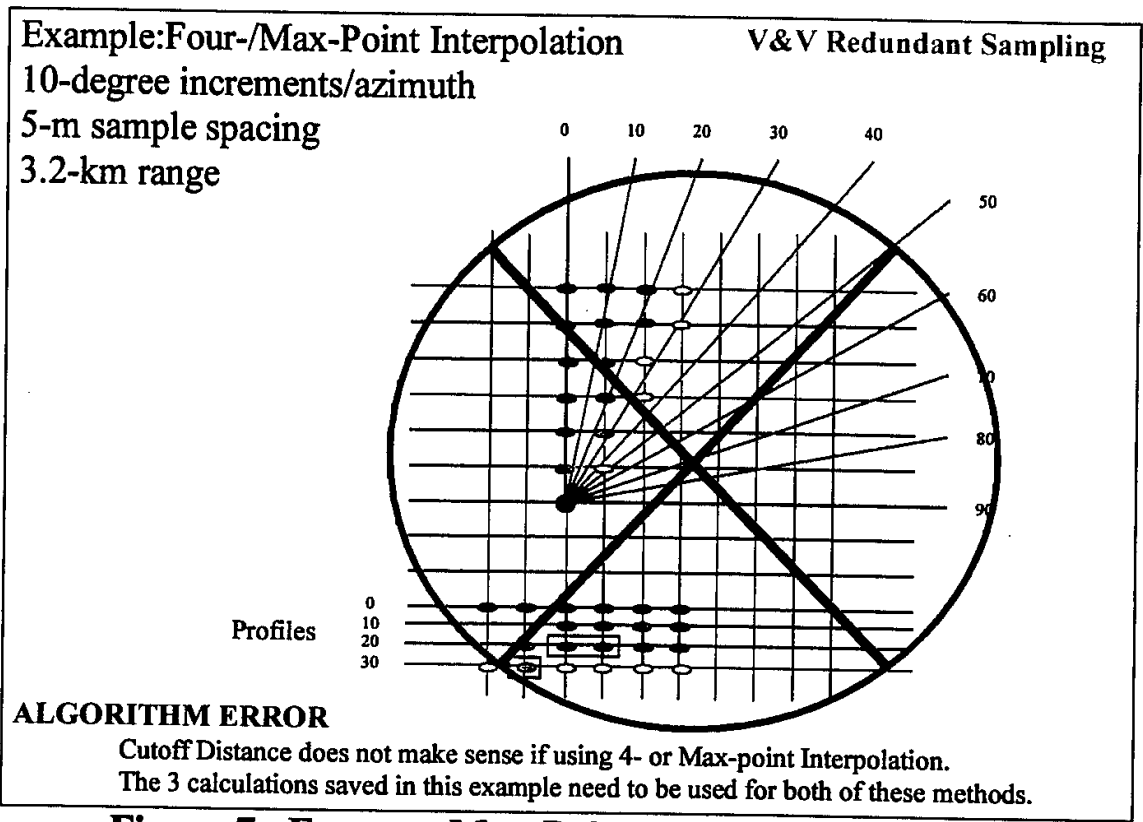

Figure 7. Four- or Max-Point Redundant Sampling

User-Entered Elevation Value. LOS results could be off drastically given a misunderstanding of how to use this aspect of the software. As an example of a misunderstanding that could be looked at as a design flaw, is the capability for the user to enter the elevation value of the observer. This is not an adjustment to the height of the observer above the terrain, but to the actual elevation on which the observer is located. Figure 8 shows the potential error that could happen if the user enters an elevation that is lower or higher than the interpolated value for the point. It is the observation of the authors that the original objective of this part of the code was to allow users to take advantage of locations on maps that depict benchmarked elevation values; however, because the LOS is relative from a site based on the underlying values in the digital elevation data, the forced entry of the benchmarked elevation value may have no relevance to the underlying data and could completely skew the LOS results. 


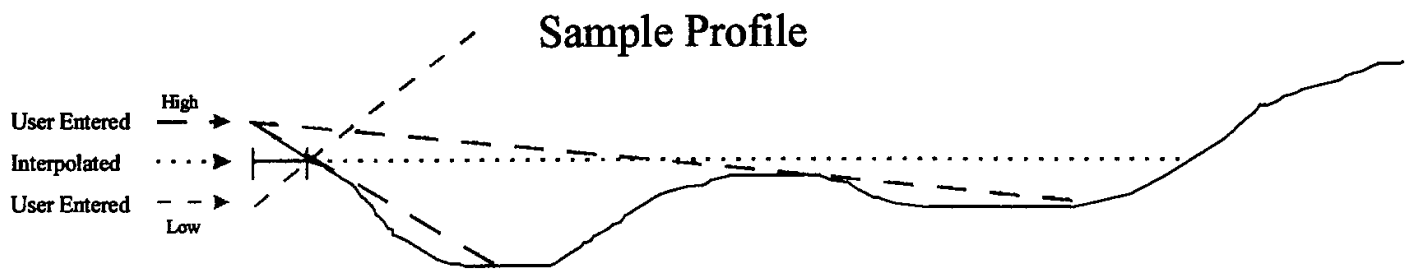

Figure 8. User-Entered Observer Elevation Value

In order to eliminate the chance of an error caused by a misunderstanding of this capability, all segments of code dealing with this issue were removed to improve the reliability of the software.

Algorithm Design. The actual design of the software is something that is hard to test. The software could be completely correct, however, the concept behind the idea may have a flaw. Within this code there are three areas that had to be modified or removed because of this problem. The first one, which was already reported in the Redundant LOS Sampling section, showed a case where the whole concept had to be removed, see Figures 6 and 7. The other two cases are described below.

Interpolation Equation. There are nine possible conditions that have to be accounted for when trying to determine the interpolated elevation of 4 points. This software had one equation attempting to handle all of these conditions; however, during White and Black Box testing of the software it became obvious that this equation could not handle all the cases. Figures 9 and 10 provide a synopsis of the problem and offer several solutions.

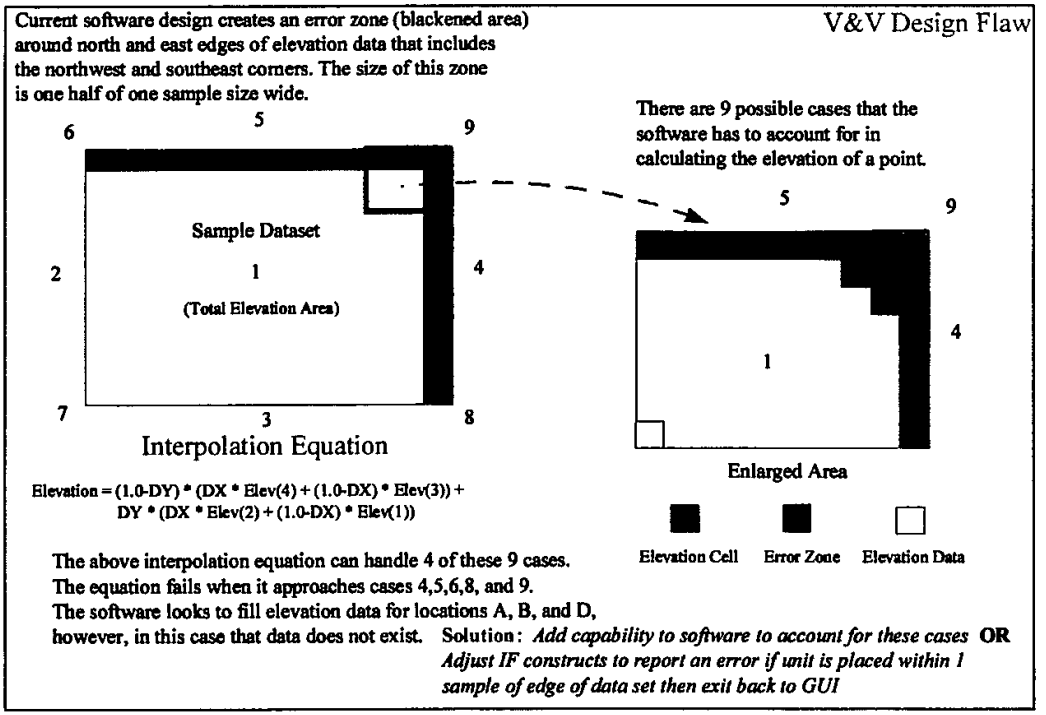

Figure 9. Interpolation Equation Design Error 


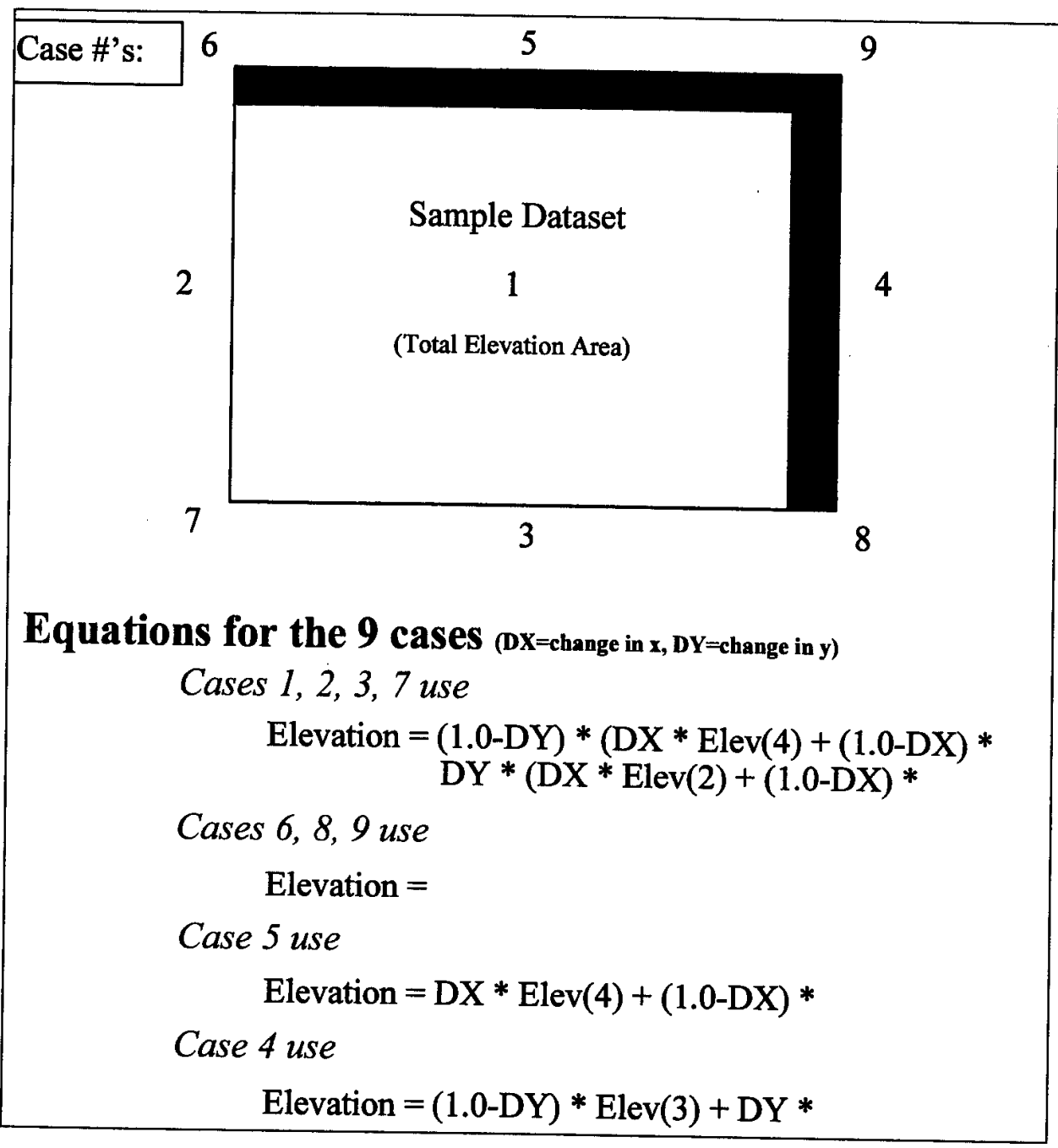

Figure 10. Solution for Interpolation Equation Error

Terrain Profile. In this case the software added two samples to the end of a profile that was already one sample distance past the end of the data. Figure 11 shows how the software is triggered when a null elevation value is read on the profile. The team could never figure out why this was the design but made the necessary changes to reflect the true end of the data along the profile.

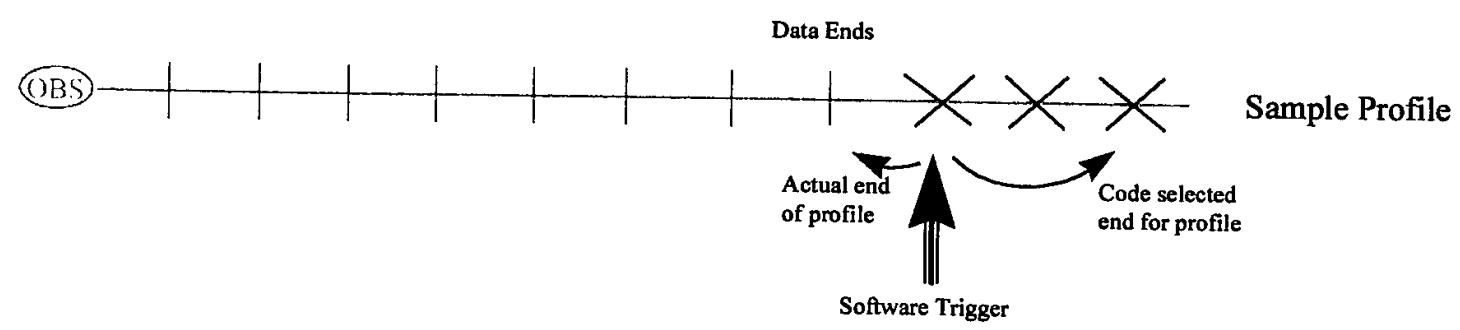

Figure 11. Terrain Profile Design Error 
Translation Errors. This is an obvious area in which errors can appear in software where no errors were before. Each time the code is moved to a different platform or translated from one program language to another, a rigorous set of tests must be conducted to ensure no new errors have emerged in the translation process. It is obvious in a previous example (Figure 4) that this is what happened. Another example that shows the need to have a complete set of tests to run is shown in Figure 12. This error would only be caught if the Easting coordinate of the end point along a terrain profile exceeded the edge of the data. To make the code correct, each of the "Northing" variables needs to be an "Easting" variable.

\section{Module: Get_Radial_Coordinates}

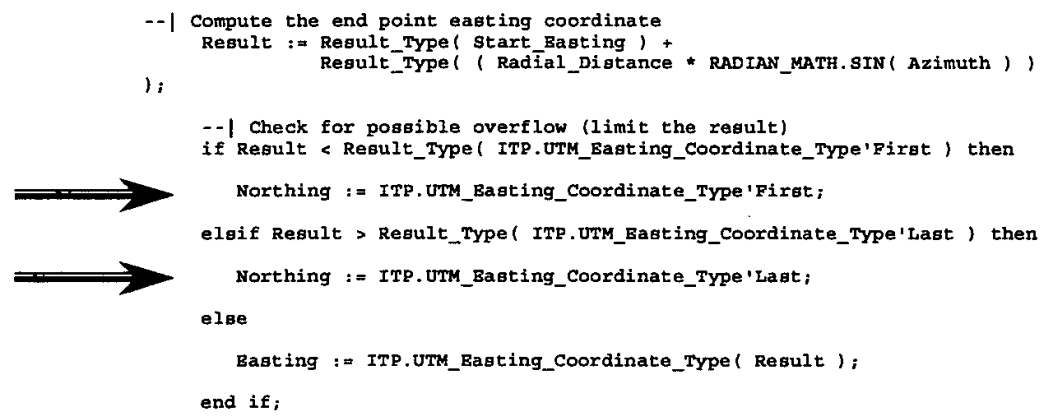

Error: Both Northing calculations change to be Easting Error occurs when Easting coordinate is on edge boundary

\section{Figure 12. Sample Translation Error}

Unused Code: Software code segments and input variables that would not be used in the reusable module along with those never used in the original code were removed. Several different procedures and functions were removed to form the final reusable package. This is a perfect place to use a formal software testing tool. $\mathrm{M}^{\mathrm{c}}$ Cabe provides a quick schematic diagram of the flow of the code and details on the similarity of procedures. With this information, those procedures and functions that were not being used were quickly uncovered. In addition, code segments that display a high similarity could be looked at, and possibly combined, as a way to reduce the complexity of the code. This last check is beneficial when the project is trying to combine the work of many programmers and their modifications over time. 
Documentation: In order for the reusable component to be certified at Level 4, a complete set of documentation is required to assist the user of the reusable component in the integration process. The team put together a Reuser Manual (i.e., Programmers Manual), Test Manual, Users Guide, and Abstract of the software to meet Level 4 requirements. The information contained in these documents is available in both Microsoft Word and WordPerfect formats and will be assembled as part of the complete software package. Test materials also will be supplied to help support the user of this reuse module. Additional test materials (digital elevation data) can be obtained from TEC to help support the development of new LOS software. 


\section{DATA}

This section provides details on the issues that surfaced in the standardization of the benchmark data sets and should be useful to others when attempting to establish the foundation data sets for their study. Many issues associated with MC\&G and surveying information are visited. Appendix $\mathrm{G}$ shows a sample survey form for anyone conducting LOS fieldwork. The information contained on this sheet will prove invaluable when the analysis begins.

Gridded Data Sets. LOS model output accuracy is dependent on several factors. Three of the most important factors are: (1) the accuracy of user entered parameters; (2) the accuracy, precision, and resolution of the terrain data over which LOS is calculated; and (3) the accuracy of the application of the mathematical constructs used in the LOS algorithm itself. Because the major thrust of this study was to measure the accuracy of a LOS algorithm, the blunders of parameter input had to be eliminated and the parameters of the elevation data were tightly controlled.

Additional concerns of this effort were to provide as much reusable and verifiable material as possible to the user community. As such, the research team not only focused on the LOS algorithm, but provided rigorous quality control for the test data sets as well. Elevation data collected over sites coinciding with ground truth, or field verified LOS rays, were used as the test data. Each data set consisted of an array of highly accurate elevation values for fixed horizontal positions at set intervals. This is commonly referred to as a gridded data set. Detailed documentation for these data sets was prepared to facilitate their insertion into the Army's MEL. This is of great value to future researchers who no longer need to expend resources collecting test data, and can instead focus on validating their terrain product(s). As a result, benchmark results over this controlled data can be produced for a standardized comparison between existing and future terrain models.

To ensure statistical compatibility of the results between the data sets, strict data management techniques were employed. Initially, each data set was rigorously researched for collection method, accuracy, resolution, reference coordinate system, and datum. The research team maintained the datums associated with each of the data sets (i.e., World Geodetic System of 1984 (WGS84) and North American Datum -1927) in order not to introduce more error into the data than is associated with the transformation process. All spatial positions are referenced in the Universal Transverse Mercator (UTM) projected coordinate system.

A total of six gridded elevation data sets were collected and managed for this research. In addition to the various collection techniques, it also was important to have elevation data representing diverse surface configurations. Data sets were used from Twentynine Palms, CA, Fort Benning, GA, Yakima Firing Center, WA, Yuma Proving Ground, AZ, and two from the National Training Center (NTC) at Fort Irwin, CA. Precision of the elevation values for Yakima and NTC East is to the nearest whole meter. Twentynine Palms, Fort Benning, and NTC West elevations are 
reported to the nearest tenth meter while Yuma elevation values were rounded to the nearest hundredth of a meter.

The resolution of each data set is determined by the size of the fixed interval between each elevation post. These data sets were collected in two resolutions: 1 - or 5-m post spacing. Because collection methods for producing higher resolution data sets are generally more expensive, they also are generally better controlled. One would expect higher resolution data sets to be more accurate and that is indeed the case for these six. The Fort Benning and Twentynine Palms data sets have a horizontal resolution of $1 \mathrm{~m}$ and their vertical accuracy is calculated in the sub-meter range. The remaining data sets have a $5-\mathrm{m}$ horizontal resolution with the vertical accuracy reported right at $1 \mathrm{~m}$.

In order to statistically measure the accuracy of the output from the LOS algorithm, several "truth" LOS rays were required. Hundreds of rays were collected and documented for studies designed to determine DEM quality and Army DEM resolution requirements. Many of the rays that were coincident with the highresolution data sets were used to check the quality of the reuse LOS output. The field methodology used for collecting each ray consisted of positioning a Total Station survey instrument on a known point at a fixed azimuth and recording the points along the azimuth where a target transitioned from visible to masked, or viceversa. Multiple profiles could be collected from each site by adjusting the survey instrument to observe along a new azimuth. The number of fixed sites and groundtruth profiles used for this study can be summed up as follows:

\begin{tabular}{lcc} 
Area & Total \# Sites & Total \# Profiles \\
\hline & & \\
Yuma & 5 & 59 \\
Yakima & 5 & 36 \\
Twentynine Palms & 3 & 29 \\
Irwin E & 5 & 34 \\
Irwin W & 4 & 32 \\
Benning & 5 & 35 \\
& --- & --- \\
Total & 27 & 225
\end{tabular}

Site positions were calculated using the Global Positioning System (GPS) differential method, which provides first order survey accuracy. The transition points also were collected at first order accuracy by using the Total Station and an integrated Electronic Distance Measurement (EDM) device. The EDM determines the orthogonal distance by compensating the straight-line measurement with the elevation angle between the survey instrument and the target. Positional accuracy for points along these profiles was calculated to be $5 \mathrm{~m}$ for Yuma, Yakima, and NTC-east, and $1 \mathrm{~m}$ for Twentynine Palms, Fort Benning, and NTC-west. 
Field Reference Data: The survey information for each profile was entered into a series of Microsoft Excel (version 7.0) spreadsheets. This facilitated the verification of profile data completeness and accuracy, while providing a streamlined and uniform method for converting the range information that defined each transition point into coordinate data. This was accomplished through the application of trigonometric formulae to the site coordinate, profile azimuth, and orthogonal distance to each transition point. The standard datum and coordinate system for the project was maintained in the field data, making statistical comparisons with LOS results more reliable. The spreadsheet format also allowed the resultant coordinate information to be imported into ESRI's ARC/Info for additional processing. ARC/Info and custom AMLs made it possible to geographically compare ground truth visibility results to $L O S$ algorithm results superimposed on shaded relief plots of the data. This provided the opportunity to visually verify and graphically compare the results.

There were some concerns regarding inherent error within the field data. Some sites were established using on-the-fly (OTF) GPS positioning. Although not nearly as precise as a static differential survey based on established geodetic control, the OTF technique still produces results with accuracy measured in the decimeter range. For some collections, the field data collection forms contained ambiguous information. Sometimes the data could be reconciled through reference to the researcher's field notes; however, when reconciliation could not be established, the profile in question was removed from consideration. In some instances, the field collection team had access to hand-held PLGR GPS receivers. The field team attempted to use these to generate coordinate positions for the transition points as redundant data points for their total station/EDM measurements. The PLGR's accuracy is reported at $+/-10 \mathrm{~m}$, but studies show that this value is more likely $+/-4$ $\mathrm{m}$. This level of accuracy was still inadequate to meet the project requirement of a sub-meter accuracy determination. Coordinate information for the project was derived by basic trigonometric functions. The EDM's accuracy does have limitations of its own. Environmental effects can reduce its usable and reliable range, however these ranges were not exceeded in profiles used for this study.

Metadata Information: During this project, 12 metadata files were generated. Each of the six data sets had two metadata files - one describing the high-resolution digital elevation data file and the other describing the field collected loss/gain Excel format data file. These metadata files provide descriptive information that allows potential users to examine the background and quality of the data in order to judge its applicability for their use.

The metadata files created are based on the Federal Geographic Data Committee (FGDC) Content Standards from June 1994. "The objectives of the standard are to provide a common set of terminology and definitions for the documentation of digital geospatial data." (FGDC 1994.) Using the metadata files, potential users can 
identify the procedures needed to acquire the data from TEC and process the information once it is received.

Metadata files contain fields for information ranging from data set identification, data quality, spatial data organization, and spatial reference system. To provide the best description of each of the data sets used during this project, information from numerous sources was researched and compiled. Because the data sets had been collected several years previously, people involved in the data generation had to revisit notes and assorted materials to recover the information that the metadata files require. After experiencing the difficulty of reconstructing data information after a few years have passed, it is strongly recommended that any information about a data file be described in a metadata file at the time of data creation. Appendices $\mathrm{D}$ and $\mathrm{E}$ provide a sample for the DEM and the Fieldwork.

Metadata Files and the Master Environmental Library (MEL). The MEL is a Defense Modeling and Simulation Office (DMSO)-sponsored distributed environmental data access system that allows users to retrieve metadata information based on user-selected search criteria. With the single point of access and data nodes for terrain, ocean, and air and space, the MEL serves as a central repository for all DOD environmental data. Additional information on the MEL can be located at the following web site:

\section{http://www-mel.nrlmry.navy.mil}

Before metadata files can be placed on the MEL site they must be validated for content and format. Many of the fields in the 'Content Standards for Digital Geospatial Metadata' are required and must be completed for the file to be accepted by the MEL validation software. Several metadata creation software packages exist including ARC/Info's DOCUMENT tool, National Biological Survey's Metamaker, and the Corps of Engineers CORPSMET. Metamaker can be accessed from the NBS site at:

http://www.emtc.nbs.gov/http_data/emtc_spatial/applications/nbiimker.html

CORPSMET can be accessed from TEC's web site at (software link):

http://www.tec.army.mil/TD/precise.html

To provide information to potential users on the high-value data sets generated for this project, the metadata files will be available on TEC's MEL Terrain Node. Based on the relevancy of the metadata information to the users needs, the user can choose to contact a TEC POC and request the applicable data file(s). 


\section{DATA ANALYSIS}

This section of the report will focus on how the data were analyzed in order to validate the results of the LOS algorithm. The following run matrix, Figure 13, was used to generate the necessary data to support the validation part of the project.

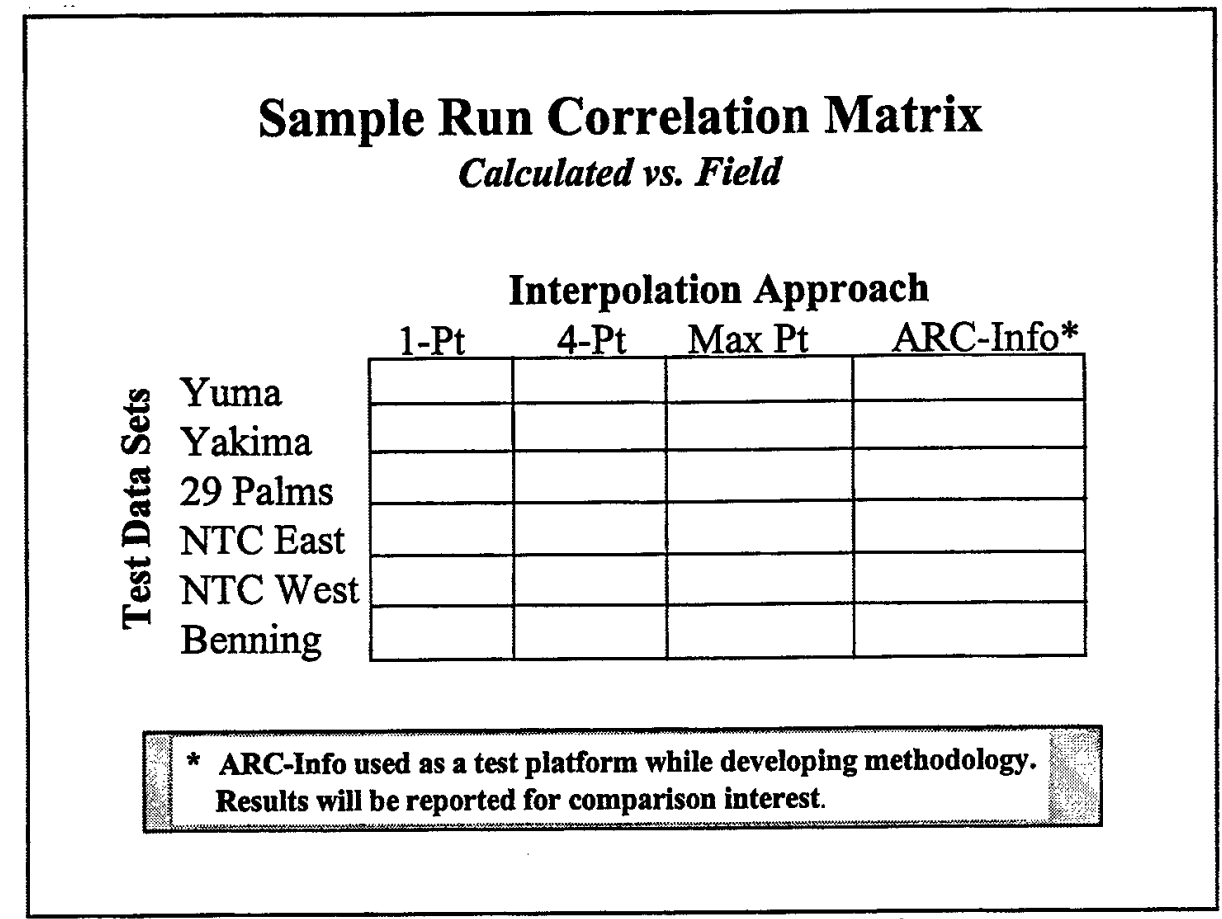

Figure 13. Validation Run Matrix

ARC/Info. The ARC/Info software package was selected to speed up the analysis of the project. With this selection, several ARC Macro Language (AML) scripts were developed to automate the analysis. Each AML is explained in more detail in the following paragraphs.

\section{Import-Gridded Elevation Data Files and Manipulate and Resample}

Excel Field Data Files. An AML was used to import elevation data into an ARC/Info grid. The elevation grid was used by the main processing AML that operated on the field collected line-of-sight segments and identified the visible and masked areas along each profile. Each LOS profile collected was saved into a single file consisting of a line segment identifier followed by the beginning-point coordinates and end-point coordinates of the line segment. 
For example, if a 3,200-m profile had two points of transition from visible to masked, then the file would be as follows:

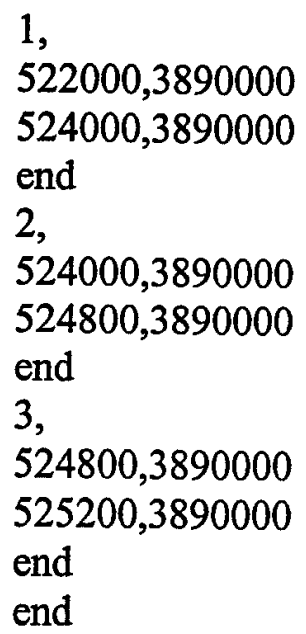

This format is readable by ARC/Info's GENERATE module, which produces a line coverage, consisting of a single line with three line segments. The AML then attributes the line, assigning a value of one for visible, to all odd-numbered segments, and zero for masked, to all even-numbered segments. This assumes that the first segment, the segment closest to the origin point, is visible. The attribute table for the resultant line coverage contains the following relevant attributes: a record number representing each line segment, the length of the line segment in meters, and the "in-view" attribute-1 indicating visible, 0 masked.

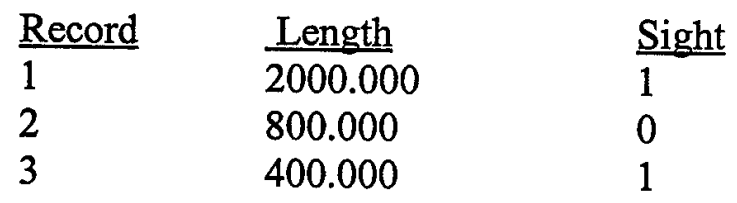

The AML then invokes several system calls that reformat the above GENERATE file into a single point file, which uses the first point of the first profile for each starting point (e.g., 522000, 3890000). This is the origin point for all rays extending from a single starting point. In addition, an origin point and an end point for each individual profile also are produced (e.g., 522000,3890000 and 525200,3890000), thus, producing a single line with no intermediate segments.

\section{Compare Field Data with Results from the LOS Algorithm/}

Interpolation Methods. The origin point (Figure 14) is used to create the $\mathrm{ARC} /$ Info derived visibility model. This point is attributed with the target height and observer height. The digital elevation grid is then used to construct all cells visible and is masked from the observer's location. The unsegmented line coverage is then converted into sampling points (Figure 
14). If the cell size of the elevation grid was $5 \mathrm{~m}$, then the line coverage is densified into 5-m segments and converted into a point coverage. This point coverage is then used in all sampling routines for that profile.

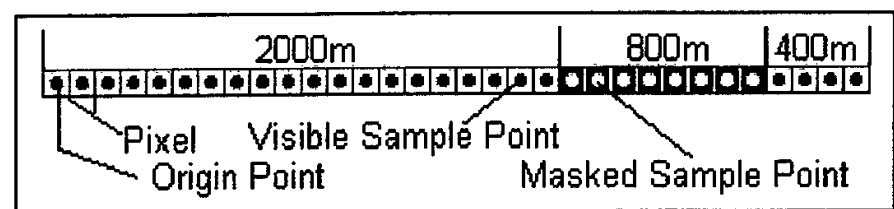

Figure 14. Example of single LOS profile set at 100-m pixel size

Once the ARC/Info visibility model and the sampling point coverages are created, the field data and the visibility model were sampled. The original line file was converted into an ARC/Info grid, the cells being populated with the value of the line segment attribute; thus, the pixels from the visible line segments are assigned the value of one, and masked segments the value of zero. The gridded line is then sampled using the sampling point coverage (Figure 14). The sampling procedure creates an ASCII file containing the $x$ and $y$ coordinates of each sampled point, the elevation of the point, and the value of the point, which is either a 1 or a 0 .

The sampling points also are used to extract the same information from the DTSS-revised algorithm results. Again, an ASCII file is created of the $x$ and $y$ coordinates, the elevation value, and the value of that point ( 0 or 1$)$.

Statistics. Using statistical reference books, software packages, and numerous journal articles, a number of statistical techniques were examined in order to identify the best technique to use to compare the visibility results generated from the algorithm versus the visibility that was recorded in the field. Discrete data, also known as nominal data, are data that fall into a particular category. In this case, the categories are 'visible' and 'masked,' or 'gain' and 'loss,' respectively, to identify whether the segment along the profile can be seen from the observer's location.

Discrete multivariate analysis techniques were chosen because the data are categorical and multinomially distributed. These techniques are useful in testing the agreement between matrices. Arranging the data into a matrix provides the following: 
Field Collected "Reference Data"

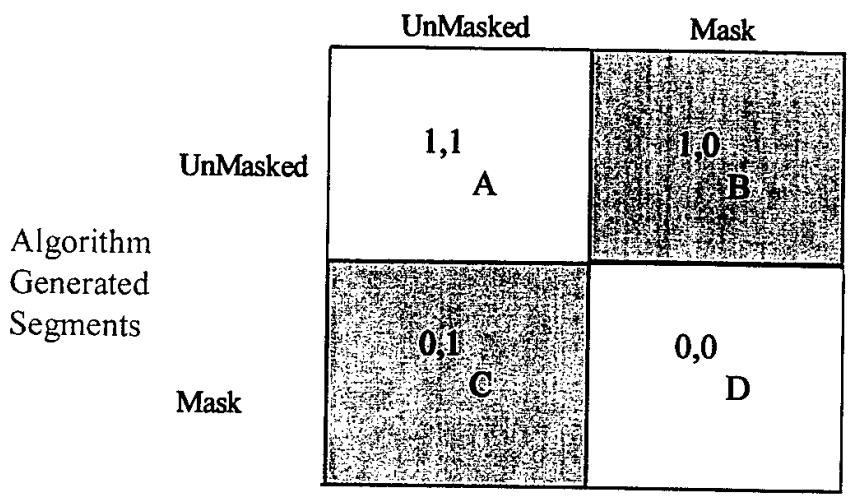

Figure 15. Contingency Table

As each gain (i.e., unmasked) or loss (i.e., masked) point along the profile is calculated using one of the four algorithm and/or interpolation methods, the result is compared, at the corresponding position, to the visibility documented along the field collected segment. The field collected visibility segments are assumed to be correct and are referred to as the reference data. Visible (i.e., unmasked) segments are coded "1's" and masked segments are coded ' 0 's." The ' $A$ ', 'B', 'C', and ' $D$ ' in the lower right of each quadrant of the matrix are used later in this report to describe the equations for each of the statistical tests used.

This matrix of possible outcomes between the field collected reference data and the algorithm generated visibility data are known as a contingency table, an error matrix, or a confusion matrix as depicted in Figure 15.

Specific Tests. Three statistical techniques were used to describe the results of the data comparisons:

- Overall Agreement

- Phi

- Kappa

Overall Agreement, Phi, and ancillary data parameters (e.g., Sigma-T) were chosen to perform calculations similar to those used in the Army Model Improvement Program (AMIP) studies $(6,7)$ that involved some of the same data sets, specifically Yakima, Ft. Irwin, and Twentynine Palms. Kappa was chosen as the preferred statistical test to rate the level of agreement between the field collected data and the algorithm/interpolation method generated values. 
Overall Agreement. The overall agreement is a widely used and easily computed matrix statistic. "Because the values on the major diagonal represent those pixels that have been correctly classified, these values are summed up and divided by the total number of pixels classified. This number is then the overall performance accuracy of an error matrix, and is the most common use of the error matrix in accuracy assessment." (Congalton, Oderwald, and Mead 1983.)

The equation:

$$
\begin{aligned}
& \text { Overall_Agreement }=\frac{(A+D)}{N} \\
& \mathrm{~N}=\mathrm{A}+\mathrm{B}+\mathrm{C}+\mathrm{D} \text { for total number of cells }
\end{aligned}
$$

The disadvantage of this technique is its inability to consider chance agreement or errors of commission and omission that will be discussed later when describing the Kappa test.

Phi \& Pearson Chi-Square. Phi, a test for independence (i.e., nonassociation) between two data sets, was chosen because it was used in a previous analysis of line-of-sight algorithms described in the 1995 TRAC/TEC studies $(6,7)$. As with Kappa, the range also is restricted from 0 to 1 . Phi was chosen instead of the Pearson Chi-Square test statistic because the value of chi-square is proportional to sample size. Since Phi is a measure of Chi-Square, independent of sample size, it allows the values generated by the multitude of contingency tables analyzed in this project to be compared.

The equation:

$$
P h i=\frac{(A D-B C)}{\sqrt{(A+B)(C+D)(A+C)(B+D)}}
$$

In the aforementioned TRAC/TEC studies $(6,7)$, values of Phi greater than 0.85 indicated an acceptable level of agreement between methods.

Kappa Test of Reliability. Cohen's Kappa is a coefficient of agreement, also called Kappa Index, Kappa Statistic, Kappa Coefficient, and KHAT. The value ranges from 0 to $1 ; 0$ for chance agreement and 1 for perfect agreement. "The upper limit of Kappa $(+1.00)$ occurs only when there is perfect agreement. The lower limit of Kappa depends on marginal distributions and is likely to have no 
practical interest." (Rosenfield 1986.) Kappa adjusts the overall accuracy by the probability of chance agreement.

The Kappa coefficient expresses the proportionate reduction in error generated by a classification process compared with the error of a completely random classification. A value of .82 would then imply that the classification process was avoiding 82 percent of the errors that a completely random classification would generate. (Congalton 1991.) In so doing, Kappa uses all of the cells in the matrix (i.e., for the 2 by 2 matrix, Kappa uses the values within each of the quadrants $\mathrm{A}, \mathrm{B}, \mathrm{C}$, and D).

The equation:

$$
K a p p a=\frac{\frac{(A+D)}{N}-\frac{(A+B)(A+C)+(C+D)(B+D)}{N^{2}}}{1-\frac{(A+B)(A+C)+(C+D)(B+D)}{N^{2}}}
$$

"KHAT is the maximum likelihood estimate from the multinomial distribution and is a measure of the actual agreement minus the chance agreement." (Congalton and Mead 1983.) Kappa also provides two additional measures of accuracy referred to as producers and users accuracy. Errors of exclusion, also known as errors of omission, pertain to the nondiagonal column cells that are misclassified by the software's interpolation algorithm. Errors of exclusion are used to define the producer's accuracy (i.e., the true value is excluded from the specific class). Errors of inclusion, also known as errors of commission, pertain to the nondiagonal row cells that are misclassified by the software's interpolation algorithm. Errors of inclusion are used to define the user's accuracy (i.e., the false occurrence of the specific class).

"Traditionally, the total number of correct pixels in a category is divided by the total number of pixels of that category as derived from the reference data (i.e., the column total). This accuracy measure indicates the probability of a reference pixel being correctly classified and is really a measure of omission error. This accuracy measure is often called "producer's accuracy" because the producer of the classification is interested in how well a certain area can be classified. On the other hand, if the total number of correct pixels in a category is divided by the total number of pixels that were classified in that category, then this result is a measure of commission error. This measure, called "user's accuracy" or reliability, is indicative of the probability that a pixel classified on the map/image actually represents that category on the ground." (Congalton 1991.) 
Both Kappa and its variance can be calculated for each contingency table. "The approximate large sample variance of KHAT can then be used to construct a hypothesis test for significant difference between error matrices. This test is possible because the large sample asymptotic distribution of KHAT is normal." (Congalton and Mead 1983.) Because of this, Kappa and its variance can be used to perform a statistical test, the z-test, to evaluate the significance of the difference between contingency tables derived from various algorithms, interpolation method, or data density.

Ancillary Parameters. For each of the data sets used in this project, several ancillary parameters were calculated to further define their characteristics. These are:

- Sigma-T,

- Total Number of Samples, and

- Total Number of Transitions.

Sigma-T. Sigma-T values are used by NIMA to provide a measure of the terrain roughness over an area of study. In this project, the Sigma-T values were computed to describe the surface roughness of the profiles used in the analysis. An average roughness is calculated for each data site (observer's position) within each of the six databases. The calculation is simply a standard deviation of all of the elevations (from the high-resolution data sets) along each of the profiles at a data site. Table 2 shows the Sigma-T's for each of the data sets used in the study.

Table 2. Data Set Sigma-T's

\begin{tabular}{|l|c|c|c|}
\hline Data Set & Minimum & Maximum & Average \\
\hline Yuma & 8 & 14 & 11 \\
\hline Yakima & 21 & 32 & 28 \\
\hline TwentyninePalms & 9 & 19 & 15 \\
\hline Irwin-West & 28 & 40 & 33 \\
\hline Irwin-East & 15 & 35 & 23 \\
\hline Benning & 3 & 8 & 6 \\
\hline
\end{tabular}

NIMA classifies Sigma-T's into the following categories:

- $0-18$

Smooth

- 19-61

Moderate

- $62-243$

Rough

- Over 243

Very Rough 
Based on this classification, the data sites are roughly divided between the smooth and the moderate categories. Both Yuma and Benning are exclusively considered smooth and both Yakima and Irwin West are exclusively considered moderate. Twentynine Palms has data sites in both the smooth and moderate classes.

In the TRAC/TEC studies $(6,7)$ the Sigma-T's were documented as:

- Yakima

- Twentynine Palms

- Irwin West

- Irwin East
47

60

As compared to the Sigma-T's calculated during this project, which are specific to the profiles under examination, the Sigma-T's in the TRAC study are calculated from the elevations within the entire database.

Total Number of Samples and Total Number of Transitions. The values for the Total Number of Samples (i.e., the total number of cells along profiles considered in the comparison) are directly related to the density of the database, the number of profiles at each data site, and the number of data sites in each data set. The Total Number of Transitions (i.e., the number of times the visibility transition from being 'visible' to being 'masked' and vice versa) is based on the field collected loss/gain information. Table 3 tabulates the total number of samples and transitions for each of the DEMs.

Table 3. Total Samples and Transitions

\begin{tabular}{|l|c|c|}
\hline Data Set & Total Number of Cells & Total Transitions \\
\hline Yuma & 34940 & 414 \\
\hline Yakima & 22588 & 171 \\
\hline Twentynine Palms & 21914 & 94 \\
\hline Irwin-East & 16339 & 65 \\
\hline Irwin-West & 17085 & 93 \\
\hline Benning & 12476 & 105 \\
\hline
\end{tabular}

Statistical Results: Various approaches were undertaken to analyze the data. In most cases the three statistical tests (Kappa, Phi, and Overall Agreement) were calculated for each of the following algorithm/interpolation methods:

ARC/Info Version 7.0.1 for UNIX

DTSS Revised Nearest-point interpolation

DTSS Revised Four-point interpolation

DTSS Revised Maximum-point interpolation 
The evaluation of the data occurred in these six stages:

Individual Data Sites within a Data Set

(i.e., Yuma 1, 3, 4, 7, and 8 within Yuma, etc.)

Cumulative for each Data Set

(i.e., Yuma, Benning, Yakima, Twentynine Palms, Irwin West and Irwin East)

Cumulative for each Data Set Organized by Ranges

(i.e., 0-499, 500-999, 1,000-1,499, etc., up to $3,200 \mathrm{~m}$ )

Conditional Agreement for Individual Map Classes

(i.e., visible vs. masked, Yuma, Yakima, Irwin West)

Cumulative for Yuma using Original Code

(i.e., Impact of enhancements/corrections)

Cumulative for Yuma using Degraded Data Resolutions

(i.e., 10-, 30-, 100-m posts - Using 4-pt interpolation)

Both the tabulated and graphical results are included in Appendices B, C, and F. The ancillary parameters of Sigma-T, total number of cells, and total number of transitions also are included in Appendix B.

Analyzing Algorithm/Interpolation Method and Level of Agreement for Individual Data Sites within a Data Set and Cumulative for each Data

Set. Kappa, Phi, and Overall Agreement were calculated for each of the individual sites using four algorithm/interpolation methods; however, because of sampling biases, especially in the Benning data set, not all of the sites were included in the analysis. The data sets had the following number of sites:

\begin{tabular}{ll} 
Data Set & Individual Sites \\
\cline { 2 - 2 } Yuma & $1,3,4,7$, and 8 \\
Yakima & $1,2,3,4$, and 5 \\
Twentynine Palms & 1,2, and 3 \\
Irwin West & $1,2,3$, and 4 \\
Irwin East & $1,2,3,4$, and 5 \\
Benning & $1,2,3,4$, and 6
\end{tabular}

Of the sites evaluated, the DTSS revised algorithm/4-point interpolation method provided the highest level of agreement the majority of the time. This was true for each of the three statistical tests. The other three interpolation methods were evenly distributed in their results.

To examine the statistics generated for the Benning and Irwin-East data set requires an explanation of a Kappa anomaly. To calculate Kappa, a random sampling of the features is required in order to distribute results within the main diagonal cells of the contingency table. At the Benning data sites, because of the predominance of visibility, a large number of the values are found only in the first main diagonal cell. "Many zeros occur in a matrix 
when an insufficient sample has been taken or when the classification is exceptionally good." (Congalton 1991.) When almost all of the values fall into just one of the main diagonal cells, leaving the other three cells near or at zero, the Kappa statistic as well as Phi produces inconsistent results and the measure of Overall Agreement is recommended as the preferred test statistic. In these cases the assumption is made that the sample used to construct the contingency table was biased towards one feature or another. For Benning, the results indicate that the profiles were largely sampled in areas of overwhelming visibility. For Irwin-East, the problem appears because of field collect inconsistencies. At site 1, Irwin-East, only one profile was left after the data were carefully examined. The contingency table reflects this with the majority of values occurring in the visibilityvisibility main diagonal cell leaving the other three cells predominately empty. The Benning data sites appear to be sampled along largely visible profiles and, in these cases, the preferred test statistic is Overall Agreement.

When viewing the data sets as a whole, both the DTSS revised algorithm/4-point interpolation and DTSS revised algorithm/maximum-point interpolation, provided the highest level of agreement the greatest number of times. Calculating Kappa for all of the data sets using the DTSS revised algorithm/4-point interpolation yields values consistently more than 0.90 or 90 percent. With Benning and its data biases excluded, the value for Kappa averaged over the remaining data sets was 0.927 . These values indicate a strong agreement between the DTSS revised algorithm/4-point interpolation generated visibility results and the field-collected reference data.

A summary of the statistical results using the totals for each of the highresolution data sets is shown in Table 4 on the first six lines. The last two rows compare the revised-DTSS algorithm and the original-DTSS algorithm using the Yuma data set. The tabulated and graphical results for each of the data sets are included in Appendix B.

Table 4. Total Kappa - All Sites - 5-m Results

\begin{tabular}{|c|c|c|c|c|}
\hline Kappa & 18 & DTSS-Revised & DTSS-Revised & DTSS-Revised \\
\hline & Arcinifo & Nearest Pt & Four-Point & Mar Pt \\
\hline Irwin West & 0.934 & 0.935 & 0.935 & 0.921 \\
\hline $\begin{array}{l}\text { Twentynine } \\
\text { Palms }\end{array}$ & 0.884 & 0.882 & 0.887 & 0.890 \\
\hline Yakima & 0.950 & 0.922 & 0.949 & 0.902 \\
\hline Irwin East & 0.285 & 0.854 & 0.924 & 0.842 \\
\hline Yuma & 0.925 & 0.931 & 0.937 & 0.922 \\
\hline Berning & 0.782 & 0.795 & 0.795 & 0.805 \\
\hline \multicolumn{5}{|l|}{45} \\
\hline Yuma - Rev & 0.925 & 0.931 & 0.937 & 0.922 \\
\hline Yuma-Orig & 0.925 & 0.930 & 0.932 & 0.918 \\
\hline
\end{tabular}




\section{Analyzing Algorithm/Interpolation Method and Level of Agreement for} Range Band Trends from Site Origin for Data Sites: The analysis of ranges was conducted on the Yuma, Yakima, Irwin West, and Twentynine Palms data sets. The data were organized by distance for each of the profiles at each data site. The distance from the observer (i.e., profile origin) was broken down as follows:

$$
\begin{array}{r}
0-499 \text { meters } \\
500-999 \text { meters } \\
1,000-1,499 \text { meters } \\
1,500-1,999 \text { meters } \\
2,000-2,499 \text { meters } \\
2,500-2,999 \text { meters } \\
3,000-3,200 \text { meters }
\end{array}
$$

The hypothesis for conducting this procedure was to test whether the statistical test showed a trend in level of agreement as the distance from the observer increased. This was not obvious in any of the database results and indeed no pattern was detected. Because the results of these analyses were inconclusive, only the tabulated and graphical results for Yuma are included in Appendix C.

Analyzing Kappa's Conditional Agreement for Individual Map Classes: As previously described in this report, Kappa's were calculated based on all of the values in the contingency table; however, to provide further insight into the results, Kappa's also can be calculated for each of the individual map classes (visible segment class, masked segment class) used in the analysis. For our purposes, the visible and masked segments can be studied separately to examine how the algorithm/interpolation methods react. All of the data sets, including the original Yuma runs and the data reduction runs, were analyzed using the following conditional Kappa equations.

$$
\begin{aligned}
& \text { CondKappa } \quad \text { vis }=\frac{\frac{A}{N}-\frac{(A+B)(A+C)}{N^{2}}}{\frac{(A+B)}{N}-\frac{(A+B)(A+C)}{N^{2}}} \\
& \text { CondKappa } \text { masked }=\frac{\frac{D}{N}-\frac{(C+D)(B+D)}{N^{2}}}{\frac{(C+D)}{N}-\frac{(C+D)(B+D)}{N^{2}}}
\end{aligned}
$$


Table 5. Kappa Analysis for all Sites

\begin{tabular}{|c|c|c|c|c|c|}
\hline Irwin West & Over Est. Vis & Over Est. Mask & $\begin{array}{l}\text { Twentynine } \\
\text { Palms }\end{array}$ & $\begin{array}{c}\text { Over Est. } \\
\text { Vis }\end{array}$ & Over Est. Mask \\
\hline ARC/Info & Yes & & ARC/Info & & Yes \\
\hline $1-\mathrm{Pt}$ & Yes & & $1-\mathrm{Pt}$ & & Yes \\
\hline 4-Pt & Yes & & 4-pt & & Yes \\
\hline $\mathrm{Max} \mathrm{Pt}$ & Yes & & $\mathrm{Max} \mathrm{Pt}$ & & Yes \\
\hline Yakima & Over Est. Vis & Over Est. Mask & Benning & $\begin{array}{c}\text { Over Est. } \\
\text { Vis }\end{array}$ & Over Est. Mask \\
\hline ARC/Info & Yes & & ARC/Info & Yes & \\
\hline $1-\mathrm{Pt}$ & & Yes & $1-\mathrm{Pt}$ & Yes & \\
\hline 4-Pt & Yes & & 4-Pt & Yes & \\
\hline $\mathrm{Max} \mathrm{Pt}$ & & Yes & $\mathrm{Max} \mathrm{Pt}$ & Yes & \\
\hline Yuma Rev & Over Est. Vis & Over Est. Mask & Yuma Org & $\begin{array}{c}\text { Over Est. } \\
\text { Vis }\end{array}$ & Over Est. Mask \\
\hline ARC/Info & Yes & & ARC/Info & Yes & \\
\hline $1-\mathrm{Pt}$ & Yes & & $1-\mathrm{Pt}$ & Yes & \\
\hline 4-Pt & Yes & & 4-Pt & Yes & \\
\hline $\operatorname{Max} \mathrm{Pt}$ & Yes & & $\operatorname{Max} \mathrm{Pt}$ & Yes & \\
\hline Yuma Org & Over Est. Vis & Over Est. Mask & Irwin East & $\begin{array}{c}\text { Over Est. } \\
\text { Vis }\end{array}$ & Over Est. Mask \\
\hline $10 \mathrm{~m}-4-\mathrm{Pt}$ & Yes & & $1-\mathrm{Pt}$ & & Yes \\
\hline $30 \mathrm{~m}-4-\mathrm{Pt}$ & Yes & & 4-Pt & Yes & \\
\hline $100 \mathrm{~m}-4-\mathrm{Pt}$ & & Yes & $\operatorname{Max} \mathrm{Pt}$ & & Yes \\
\hline Yuma Rev & Over Est. Vis & Over Est. Mask & & & \\
\hline $10 \mathrm{~m}-4-\mathrm{Pt}$ & Yes & & & & \\
\hline $30 \mathrm{~m}-4-\mathrm{Pt}$ & & Yes & & & \\
\hline $100 \mathrm{~m}-4-\mathrm{Pt}$ & Yes & & & & \\
\hline
\end{tabular}

The data sets along with the interpolation algorithms had a tendency to overestimate the visible portions of the line segments. The 4-point interpolation method reliably overestimated the visible segments except when the data were thinned to a 30-m grid. The 1-point and maximum-point methods have a tendency to overestimate the masked segments. The higher level of agreement along the masked segments means that the areas calculated as being masked correspond to the actual field collected masked segments to a greater degree than those areas calculated as being visible. While in Yakima, the nearest point and maximum point interpolation methods routinely resulted in higher levels of agreement for the masked segments than for the visible segments. In Twentynine Palms, the masked 
areas provided a higher level of agreement for all algorithm/interpolation methods.

Interpreted another way, in cases where the level of agreement is greater for the "masked" map class, the algorithm/interpolation method is misclassifying more visible segments as masked than it is misclassifying masked segments as visible. It then follows that in cases where the level of agreement is greater for the "visible" map class, the algorithm/interpolation method is misclassifying more masked segments as visible than it is misclassifying visible segments as masked.

In all of the studied data sets the bias was toward a greater level of agreement for the masked segments along the profile. The tactical significance of this may be that those areas that are denoted as masked can more definitively be considered masked; however, because some areas are designated visible that should be denoted as masked by the interpolation method, there may be a false sense of security for those visible areas.

Analyzing Original DTSS Algorithm versus Revised DTSS Algorithm using Multiple Resolutions of Data. The revised and original DTSS algorithms were compared using the Yuma data set at its original 5-m highresolution data density and at a degraded 10-, 30-, and 100-m data density (Table 5, Figure 15). The 10-, 30-, and 100-m densities reflect the resolution of data in Digital Terrain Elevation Data (DTED) Level 3, 2, and 1, respectively. By selecting every $2^{\text {nd }}, 6^{\text {th }}$ and $20^{\text {th }}$ point, DEMS were created with 10-, 30- and 100-m grid spacing. Today most military applications still rely on the 100-m DTED Level 1 product. Table 5 and Figure 16 summarizes the results of this analysis.

Table 6. Yuma Site Kappas

\begin{tabular}{|l|c|c|c|c|c|c|c|c|}
\hline Kappa & New & Orig & New & Orig & New & Orig & New & Orig \\
\hline 4-Point & DTSS & DTSS & DTSS & DTSS & DTSS & DTSS & DTSS & DTSS \\
\hline & 5 meter & 5 meter & 10 meter & 10 meter & $\mathbf{3 0}$ meter & 30 meter & $\mathbf{1 0 0 ~ m e t e r ~}$ & 100 meter \\
\hline Yuma - 1 & 0.953 & 0.948 & 0.941 & 0.932 & 0.798 & 0.798 & 0.640 & 0.509 \\
\hline Yuma - 3 & 0.888 & 0.892 & 0.890 & 0.893 & 0.742 & 0.726 & 0.521 & 0.213 \\
\hline Yuma - 4 & 0.940 & 0.938 & 0.931 & 0.933 & 0.868 & 0.874 & 0.529 & 0.449 \\
\hline Yuma - 7 & 0.946 & 0.922 & 0.948 & 0.923 & 0.918 & 0.892 & 0.800 & 0.809 \\
\hline Yuma - 8 & 0.943 & 0.942 & 0.900 & 0.900 & 0.856 & 0.762 & 0.719 & 0.188 \\
\hline Total & 0.937 & 0.932 & 0.926 & 0.921 & 0.851 & 0.824 & 0.677 & 0.384 \\
\hline
\end{tabular}


The first point to notice is that for each of the sites there is a general decrease in the level of agreement as the resolution of the database changes from $5 \mathrm{~m}$ to $100 \mathrm{~m}$. This trend occurs for both the revised DTSS and the original DTSS algorithm. The second point is the difference between the revised DTSS and the original DTSS algorithm as the resolution of the database changes from $5 \mathrm{~m}$ to $100 \mathrm{~m}$. While the level of agreement for the revised and original algorithms is comparable at the high-resolution 5-m data density, the difference between the two becomes quite apparent as the density of the data decreases. This is shown in Table 6.

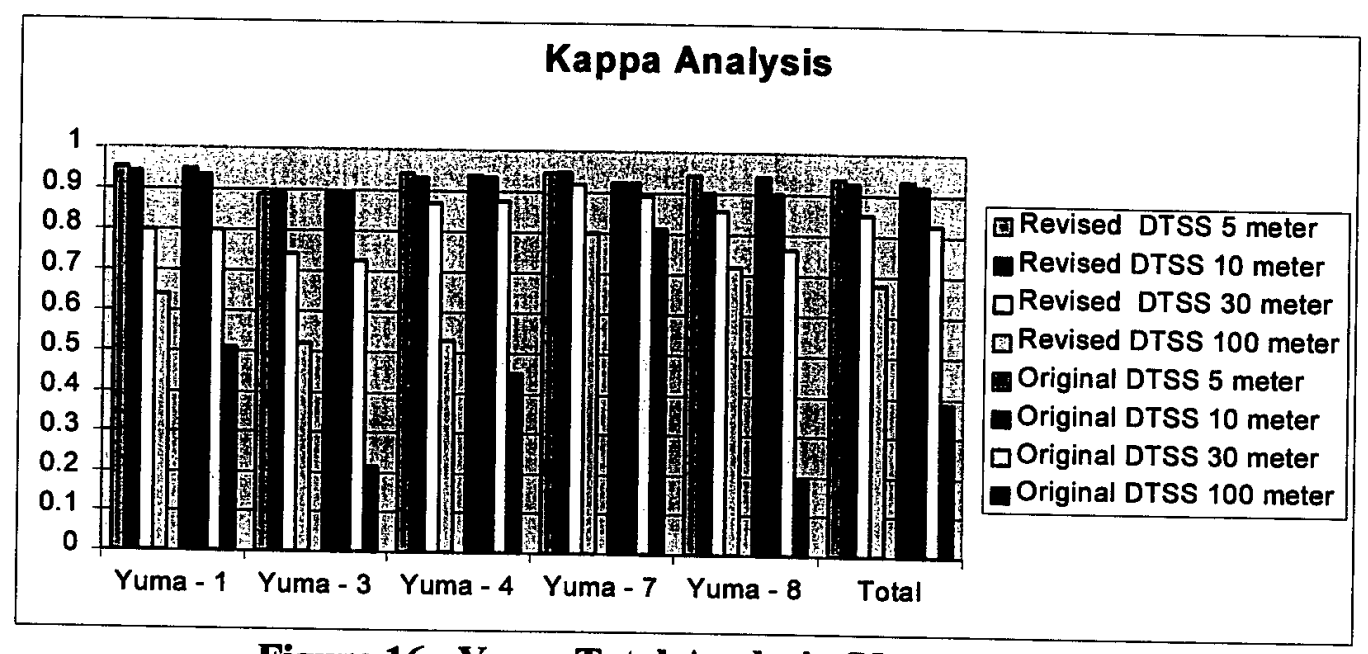

Figure 16. Yuma Total Analysis (New vs. Original)

Table 7. Kappa vs. Data Density

\begin{tabular}{|c|c|c|}
\hline \multicolumn{3}{|c|}{ Data Density } \\
\hline Algorithm & $\mathbf{5 ~ m}$ & $100 \mathrm{~m}$ \\
\hline New & .937 & .677 \\
\hline Orig. & .932 & .384 \\
\hline
\end{tabular}

These results indicate that at high data densities either of the two algorithms could possibly be used; however, as the density of the data decreases, the results of the algorithm improvements are noticeable. This would indicate that LOS applications need to be tested with data that are equivalent to DTED1 spacing in order to quickly determine errors in the software. The higher the data density, the more likely the errors in the software will not be as apparent.

Analyzing Timing vs. Data Density vs. Solution Accuracy. As the density of the elevation data is reduced there is a corresponding reduction in the time required to generate $\operatorname{LOS}$ results. 
- $100 \mathrm{~m}$

11 seconds

- $30 \mathrm{~m}$

13 seconds

- $10 \mathrm{~m}$

26 seconds

- $5 \mathrm{~m}$

146 seconds

These times were generated on a Sun/SPARC 10 running Solaris 2.5.1 with 32 Mbytes of memory. A site was selected over the Yuma data set and a complete 360 degree LOS test was conducted. For this test, LOS profiles were generated every 10 degrees, profiles lengths were $3.2 \mathrm{~km}$, LOS samples were taken every meter along the profile, and elevations were calculated using the DTSS 4-point interpolation method.

From this information and the results reported in Table 5, the user of the software has the ability to pick the reliability of the software, given the timing constraints of the problem. If the 85 percent solution is all that is required, then running data densities greater than $30 \mathrm{~m}$ is a waste of time. In this case, as much as 133 seconds can be saved per the example test run. There also is the benefit of reducing the amount of storage required for the application. Table 7 encapsulates the findings for the $10 \mathrm{~km}$ by $9.55 \mathrm{~km}$ Yuma data set.

Table 8. Density/Solution Accuracy/Time/Storage Analysis

\begin{tabular}{|c|c|c|c|}
\hline $\begin{array}{c}\text { Grid Density } \\
\text { (meters) }\end{array}$ & $\begin{array}{c}\text { Accuracy } \\
\text { (Kappa) }\end{array}$ & $\begin{array}{c}\text { Time } \\
\text { (seconds) }\end{array}$ & $\begin{array}{c}\text { Storage } \\
\text { (Kbytes) }\end{array}$ \\
\hline 100 & $67.7 \%$ & 11 & 38 \\
\hline 30 & $85.1 \%$ & 13 & 417 \\
\hline 10 & $92.6 \%$ & 26 & 3739 \\
\hline 5 & $93.7 \%$ & 146 & 14938 \\
\hline
\end{tabular}




\section{RECOMMENDATIONS}

1. Increased attention to detail is crucial when conducting analysis in the field. Acquiring "ground truth" data can be very time consuming and expensive. To allow a continued and confident use of the collected information requires that all details concerning the field procedures be carefully documented. Attention to detail and pre-fieldwork meetings are required to make sure everyone understands the procedures and goals of the work.

2. For the data to remain useful in the future, metadata information must be collected and documented at the time of data creation. In this case, metadata information was required for both the fieldwork and the DEM creation process.

3. Revisions to the ARC Reuse Manual categories are needed to allow the software documentation to more closely follow the structure of the code. Information in the documentation needs to be organized such that the definitions of variables, structures, and types are defined before they are presented in the documentation.

4. Standardize field survey collection sheets to assist in the data entry of this information. Appendix $\mathrm{G}$ has a sample survey form that can be used as an example for anyone conducting LOS fieldwork. Helpful information about each of the fields is provided with the survey form.

5. DTSS needs to implement the recommended changes to the software to improve its LOS Masked Area Plot product. These changes are described in great detail at the beginning of this report. In addition, all software enhancements implemented by the program must go through a rigorous software-testing phase (software-testing tool recommended) that tests the new module in a stand-alone configuration along with integration testing.

6. Use a standard set of software tests for each particular function to ensure consistency of software results. A LOS validation test plan has been generated and the results recorded for the DTSS LOS Masked Area Plot module, and are available at the ARC along with additional documentation on the software. 


\section{CONCLUSIONS}

1. As the resolution of the database is degraded (i.e., the density of the data is reduced from $5 \mathrm{~m}$ to $100 \mathrm{~m}$ ), the level of agreement between the algorithmgenerated visibility and the field reference data decreases. In other words, as the database resolution decreases, the reliability of the algorithm results also decreases. The original DTSS code should not be used with DTED Level 1 data where the level of agreement between the algorithm and the field reference data is poor.

2. While the level of agreement for the revised DTSS and the original DTSS algorithms is comparable using the $5-\mathrm{m}$ high-resolution data, the difference between the two becomes quite apparent as the resolution of the data decreases. This indicates that at high data densities either of the two algorithms could possibly be used; however, as the density of the data decreases, the improvements and corrections made to the DTSS-revised algorithm result in a higher level of reliability.

3. The Yuma data set was used to study the change in accuracy results as the highresolution data set was degraded from $5 \mathrm{~m}$ to $100 \mathrm{~m}$. Using the four-point interpolation and the 5-m resolution data, the Yuma results reflected approximately the same level of agreement as the other five data sets. These close results at high resolutions led to the assumption that as the data are degraded, the Yuma results will be representative of the other data sets. At a data resolution of $5 \mathrm{~m}$, both the original DTSS and the revised DTSS algorithm provided strong agreement with field reference data. As the resolution of the data decreases from 5 to $100 \mathrm{~m}$, the Kappa results of the original DTSS algorithm decrease from strong agreement (at the 5-, 10-, and 30-m level), to poor agreement at the $100-\mathrm{m}$ level. The same approach for the revised DTSS algorithm measures Kappa changing from strong agreement (at the 5-, 10-, and $30-\mathrm{m}$ level), to fair to good agreement at the $100-\mathrm{m}$ level. To ensure that the terrain units generate the best possible product results using data resolutions such as DTED Level 1, which is easily available and widely distributed, they must use the revised DTSS algorithm. If the terrain units have access to higher resolution data sets, they should be used at the high resolution and not degraded to lower resolutions in the interest of computational speed or data storage costs.

4. Conditional Kappa analysis over Irwin West, Yakima, and Yuma showed the LOS algorithm overestimating visible LOS segments, thus, underestimating masked LOS segments. This would indicate that the user of the software needs to know that the masked portions of the LOS profile are most likely masked, and that placement of ground units in masked areas will need little, if any, fine tuning to ensure the location is masked. 
5. The DTSS code submitted to the project benefited greatly from the reusability assessment analysis. The recommendations achieved from the in-depth inspection of the code will allow the fielded system to provide terrain teams with a much-improved product and guidelines for optimum data density for its use. 


\section{REFERENCES}

1. Andrews, F.M., L. Klem, T.N. Davidson, P.M. O'Malley, and W.L. Rodgers, 1981. A Guide for Selecting Statistical Techniques for Analyzing Social Science Data, $2^{\text {nd }}$ Edition. University of Michigan.

2. Aronoff, S., 1982. The Map Accuracy Report: A User's View. PE\&RS. Vol. 48, No. 8, pp. 1,309-1,312.

3. Aronoff, S., 1982. Classification Accuracy: A User Approach. PE\&RS. Vol. 48, No. 8 , pp. 1,299-1,307.

4. Aronoff, S., 1985. The Minimum Accuracy Value as an Index of Classification Accuracy. PE\&RS. Vol. 51, No. 1, pp. 99-111.

5. BMDP Statistical Software, Inc., Cork Technology Park, Cork, Ireland.

6. Champion, D.C., B.L. Watson, P.J. Deason, and L.A. Fatale, 1993. The Effects of Digital Terrain Elevation Data Representation of Combat Simulations. TRADOC Analysis Center - WSMR. TRAC-WSMR-TR-93-031R.

7. Champion, D.C., K.G. Pankratz, and L.A. Fatale, 1995. The Effects of Different Line-of-Sight Algorithms and Terrain Elevation Representations on Combat Simulations. TRADOC Analysis Center - WSMR. TRAC-WSMR-TR-95032R.

8. Cohen, J., 1960. A Coefficient of Agreement for Nominal Scales. Educational and Psychological Measurement, Vol. 20, No. 1.

9. Colvocoresses, A.P. The Gridded Map. PE\&RS, Vol. 63, No. 4, pp. 377-380.

10. Congalton, R.G. and R.A. Mead, 1983. A Quantitative Method to Test for Consistency and Correctness in Photointerpretation. Photogrammetric Engineering and Remote Sensing, Vol. 49, No. 1, pp. 60-74.

11. Congalton, R.G., R.G. Oderwald, and R.A. Mead, 1983. Assessing Landsat Classification Accuracy Using Discrete Multivariate Analysis Statistical Techniques. PE\&RS, Vol. 49, No. 12, pp. 1,671-1,678.

12. Congalton, 1991. A Review of Assessing the Accuracy of Classifications of Remotely Sensed Data. Remote Sensing Environment, Vol. 37, pp. 35-46.

13. Doyle, F.J., 1997. Map Conversion and the UTM Grid. PE\&RS, Vol. 63, No.4, pp. 367-370. 
14. Federal Geographic Data Committee, 1984. Content Standards for Digital Geospatial Metadata (June 8). Federal Geographic Data Committee.

Washington, D.C.

15. Foody, G.M., 1992. On the Compensation for Chance Agreement in Image Classification Accuracy Assessment. PE\&RS, Vol. 58, No. 10, pp. 1,459-1,460.

16. Gloeckler, F., R. Joy, J. Simpson, and D. Specht, 1996. Handbook for Transformation of Datums, Projections, Grids, and Common Coordinate Systems, TEC-SR-7, U.S. Army Topographic Engineering Center, VA.

17. Hildebrand, D.K., J.D. Laing, and H. Rosenthal, 1977. Prediction Analysis of Cross Classification. New York:Wiley.

18. Hudson, W.D. and C.W. Ramm, 1987. Correct Formulation of the Kappa Coefficient of Agreement. PE\&RS. Vol. 53, No. 4, pp. 421-422.

19. Jordan's Handbook of Geodesy (Jordan-Eggert: Hanbuch der Vermessungskunde) 1962, Army Map Service, Manual of Photogrammetry.

20. Kraemer, H.C., 1982. Kappa Coefficient. Encyclopedia of Statistical Sciences. Editors-In-Chief, S. Skatz, N.L. Johnson, New York:Wiley. pp. 352-354.

21. Military Handbook, 1990. Transformation of Datums, Projections, Grids, and Common Coordinate Systems. MIL-HDBK-600008 U.S. Army Engineer Topographic Laboratories, VA.

22. PhotoScience, Inc., 1994. Airborne GPS Report for Fort Irwin, CA. Prepared for U.S. Army Topographic Engineering Center, VA.

23. PhotoScience, Inc., 1994. Aero Triangulation Report for Fort Irwin, CA. Prepared for U.S. Army Topographic Engineering Center, VA.

24. PhotoScience, Inc., 1994. Airborne GPS Report for Yakima, WA. Prepared for U.S. Army Topographic Engineering Center, VA.

25. PhotoScience, Inc., 1994. Aero Triangulation Report for Yakima, WA. Prepared for U.S. Army Topographic Engineering Center, VA.

26. Rosenfield, G.H. and K. Fitzpatrick-Lins, 1986. A Coefficient of Agreement as a Measure of Thematic Classification Accuracy. PE\&RS, Vol. 52, No. 2, pp. 223227.

27. Snedecor, G.W. and W.G. Cochran, 1980. Statistical Methods: Ames, Iowa State University Press, IA. 
28. Stehman, S.V., 1996. Estimating the Kappa Coefficient and its Variance under Stratified Random Sampling. PE\&RS, Vol. 62, No. 4, pp. 401-402.

29. Story, M. and R.G. Congalton, 1986. Accuracy Assessment: A User's Perspective. PE\&RS, Vol. 52, No. 3, pp. 397-399.

30. Watts, J.M., 1997. Accuracy Assessment Procedures. In Development and Testing of Army Guidelines for Vegetation Mapping, A. Hill and J. O'Neil, Eds. Report to the Army Environmental Center.

31. Welch, R. and A. Homsey, 1997. Datum Shifts for UTM Coordinates. PE\&RS, Vol. 63, No. 4, pp.371-375. 


\section{ACRONYMS}

AMIP

AML

ARC

BIL

CPU

DEM

DMSO

DTSS

DYNTACS

FGDC

FLIR

GPS

GUI

IEEE

KHAT

LOS

MC\&G

MEL

MOBA

ModSAF

NASA

NBS

NIMA

NV

PLGR

QA

SEM

STC

TEC

TIREM

TMPO

TRAC

TRADOC

TS

USD(A\&T)

V\&V

WGS

WSMR
Army Model Improvement Program

Arc/Info Macro Language

Army Repository Center

Band Interleaved by Line

Central Processing Unit

Digital Elevation Model

Defense Modeling \& Simulation Office

Digital Topographic Support System

Dynamic Tactical Simulation

Federal Geographic Data Committee

Forward-Looking Infrared Radar

Global Positioning System

Graphical User Interface

Institute of Electronic and Electrical Engineers

Kappa Estimated

Line-of-Sight

Mapping, Charting, and Geodesy

Master Environmental Library

Military Operations in Built-Up Areas

Modular Semi-Automated Forces

National Aeronautics and Space Administration

National Biological Survey

National Imagery and Mapping Agency

Night Vision

Precision Lightweight GPS System

Quality Assurance

Smooth Earth Model

Science \& Technology Center

U.S. Army Topographic Engineering Center

Terrain Integrated Rough Earth Model

Terrain Modeling Program Office

TRADOC Analysis Command

Training and Doctrine Command

Total Station

Under Secretary of Defense (Acquisition \& Technology)

Verification and Validation

World Geodetic System

White Sands Missile Range 


\section{APPENDIX A}

\section{Reuse Methodology for LOS Applications}




\section{Purpose}

To provide well-tested and documented Line-of-Sight (LOS) applications for Department of Defense (DOD) and Army developers. To define high-resolution data sets with documentation that enables LOS applications to be verified and validated. To assist future developers in understanding the LOS applications and their limitations that are available at the Army Reuse Center (ARC). The initial deliverable to the ARC was at the beginning of the $1^{\text {st }}$ Qtr FY98.

\section{Goals}

- Re-engineer an existing optical LOS application/algorithm to meet ARC requirements

- Verify and Validate (V\&V) LOS applications/algorithms

- Document LOS applications

\section{Methodology}

1. Verify database accuracies and Identify benchmark parameters (Using cross correlation technique).

2. Verify that the algorithm is correct and error free and provides the intended information to the user.

- Black Box Testing

- White Box Testing

- Platform Testing

- Mathematical Correctness

- Software Design Integrity

3. Perform Sensitivity analysis:

- Understand the impact of various accuracies, resolutions, and site specific terrain information on the LOS application/algorithm by comparing generated results with field survey data.

- Run multiple statistical techniques on the application vs. field results.

4. Document results of V\&V and sensitivity analysis.

\section{FY97 Deliverables}

1. Methodology for evaluating other optical LOS applications/algorithms

2. Deliver reusable code to the ARC - $1^{\text {st }} \mathrm{Qtr}$ FY98

3. Software Reuse Documentation

- Abstract

- Reuser Manual

- Users Guide with additional appendices.

4. Out brief of results/lessons learned/recommendations 


\section{Data Sets}

1.0 Benchmark Data Sets

1.0.1 High-Resolution Digital Elevation Data

- Fort Irwin - National Training Center (NTC) - East ( 5-m DEM )

- Fort Irwin - NTC - West ( 5-m DEM)

- Yakima Firing Center( 5-m DEM)

- Twentynine Palms ( 1-m DEM)

- Yuma Proving Grounds( 5 meter DEM )

- Fort Benning ( 1-m DEM)

1.1 High-Value Field Collected Reference Data

- Fort Irwin East, Yakima Firing Center, Yuma Proving Grounds

- 5-m survey accuracy

- Irwin West, Fort Benning, Twentynine Palms

- 1-m survey accuracy

2.1 Data Scrub of Benchmark Data Sets

2.1.1 Accuracy of DEMs

- Projection Datum Verification

- Coordinating Information into Metadata File Standard

2.1.2 Accuracy of Field Survey

- Origin Points

- LOS profiles

- Projection Datum Verification

- Coordinating Information into Metadata File Standard

\subsection{Metadata}

2.2.1 DEMs

- Documentation of spatial coordinates and reference information

- Documentation of vertical and horizontal accuracy

- Documentation of source information

- Documentation of data generation process description

2.2.2 Field Survey

- Documentation of spatial coordinates and reference information

- Documentation of vertical and horizontal accuracy

- Documentation of source information

- Documentation of methodology of field collect process description

2.2.3 Standardize output for DOD's Master Environmental Library 


\section{Verification/Validation}

3.0 Verification Testing (Are we building the product right?)

Validation Testing (Are we building the right product?)

3.1 Functional Testing (Black Box)

3.1.1 Test Different Inputs - Check for Correct Output

- Reciprocal LOS ( Observer-to-Target and Target-to-Observer )

3.1.2 Test Error Handling

3.1.2.1 Input Handler

- Real

- Integer

- String

- Character

3.1.2.2 Exception Handling

- Underflow/Overflow

- Bound checking

- I/O problems

3.1.3 User's Guide

3.2 Structural Testing (White Box)

3.2.1 Software Correctness

- Loop construction

- If/Then/Else (True/False Cases)

3.2.2 Completeness Testing

3.2.3 Platform Testing

- Identify System Dependencies

- Rounding/Truncation

3.2.4 Mathematical Correctness

- Earth Curvature

- Flat Earth

- Spherical Earth

- Interpolation Method

3.2.5 Programmer's Guide

3.3 $\mathrm{S} / \mathrm{W}$ Design Integrity

3.3.1 Algorithm/Application correctness 


\section{Sensitivity Analysis}

\subsection{Statistical Analysis}

4.0.1 Statistical Methods

- Kappa

- Measure of Agreement

- Phi

4.0.2 Algorithms

- ARC/Info

- Nearest Point

- 4-Point

- Max Point

4.0.3 Correlation Tests

- Individual Data sites within a Data Set (i.e., Yuma 1,3,4,7 and 8)

- Cumulative correlation for each Data Set (i.e., Yuma, Benning, Twentynine Palms, NTC, Yakima)

- Cumulative correlation for each Data Set Organized by ranges (0-500, 500-1000, 1000-1500, etc.)

- Cumulative using original algorithm

- Cumulative for Yuma using Degraded Data Resolutions - 10, 30, 100 (Original and revised algorithm)

4.0.4 Ancillary Parameters Associated with the Data Sets (Field Data)

- Sigma-T's for each site

- Total number of Samples - based on data resolution

- Total Transitions (masked to unmasked and vice versa)

4.0.5 Results (vs. Field Work)

- Level of Agreement for the revised algorithm

- Difference from revised algorithm vs. original configuration

- Impact of Density Reduction compared to High-Resolution Analysis 


\section{APPENDIX B}

\section{Statistical Results for All Locations at 5-m Resolution}


Yuma - 5-m Data Set

Statistical Summary of Results for Revised DTSS Algorithm and ARC/Info's LOS

Routine

\begin{tabular}{|c|c|c|c|}
\hline Interpolation & Kappa & Phi & MoA \\
\hline $1-\mathrm{ARC} / \mathrm{Info}$ & 0.951 & 0.951 & 0.977 \\
\hline 1 - Nearest & 0.951 & 0.952 & 0.977 \\
\hline 1 - FourPt & 0.953 & 0.953 & 0.978 \\
\hline 1 - MaxPt & 0.943 & 0.944 & 0.973 \\
\hline 3 - ARC/Info & 0.870 & 0.874 & 0.937 \\
\hline 3 - Nearest & 0.884 & 0.886 & 0.943 \\
\hline 3 - FourPt & 0.888 & 0.892 & 0.946 \\
\hline 3 - MaxPt & 0.885 & 0.886 & 0.944 \\
\hline 4 - ARC/Info & 0.933 & 0.934 & 0.967 \\
\hline 4 - Nearest & 0.937 & 0.937 & 0.968 \\
\hline 4 - FourPt & 0.940 & 0.940 & 0.970 \\
\hline 4 - MaxPt & 0.923 & 0.923 & 0.961 \\
\hline 7 - ARC/Info & 0.949 & 0.949 & 0.975 \\
\hline 7 - Nearest & 0.928 & 0.928 & 0.965 \\
\hline 7 - FourPt & 0.946 & 0.947 & 0.973 \\
\hline 7 - MaxPt & 0.912 & 0.913 & 0.957 \\
\hline 8 - ARC/Info & 0.906 & 0.907 & 0.973 \\
\hline 8 - Nearest & 0.937 & 0.938 & 0.982 \\
\hline 8 - FourPt & 0.943 & 0.943 & 0.984 \\
\hline 8 - MaxPt & 0.926 & 0.926 & 0.979 \\
\hline Ttl ARC/Info & 0.925 & 0.925 & 0.965 \\
\hline Ttl Nearest & 0.931 & 0.931 & 0.967 \\
\hline Ttl FourPt & 0.937 & 0.937 & 0.970 \\
\hline Ttl MaxPt & 0.922 & 0.923 & 0.964 \\
\hline
\end{tabular}

$\begin{array}{lccc} & \text { Total Samples } & \text { Sigma-T } & \text { Total Trans } \\ \text { Yuma-1 } & 4499 & 8 & 72 \\ \text { Yuma-3 } & 7710 & 14 & 112 \\ \text { Yuma-4 } & 5837 & 11 & 82 \\ \text { Yuma-7 } & 6429 & 9 & 50 \\ \text { Yuma-8 } & 10461 & 12 & 98\end{array}$




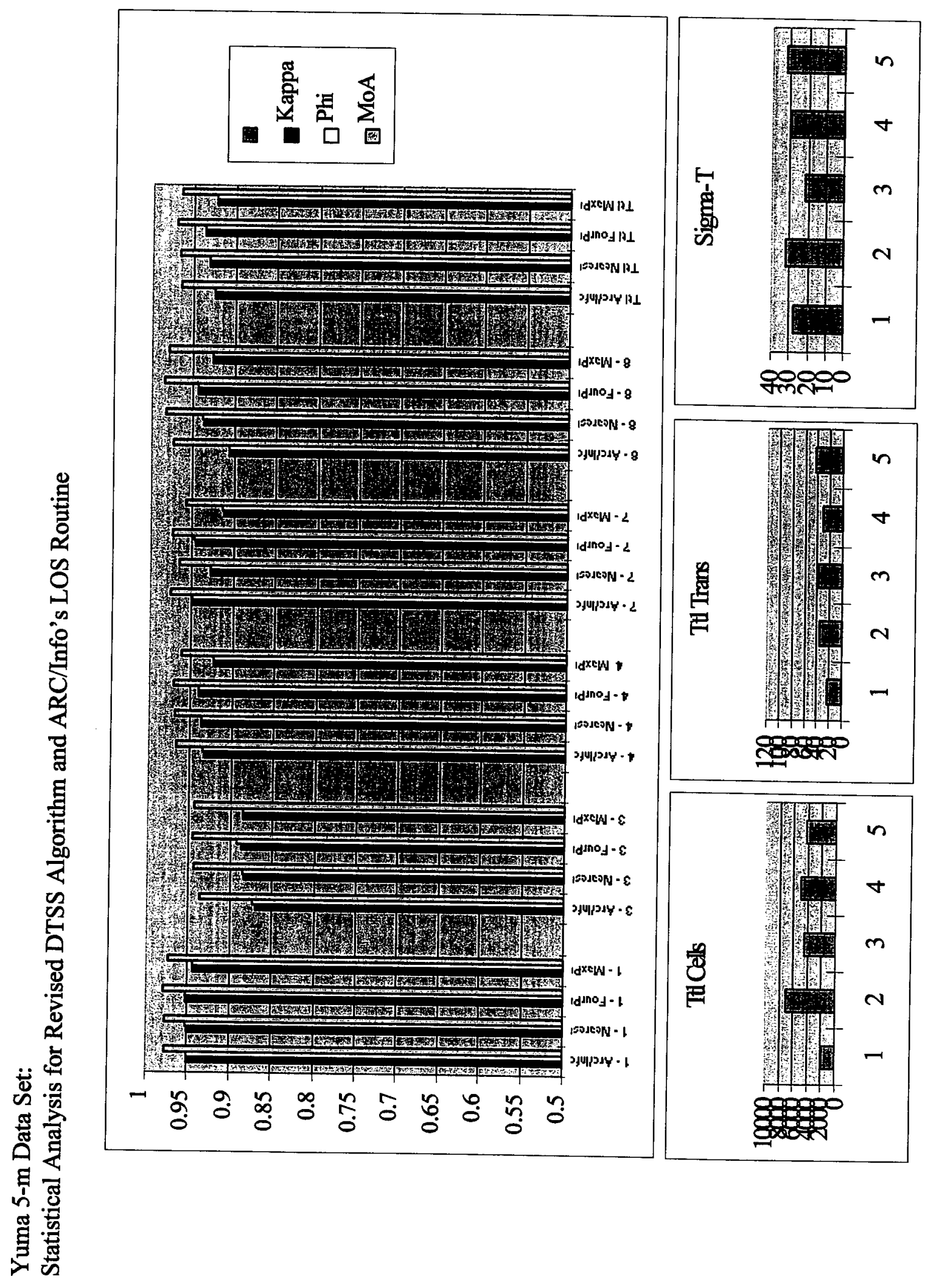


Yakima - 5-m Data Set

Statistical Summary of Results for Revised DTSS Algorithm and ARC/Info's LOS Routine

\begin{tabular}{|c|c|c|c|}
\hline Interpolation & Kappa & Phi & MoA \\
\hline $1-\mathrm{ARC} / \mathrm{Info}$ & 0.905 & 0.907 & 0.954 \\
\hline 1 - Nearest & 0.889 & 0.89 & 0.947 \\
\hline 1 - FourPt & 0.902 & 0.906 & 0.953 \\
\hline 1 - MaxPt & 0.866 & 0.866 & 0.935 \\
\hline 2 - ARC/Info & 0.962 & 0.962 & 0.984 \\
\hline 2 - Nearest & 0.961 & 0.961 & 0.984 \\
\hline 2 - FourPt & 0.969 & 0.969 & 0.988 \\
\hline 2 - MaxPt & 0.957 & 0.957 & 0.983 \\
\hline 3 - ARC/Info & 0.952 & 0.953 & 0.977 \\
\hline 3 - Nearest & 0.935 & 0.936 & 0.969 \\
\hline 3 - FourPt & 0.944 & 0.945 & 0.972 \\
\hline $3 \mathrm{MaxPt}$ & 0.927 & 0.929 & 0.964 \\
\hline 4 - ARC/Info & 0.943 & 0.944 & 0.982 \\
\hline 4 - Nearest & 0.796 & 0.806 & 0.927 \\
\hline 4 - FourPt & 0.929 & 0.931 & 0.978 \\
\hline 4-MaxPt & 0.740 & 0.759 & 0.902 \\
\hline 5 - ARC/Info & 0.907 & 0.907 & 0.958 \\
\hline 5 - Nearest & 0.909 & 0.909 & 0.959 \\
\hline 5 - FourPt & 0.911 & 0.912 & 0.961 \\
\hline 5-MaxPt & 0.884 & 0.885 & 0.947 \\
\hline Ttl ARC/Info & 0.950 & 0.950 & 0.975 \\
\hline Ttl Nearest & 0.922 & 0.922 & 0.961 \\
\hline Ttl FourPt & 0.949 & 0.949 & 0.974 \\
\hline Ttl MaxPt & 0.902 & 0.903 & 0.951 \\
\hline
\end{tabular}

$\begin{array}{cccc} & \text { Total Samples } & \text { Sigma-T } & \text { Total Trans } \\ \text { Yakima-1 } & 1929 & 28 & 23 \\ \text { Yakima-2 } & 7069 & 32 & 35 \\ \text { Yakima-3 } & 4494 & 21 & 38 \\ \text { Yakima-4 } & 4801 & 29 & 31 \\ \text { Yakima-5 } & 4295 & 32 & 44\end{array}$




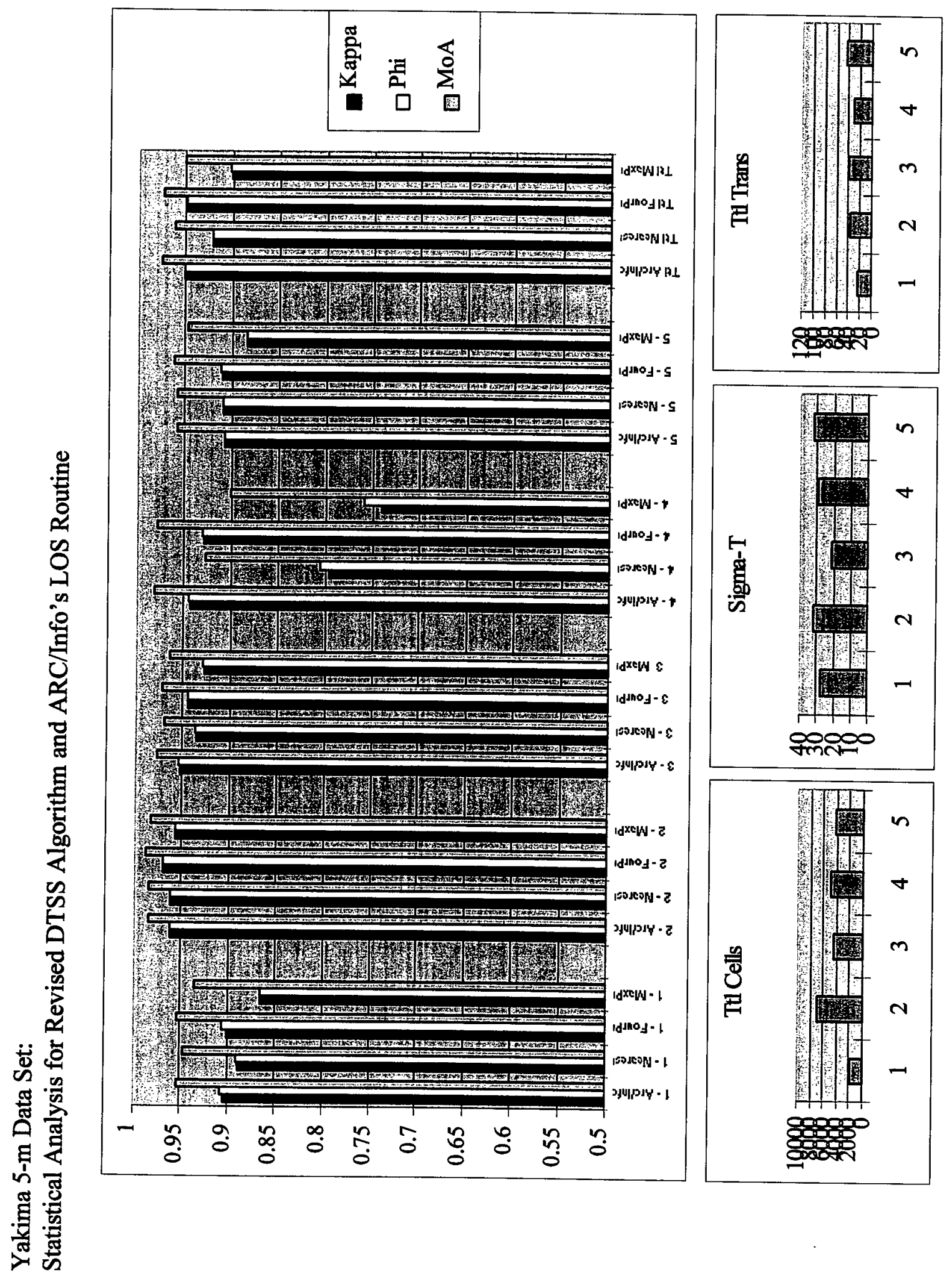


Twentynine Palms - 1-m Data Set

Statistical Summary of Results for Revised DTSS Algorithm and ARC/Info's LOS Routine

Interpolation

1 - ARC/Info

1 - Nearest

1 - FourPt

$1-\mathrm{MaxPt}$

2 - ARC/Info

2 - Nearest

2 - FourPt

2 - MaxPt

3 - ARC/Info

3 - Nearest

3 - FourPt

$3 \mathrm{MaxPt}$

Ttl ARC/Info

Ttl Nearest

Ttl FourPt

Ttl MaxPt
Kappa

0.894

0.885

0.9

0.89

0.761

0.761

0.761

0.762

0.869

0.873

0.871

0.903

0.859

0.857

0.862

0.866
Phi

0.896

0.886

0.901

0.892

0.767

0.767

0.766

0.77

0.869

0.873

0.871

0.904

0.861

0.858

0.863

0.868
MoA

0.948

0.944

0.951

0.946

0.916

0.916

0.916

0.915

0.935

0.937

0.935

0.952

0.932

0.931

0.933

0.935

TwentyninePalms-1

Total Samples

8093

9363

5021

\section{Sigma-T}

17

38

9
Total Trans

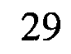

27

40 


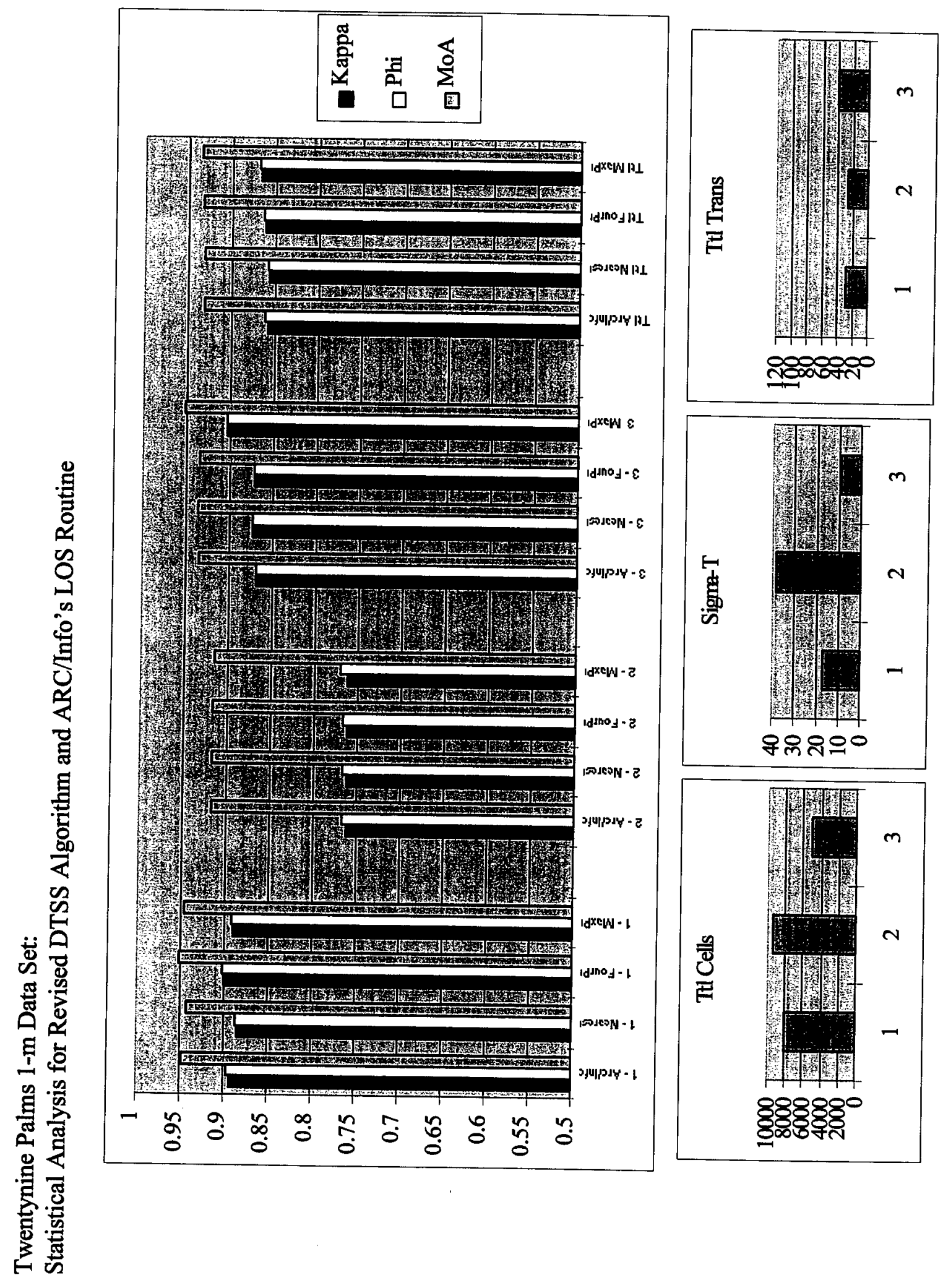


Irwin West - 5-m Data Set

Statistical Summary of Results for Revised DTSS Algorithm and ARC/Info's LOS Routine

$\begin{array}{lccc}\text { Interpolation } & \text { Kappa } & \text { Phi } & \text { MoA } \\ \text { 1 - ARC/Info } & 0.935 & 0.936 & 0.981 \\ \text { 1 - Nearest } & 0.936 & 0.937 & 0.981 \\ \text { 1 - FourPt } & 0.935 & 0.936 & 0.981 \\ \text { 1 - MaxPt } & 0.906 & 0.908 & 0.973 \\ & & & \\ \text { 2 - ARC/Info } & 0.955 & 0.955 & 0.981 \\ \text { 2 - Nearest } & 0.951 & 0.952 & 0.979 \\ \text { 2 - FourPt } & 0.951 & 0.955 & 0.980 \\ \text { 2 - MaxPt } & 0.943 & 0.944 & 0.976 \\ & & & \\ \text { 3 - ARC/Info } & 0.780 & 0.784 & 0.994 \\ \text { 3 - Nearest } & 0.759 & 0.759 & 0.993 \\ \text { 3 - FourPt } & 0.803 & 0.811 & 0.995 \\ \text { 3 MaxPt } & 0.739 & 0.740 & 0.992 \\ & & & \\ \text { 4 - ARC/Info } & 0.853 & 0.860 & 0.978 \\ \text { 4 - Nearest } & 0.868 & 0.875 & 0.980 \\ \text { 4 - FourPt } & 0.855 & 0.863 & 0.978 \\ \text { 4 - MaxPt } & 0.863 & 0.869 & 0.979 \\ \text { Ttl ARC/Info } & 0.934 & & 0.982 \\ \text { Ttl Nearest } & 0.935 & 0.935 & 0.982 \\ \text { Ttl FourPt } & 0.935 & 0.935 & 0.982 \\ \text { Ttl MaxPt } & 0.921 & 0.936 & 0.978\end{array}$

$\begin{array}{lccc} & \text { Total Samples } & \text { Sigma-T } & \text { Total Trans } \\ \text { IrwinW-1 } & 4501 & 31 & 16 \\ \text { IrwinW-2 } & 5141 & 28 & 34 \\ \text { IrwinW-3 } & 2432 & 40 & 15 \\ \text { IrwinW-4 } & 5011 & 31 & 28\end{array}$




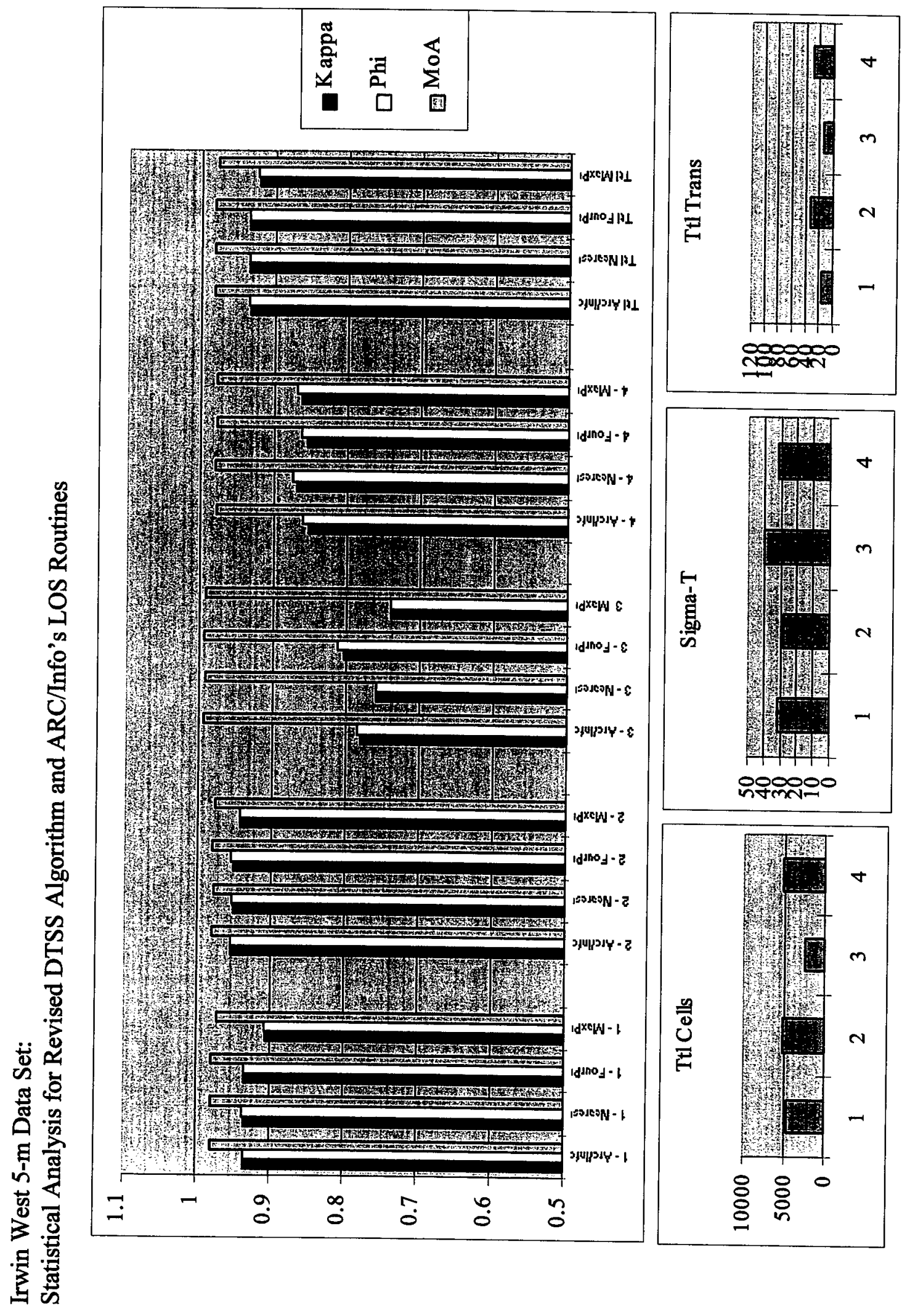


Irwin East - 5-m Data Set

Statistical Summary of Results for Revised DTSS Algorithm and ARC/Info's LOS Routine

\begin{tabular}{|c|c|c|}
\hline Interpolation & Kappa & MoA \\
\hline 1 - ARC/Info & 0.017 & 0.936 \\
\hline 1 - Nearest & 0.343 & 0.973 \\
\hline 1 - FourPt & 0.398 & 0.993 \\
\hline $1-\mathrm{MaxPt}$ & 0.014 & 0.966 \\
\hline 2 - ARC/Info & 0.596 & 0.824 \\
\hline 2 - Nearest & 0.800 & 0.922 \\
\hline 2 - FourPt & 0.958 & 0.985 \\
\hline 2 - MaxPt & 0.929 & 0.975 \\
\hline 3 - ARC/Info & 0.473 & 0.770 \\
\hline 3 - Nearest & 0.845 & 0.925 \\
\hline 3 - FourPt & 0.919 & 0.963 \\
\hline $3 \mathrm{MaxPt}$ & 0.788 & 0.896 \\
\hline 4 - ARC/Info & 0.118 & 0.566 \\
\hline 4 - Nearest & 0.699 & 0.853 \\
\hline 4 - FourPt & 0.942 & 0.971 \\
\hline 4 - MaxPt & 0.682 & 0.845 \\
\hline 5 - ARC/Info & 0.181 & 0.485 \\
\hline 5 - Nearest & 0.882 & 0.957 \\
\hline 5 - FourPt & 0.861 & 0.945 \\
\hline $5-\mathrm{MaxPt}$ & 0.828 & 0.939 \\
\hline Ttl ARC/Info & 0.285 & 0.643 \\
\hline Ttl Nearest & 0.854 & 0.927 \\
\hline Ttl FourPt & 0.924 & 0.962 \\
\hline Ttl MaxPt & 0.842 & 0.921 \\
\hline
\end{tabular}

$\begin{array}{lccc} & \text { Total Samples } & \text { Sigma-T } & \text { Total Trans } \\ \text { IrwinE-1 } & 409 & 35 & 1 \\ \text { IrwinE-2 } & 2947 & 17 & 19 \\ \text { IrwinE-3 } & 4204 & 15 & 9 \\ \text { IrwinE-4 } & 2451 & 27 & 18 \\ \text { IrwinE-5 } & 6328 & 30 & 18\end{array}$




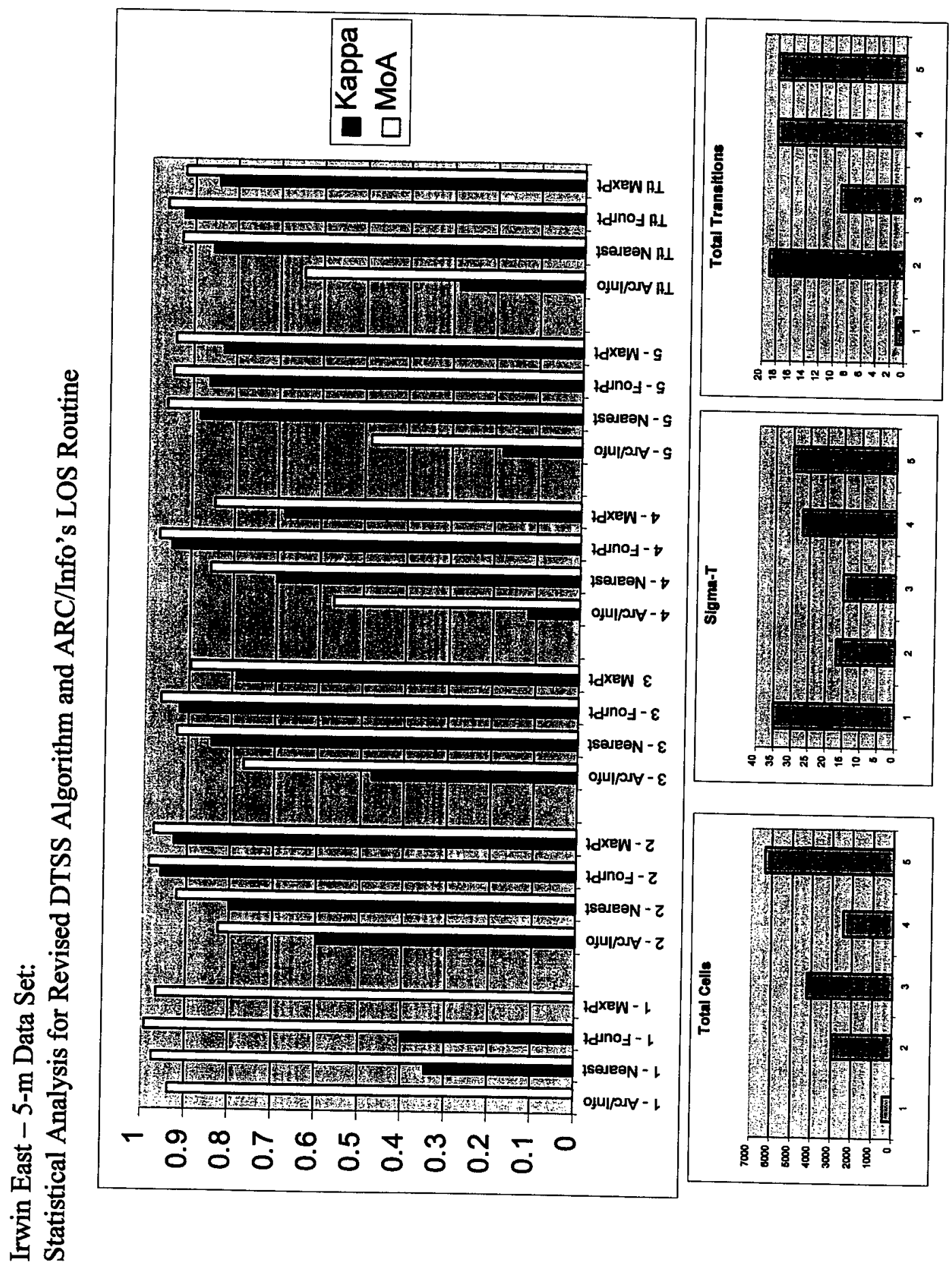


Benning - 1-m Data Set

Statistical Summary of Results for Revised DTSS Algorithm and Arc/Info's LOS

Routine

$\begin{array}{lccc}\text { Interpolation } & \text { Kappa } & \text { Phi } & \text { MoA } \\ \text { 1 - ARC/Info } & 0.431 & 0.497 & 0.985 \\ \text { 1 - Nearest } & 0.408 & 0.471 & 0.984 \\ \text { 1 - FourPt } & 0.423 & 0.508 & 0.985 \\ \text { 1 - MaxPt } & 0.522 & 0.579 & 0.986 \\ & & & \\ \text { 2 - ARC/Info } & 0.595 & 0.641 & 0.914 \\ \text { 2 - Nearest } & 0.614 & 0.665 & 0.919 \\ \text { 2 - FourPt } & 0.607 & 0.660 & 0.918 \\ \text { 2 - MaxPt } & 0.623 & 0.673 & 0.920 \\ & & & \\ \text { 3 - ARC/Info } & 0.898 & 0.900 & 0.983 \\ \text { 3 - Nearest } & 0.91 & 0.913 & 0.985 \\ \text { 3 - FourPt } & 0.908 & 0.912 & 0.985 \\ \text { 3 MaxPt } & 0.908 & 0.912 & 0.985 \\ & & & \\ \text { 4 - ARC/Info } & -0.002 & -0.003 & 0.990 \\ \text { 4 - Nearest } & -0.003 & -0.004 & 0.989 \\ \text { 4 - FourPt } & -0.001 & -0.002 & 0.991 \\ \text { 4 - MaxPt } & 0.273 & 0.319 & 0.992 \\ & & & \\ \text { 5 - ARC/Info } & 0.924 & 0.925 & 0.980 \\ \text { 5 - Nearest } & 0.948 & 0.949 & 0.987 \\ \text { 5 - FourPt } & 0.941 & 0.942 & 0.985 \\ \text { 5 - MaxPt } & 0.944 & 0.946 & 0.986 \\ & & & \\ \text { Ttl ARC/Info } & 0.782 & 0.796 & 0.975 \\ \text { Ttl Nearest } & 0.795 & 0.809 & 0.975 \\ \text { Ttl FourPt } & 0.795 & 0.811 & 0.976 \\ \text { Ttl MaxPt } & 0.805 & 0.820 & 0.977\end{array}$

$\begin{array}{lccc} & \text { Total Samples } & \text { Sigma-T } & \text { Total Trans } \\ \text { Benning-1 } & 3157 & 6 & 24 \\ \text { Benning-2 } & 1932 & 8 & 10 \\ \text { Benning-3 } & 3739 & 3 & 14 \\ \text { Benning-4 } & 2502 & 7 & 16 \\ \text { Benning-5 } & 1146 & 7 & 41\end{array}$




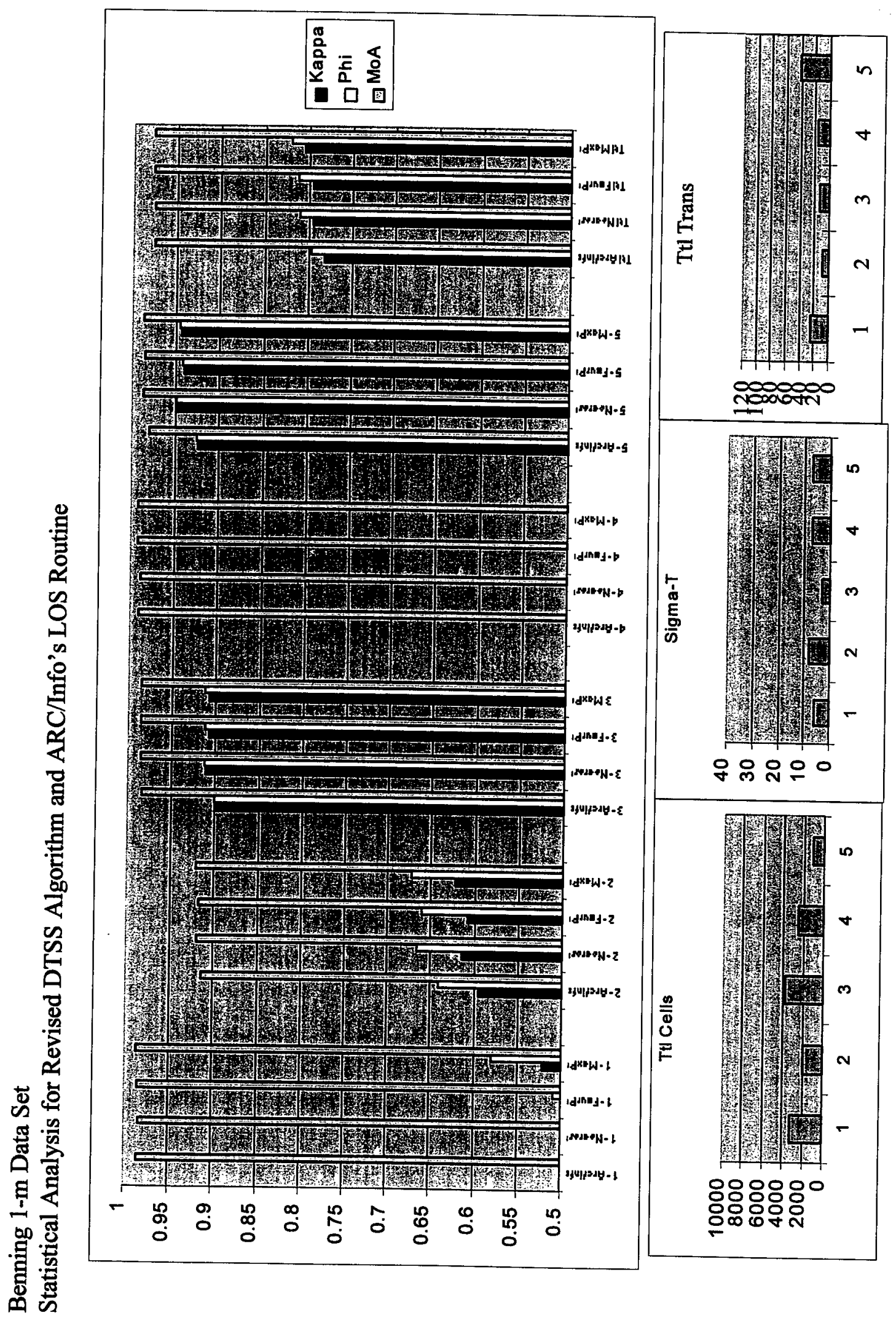




\section{APPENDIX C}

Yuma Range Band Analysis 


\begin{tabular}{|c|c|c|c|c|}
\hline Yuma - 1 & Interpolation & Kappa & Phi & MoA \\
\hline & ARC/Info & 0.806 & 0.806 & 0.990 \\
\hline & Nearest & 0.750 & 0.750 & 0.987 \\
\hline & 4-pt & 0.744 & 0.750 & 0.989 \\
\hline & $\operatorname{Max}$ & 0.750 & 0.750 & 0.987 \\
\hline \multicolumn{5}{|l|}{$500-999$} \\
\hline & ARC/Info & 0.903 & 0.904 & 0.977 \\
\hline & Nearest & 0.914 & 0.916 & 0.980 \\
\hline & 4-pt & 0.907 & 0.910 & 0.979 \\
\hline & $\operatorname{Max}$ & 0.894 & 0.897 & 0.976 \\
\hline \multicolumn{5}{|l|}{$1000-1499$} \\
\hline & ARC/Info & 0.941 & 0.941 & 0.973 \\
\hline & Nearest & 0.940 & 0.940 & 0.973 \\
\hline & 4-pt & 0.946 & 0.947 & 0.976 \\
\hline & Max & 0.914 & 0.915 & 0.961 \\
\hline \multicolumn{5}{|l|}{ 1500-1999 } \\
\hline & ARC/Info & 0.907 & 0.911 & 0.959 \\
\hline & Nearest & 0.923 & 0.925 & 0.966 \\
\hline & 4-pt & 0.916 & 0.919 & 0.963 \\
\hline & $\operatorname{Max}$ & 0.939 & 0.940 & 0.973 \\
\hline \multicolumn{5}{|l|}{$2000-2499$} \\
\hline & ARC/Info & 0.983 & 0.983 & 0.992 \\
\hline & Nearest & 0.980 & 0.980 & 0.990 \\
\hline & 4-pt & 0.983 & 0.983 & 0.992 \\
\hline & Max & 0.974 & 0.974 & 0.987 \\
\hline \multicolumn{5}{|l|}{ 2500-2999 } \\
\hline & ARC/Info & 0.938 & 0.939 & 0.970 \\
\hline & Nearest & 0.924 & 0.925 & 0.963 \\
\hline & 4-pt & 0.942 & 0.943 & 0.971 \\
\hline & $\operatorname{Max}$ & 0.901 & 0.905 & 0.951 \\
\hline \multicolumn{5}{|l|}{$3000-3200$} \\
\hline & ARC/Info & 0.929 & 0.929 & 0.976 \\
\hline & Nearest & 0.950 & 0.950 & 0.983 \\
\hline & 4-pt & 0.907 & 0.908 & 0.969 \\
\hline & $\operatorname{Max}$ & 0.930 & 0.931 & 0.976 \\
\hline
\end{tabular}




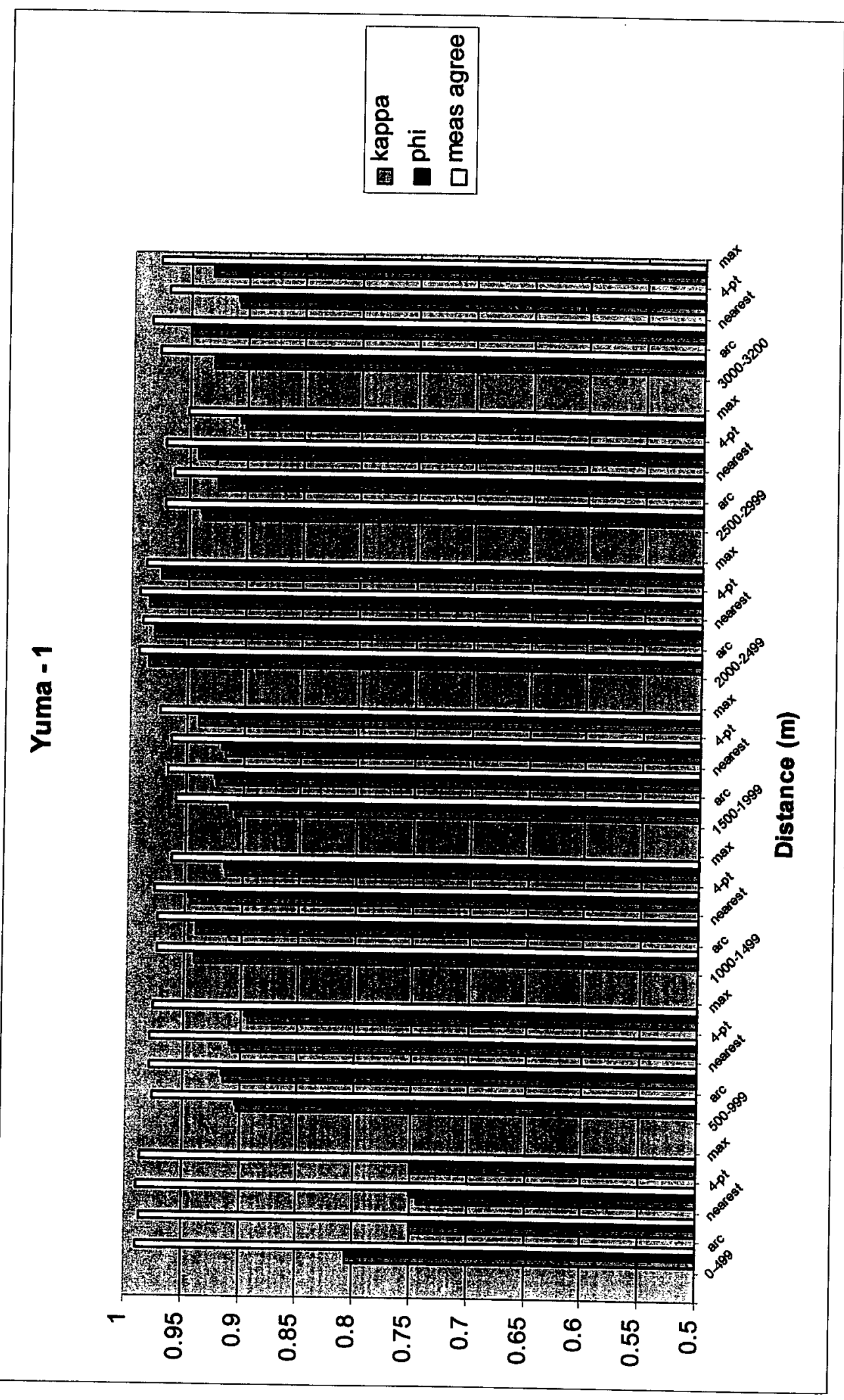




\begin{tabular}{|c|c|c|c|c|}
\hline \multirow{5}{*}{$\begin{array}{l}\text { Yuma - 3 } \\
0-499\end{array}$} & Interpolation & Kappa & Phi & MoA \\
\hline & ARC/Info & 0.653 & 0.685 & 0.825 \\
\hline & Nearest & 0.671 & 0.698 & 0.834 \\
\hline & 4-pt & 0.670 & 0.709 & 0.833 \\
\hline & $\operatorname{Max}$ & 0.661 & 0.681 & 0.829 \\
\hline \multicolumn{5}{|l|}{$500-999$} \\
\hline & ARC/Info & 0.913 & 0.914 & 0.957 \\
\hline & Nearest & 0.939 & 0.940 & 0.97 \\
\hline & 4-pt & 0.933 & 0.934 & 0.967 \\
\hline & $\operatorname{Max}$ & 0.924 & 0.924 & 0.963 \\
\hline \multicolumn{5}{|l|}{ 1000-1499 } \\
\hline & ARC/Info & 0.866 & 0.872 & 0.934 \\
\hline & Nearest & 0.924 & 0.925 & 0.963 \\
\hline & 4-pt & 0.913 & 0.915 & 0.957 \\
\hline & $\operatorname{Max}$ & 0.933 & 0.933 & 0.967 \\
\hline \multicolumn{5}{|l|}{ 1500-1999 } \\
\hline & ARC/Info & 0.924 & 0.924 & 0.963 \\
\hline & Nearest & 0.880 & 0.881 & 0.941 \\
\hline & 4-pt & 0.935 & 0.936 & 0.968 \\
\hline & $\operatorname{Max}$ & 0.907 & 0.909 & 0.954 \\
\hline \multicolumn{5}{|l|}{ 2000-2499 } \\
\hline & ARC/Info & 0.959 & 0.959 & 0.983 \\
\hline & Nearest & 0.980 & 0.980 & 0.992 \\
\hline & 4-pt & 0.978 & 0.978 & 0.991 \\
\hline & $\operatorname{Max}$ & 0.966 & 0.966 & 0.986 \\
\hline \multicolumn{5}{|l|}{$2500-2999$} \\
\hline & ARC/Info & 0.851 & 0.861 & 0.943 \\
\hline & Nearest & 0.858 & 0.867 & 0.945 \\
\hline & 4-pt & 0.851 & 0.861 & 0.943 \\
\hline & $\operatorname{Max}$ & 0.874 & 0.881 & 0.951 \\
\hline \multicolumn{5}{|l|}{$3000-3200$} \\
\hline & ARC/Info & 0.931 & 0.933 & 0.980 \\
\hline & Nearest & 0.931 & 0.933 & 0.980 \\
\hline & 4-pt & 0.931 & 0.933 & 0.980 \\
\hline & Max & 0.931 & 0.933 & 0.980 \\
\hline
\end{tabular}




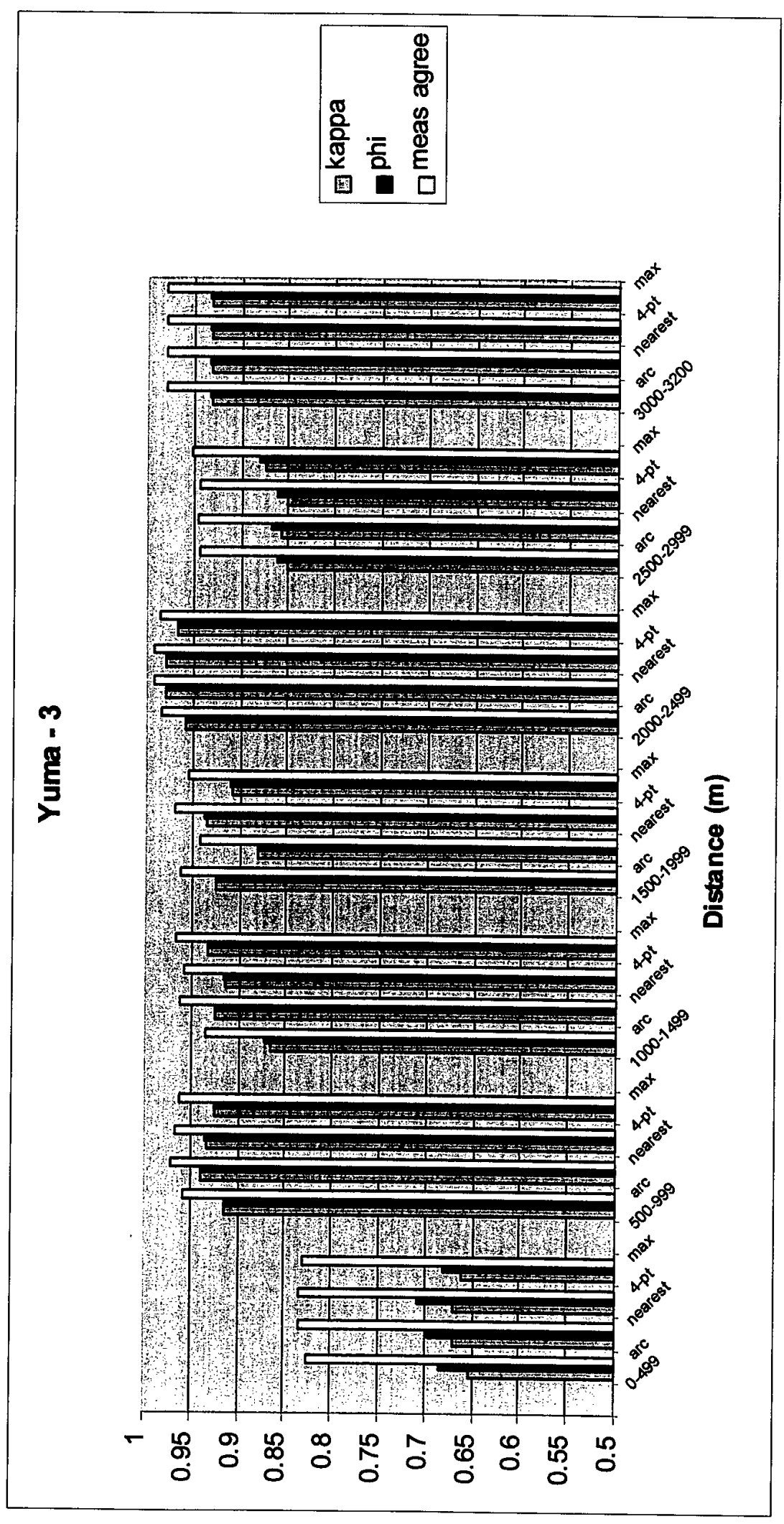




\begin{tabular}{|c|c|c|c|c|}
\hline \multirow{5}{*}{$\begin{array}{l}\text { Yuma - } 4 \\
0-499\end{array}$} & \multirow{2}{*}{$\begin{array}{l}\text { Interpolation Kappa } \\
\text { ARC/Info }\end{array}$} & \multirow{2}{*}{$\begin{array}{l}\text { Phi } \\
0.645\end{array}$} & \multicolumn{2}{|l|}{ MoA } \\
\hline & & & 0.655 & 0.971 \\
\hline & Nearest & 0.724 & 0.730 & 0.978 \\
\hline & 4-pt & 0.715 & 0.716 & 0.979 \\
\hline & $\operatorname{Max}$ & 0.699 & 0.702 & 0.981 \\
\hline \multicolumn{5}{|l|}{$500-999$} \\
\hline & ARC/Info & 0.917 & 0.917 & 0.958 \\
\hline & Nearest & 0.920 & 0.920 & 0.960 \\
\hline & 4-pt & 0.923 & 0.923 & 0.962 \\
\hline & Max & 0.900 & 0.900 & 0.950 \\
\hline \multicolumn{5}{|l|}{$1000-1499$} \\
\hline & ARC/Info & 0.891 & 0.893 & 0.946 \\
\hline & Nearest & 0.888 & 0.889 & 0.945 \\
\hline & 4-pt & 0.891 & 0.893 & 0.946 \\
\hline & $\operatorname{Max}$ & 0.872 & 0.874 & 0.937 \\
\hline \multicolumn{5}{|l|}{$1500-1999$} \\
\hline & ARC/Info & 0.970 & 0.971 & 0.986 \\
\hline & Nearest & 0.968 & 0.969 & 0.985 \\
\hline & 4-pt & 0.979 & 0.979 & 0.990 \\
\hline & $\operatorname{Max}$ & 0.945 & 0.947 & 0.973 \\
\hline \multicolumn{5}{|l|}{$2000-2499$} \\
\hline & $\mathrm{ARC} /$ Info & 0.914 & 0.915 & 0.971 \\
\hline & Nearest & 0.924 & 0.925 & 0.975 \\
\hline & 4-pt & 0.919 & 0.920 & 0.973 \\
\hline & $\operatorname{Max}$ & 0.882 & 0.886 & 0.960 \\
\hline \multicolumn{5}{|l|}{$2500-2999$} \\
\hline & ARC/Info & 0.736 & 0.763 & 0.972 \\
\hline & Nearest & 0.722 & 0.752 & 0.970 \\
\hline & 4-pt & 0.751 & 0.775 & 0.974 \\
\hline & Max & 0.695 & 0.730 & 0.966 \\
\hline \multicolumn{5}{|l|}{$3000-3200$} \\
\hline & ARC/Info & 0 & 0 & 1 \\
\hline & Nearest & 0 & 0 & 1 \\
\hline & 4-pt & 0 & 0 & 1 \\
\hline & Max & 0 & 0 & 1 \\
\hline
\end{tabular}




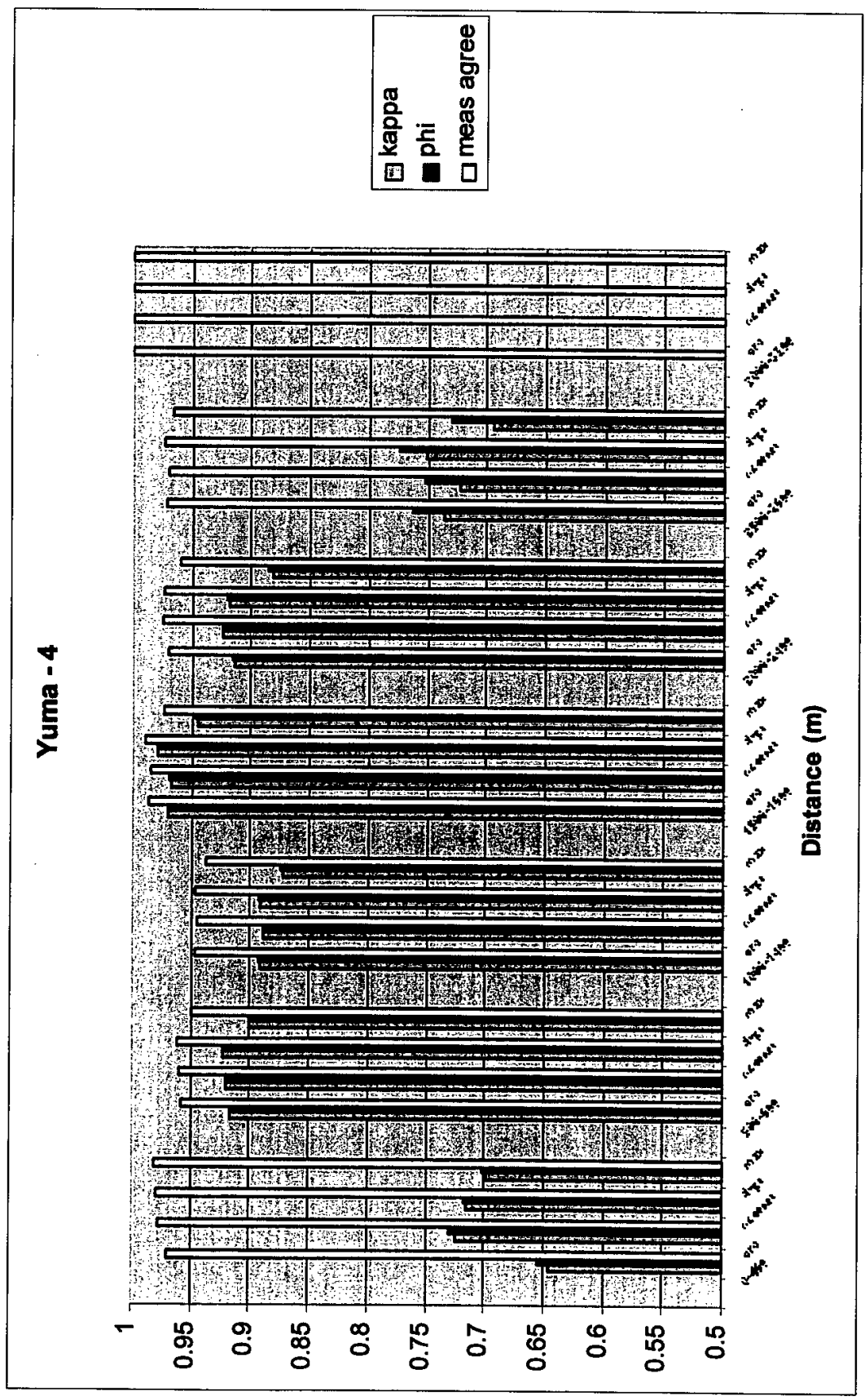




\begin{tabular}{|c|c|c|c|c|}
\hline \multirow{5}{*}{$\begin{array}{l}\text { Yuma - } 7 \\
0-499\end{array}$} & Interpolation & Kappa & Phi & MoA \\
\hline & ARC/Info & 1 & 1 & 1 \\
\hline & Nearest & 0.947 & 0.948 & 0.999 \\
\hline & 4-pt & 0.888 & 0.894 & 0.998 \\
\hline & Max & 0.998 & 0.998 & 0.998 \\
\hline \multicolumn{5}{|l|}{$500-999$} \\
\hline & ARC/Info & 0.976 & 0.976 & 0.990 \\
\hline & Nearest & 0.967 & 0.967 & 0.986 \\
\hline & 4-pt & 0.967 & 0.967 & 0.986 \\
\hline & $\operatorname{Max}$ & 0.955 & 0.956 & 0.981 \\
\hline \multicolumn{5}{|l|}{ 1000-1499 } \\
\hline & ARC/Info & 0.950 & 0.950 & 0.976 \\
\hline & Nearest & 0.950 & 0.950 & 0.976 \\
\hline & 4-pt & 0.942 & 0.942 & 0.972 \\
\hline & $\operatorname{Max}$ & 0.942 & 0.942 & 0.972 \\
\hline \multicolumn{5}{|l|}{ 1500-1999 } \\
\hline & ARC/Info & 0.913 & 0.913 & 0.964 \\
\hline & Nearest & 0.959 & 0.960 & 0.983 \\
\hline & 4-pt & 0.966 & 0.966 & 0.986 \\
\hline & $\operatorname{Max}$ & 0.943 & 0.943 & 0.976 \\
\hline \multicolumn{5}{|l|}{$2000-2499$} \\
\hline & ARC/Info & 0.961 & 0.961 & 0.986 \\
\hline & Nearest & 0.977 & 0.977 & 0.992 \\
\hline & 4-pt & 0.975 & 0.975 & 0.991 \\
\hline & Max & 0.939 & 0.941 & 0.978 \\
\hline \multicolumn{5}{|l|}{$2500-2999$} \\
\hline & ARC/Info & 0.844 & 0.855 & 0.945 \\
\hline & Nearest & 0.559 & 0.560 & 0.864 \\
\hline & 4-pt & 0.804 & 0.812 & 0.932 \\
\hline & $\operatorname{Max}$ & 0.545 & 0.545 & 0.856 \\
\hline \multicolumn{5}{|l|}{$3000-3200$} \\
\hline & ARC/Info & 0.822 & 0.835 & 0.940 \\
\hline & Nearest & 0.803 & 0.819 & 0.933 \\
\hline & 4-pt & 0.756 & 0.779 & 0.914 \\
\hline & $\operatorname{Max}$ & 0.727 & 0.756 & 0.902 \\
\hline
\end{tabular}




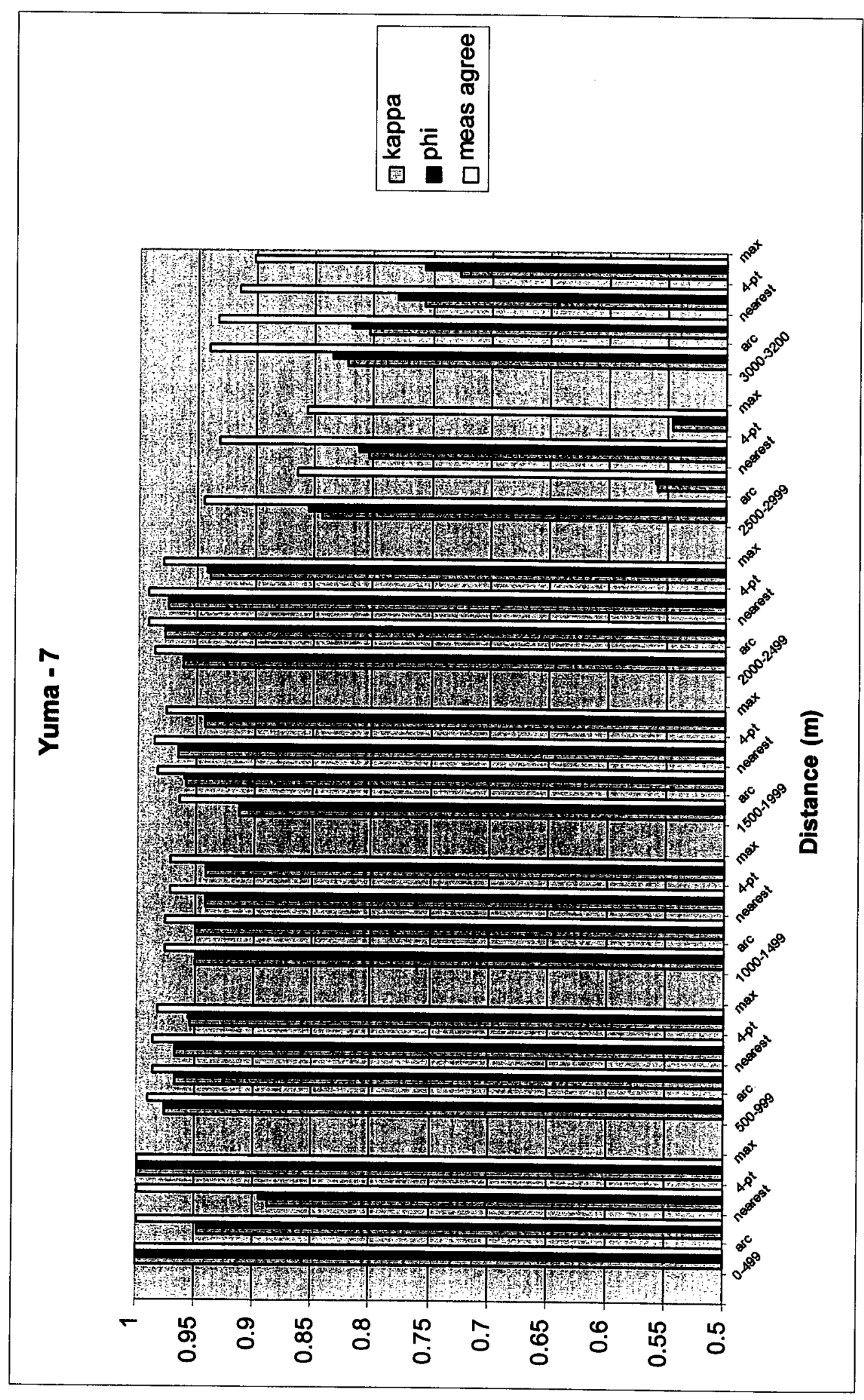




\begin{tabular}{|c|c|c|c|c|}
\hline \multirow{5}{*}{$\begin{array}{l}\text { Yuma - 8 } \\
0-499\end{array}$} & Interpolation & Kappa & Phi & $\mathbf{M o A}$ \\
\hline & ARC/Info & 0.879 & 0.879 & 0.994 \\
\hline & Nearest & 0.979 & 0.979 & 0.999 \\
\hline & 4-pt & 0.966 & 0.967 & 0.998 \\
\hline & $\operatorname{Max}$ & 0.937 & 0.938 & 0.997 \\
\hline \multicolumn{5}{|l|}{$500-999$} \\
\hline & ARC/Info & 0.734 & 0.754 & 0.969 \\
\hline & Nearest & 0.884 & 0.885 & 0.989 \\
\hline & 4-pt & 0.916 & 0.920 & 0.993 \\
\hline & $\operatorname{Max}$ & 0.873 & 0.873 & 0.988 \\
\hline \multicolumn{5}{|l|}{$1000-1499$} \\
\hline & ARC/Info & 0.671 & 0.700 & 0.958 \\
\hline & Nearest & 0.908 & 0.911 & 0.991 \\
\hline & 4-pt & 0.952 & 0.952 & 0.996 \\
\hline & $\operatorname{Max}$ & 0.938 & 0.938 & 0.994 \\
\hline \multicolumn{5}{|l|}{$1500-1999$} \\
\hline & ARC/Info & 0.938 & 0.938 & 0.988 \\
\hline & Nearest & 0.941 & 0.941 & 0.988 \\
\hline & 4-pt & 0.937 & 0.938 & 0.988 \\
\hline & $\operatorname{Max}$ & 0.913 & 0.914 & 0.983 \\
\hline \multicolumn{5}{|l|}{$2000-2499$} \\
\hline & ARC/Info & 0.973 & 0.974 & 0.989 \\
\hline & Nearest & 0.970 & 0.970 & 0.987 \\
\hline & 4-pt & 0.975 & 0.975 & 0.989 \\
\hline & $\operatorname{Max}$ & 0.953 & 0.954 & 0.980 \\
\hline \multicolumn{5}{|l|}{$2500-2999$} \\
\hline & ARC/Info & 0.946 & 0.946 & 0.973 \\
\hline & Nearest & 0.942 & 0.942 & 0.971 \\
\hline & 4-pt & 0.945 & 0.945 & 0.972 \\
\hline & $\operatorname{Max}$ & 0.929 & 0.929 & 0.965 \\
\hline \multicolumn{5}{|l|}{$3000-3200$} \\
\hline & ARC/Info & 0.746 & 0.770 & 0.871 \\
\hline & Nearest & 0.742 & 0.765 & 0.870 \\
\hline & 4-pt & 0.738 & 0.761 & 0.868 \\
\hline & Max & 0.727 & 0.749 & 0.862 \\
\hline
\end{tabular}




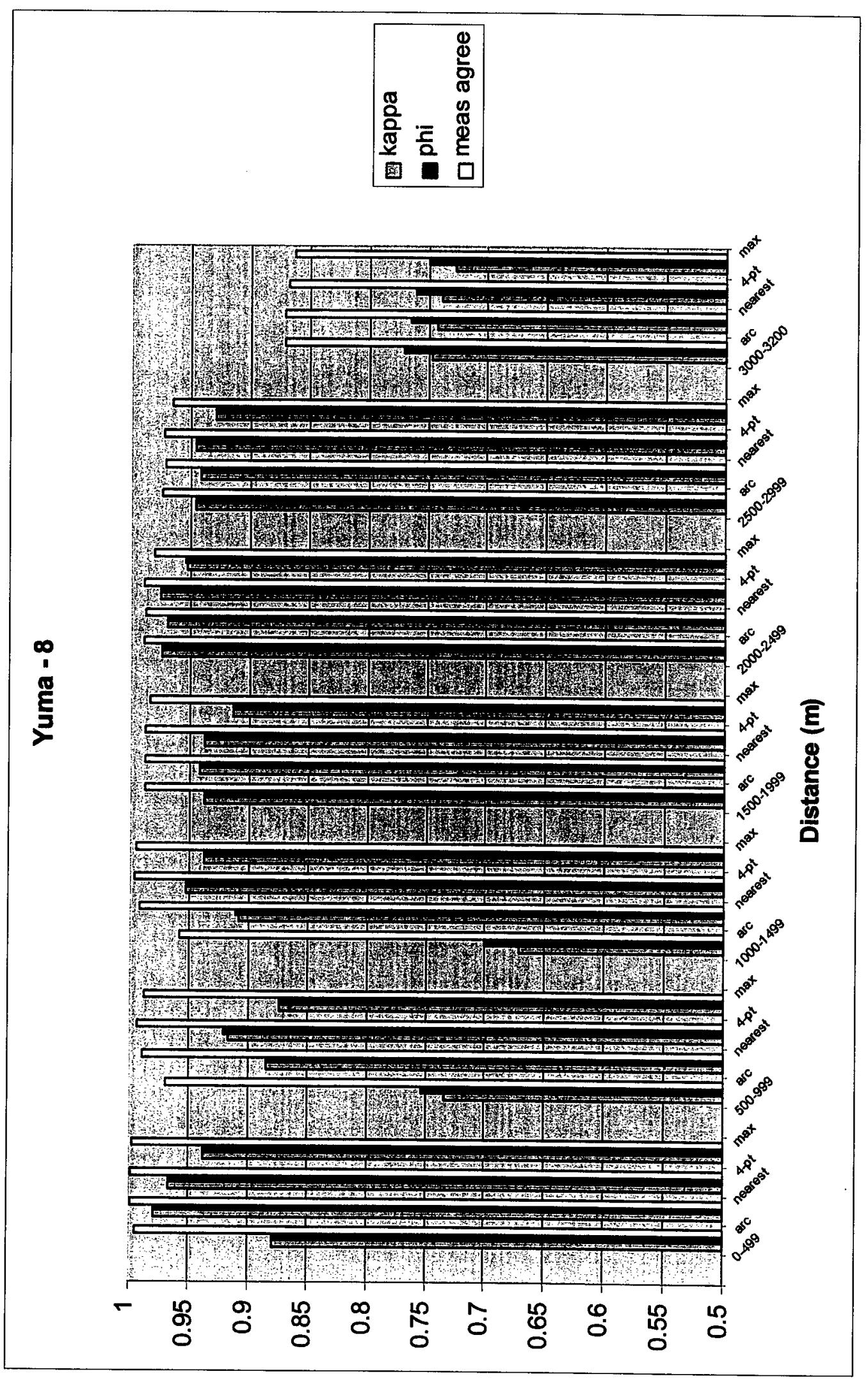




\section{APPENDIX D}

Example Metadata Information

Yuma DEM 
Metadata File for Digital Elevation Data over Yuma Proving Ground

Identification_Information:

Citation:

Citation_Information:

Originator: U.S. Army Topographic Engineering Center

Publication_Date: 19960102

Title: Yuma_5m_gridded_UTM_WGS84

Description:

Geospatial_Data_Presentation_Form: model

Abstract:

A high-resolution, high-accuracy Digital Elevation Model (DEM) covering an area approximately 10- x 9.55-kilometers of Yuma Proving Ground. The elevation 'posts' spaced at 5-meter intervals have been generated to sub-meter

Purpose: vertical accuracy.

To support on-going and future projects over the Yuma Proving Grounds for a variety of missions.

Time_Period_of_Content:

Time_Period_Information:

Single_Date/Time:

Currentness_Reference:

Calendar_Date:

19960102

Date of Fly-Over

Status:

Progress:

Maintenance_and_Update_Frequency:

complete

none planned

Spatial_Domain:

Bounding_Coordinates:

West_Bounding_Coordinate:

East_Bounding_Coordinate:

North_Bounding_Coordinate:

$-114.45678$

South_Bounding_Coordinate:

Keywords:

Theme:

Theme_Keyword_Thesaurus:

none

Theme_Keyword:

Theme_Keyword:

33.15134

33.06752

Theme_Keyword:

High-Resolution Elevation Data

Digital Elevation Model

DEM

Place:

Access_Constraints:

Place_Keyword_Thesaurus: none

Place_Keyword:

AZ

Place_Keyword:

Yuma Proving Ground

Place_Keyword:

Fort Huachucha

Place_Keyword:

Sierra Vista

None

Use_Constraints:

None

Point of Contact:

Contact_Information:

Contact_Organization_Primary:

Contact_Organization: Topographic Engineering Center

Contact_Position: Mr. Robert Atkins, Computer Scientist 
Contact_Address:

Address_Type: mailing and physical address

Address:

7701 Telegraph Road

City:

Alexandria

State_or_Province: VA

Postal_Code:

Country:

22315-3864

Contact_Voice_Telephone:

(703) 428-6505

Contact_Facsimile_Telephone:

(703) 428-6991

Contact_Electronic_Mail_Address: ratkins@tec.army.mil

Hours_of_Service:

0800 - 1700 EST

Data_Quality_Information:

Attribute_Accuracy:

Attribute_Accuracy_Report: see Lineage Process Description

Logical_Consistency_Report: No Logical Consistency information found in documentation.

Completeness_Report: No Completeness information found in documentation

Positional_Accuracy:

Horizontal_Positional_Accuracy:

Horizontal_Positional_Accuracy_Report:

Survey control points using NAD83/91 control tied to 3 NGS HARN points. Control was transferred from the survey control to a base station origin point by using GPS baselines with carrier-phase differential GPS.

Quantitative_Horizontal_Positional_Accuracy_Assessment:

Horizontal_Positional_Accuracy_Value:

Horizontal_Positional_Accuracy_Explanation:

When NAD $8 \overline{3}$ \& WGS84 transformation parameters are implemented the horizontal accuracy of approximately 1.5 meters with regard to WGS84 (absolute) meters. Baseline

Vertical_Positional_Accuracy: accurate to within $+/-3$ centimeters.

Vertical_Positional_Accuracy_Report: see Lineage Process Description

Quantitative_Vertical_Positional_Accuracy_Assessment:

Vertical_Positional_Accuracy_Value: $\quad 1.0$

Lineage:

Vertical_Positional_Accuracy_Explanation: RMSE

Source Information:

Source_Citation:

Citation_Information:

Originator: YPG Survey Branch/Atlantic Technologies

Publication_Date: 19960102

Title:

Aerial photographs

Geospatial_Data_Presentation_Form: view

Type_of_Source_Media: optical aerial photographs 
Source Time_Period_of_Content:

Time Period Information:

Single_Date/Time:

Calendar_Date: 19960102

Source_Currentness_Reference: Date of Fly-Over

Source_Citation_Abbreviation: AIRPHOTO

Source_Contribution: see Lineage Process Description

Process_Step:

Process_Description:

Yuma Proving Ground (YPG) contracted with Atlantic Technologies to create a digital elevation model (DEM) for an area approximately 10- $x$ 9.55-kilometers over the training area. Yuma asked the

Training and Doctrine Command (TRADOC) Analysis Center-White Sands Missile Range (TRAC-WSMR) and the Topographic Engineer Center (TEC) to conduct a LOS analysis of the YPG DEM in order to verify and validate the accuracy of the DEM.

Source_Used_Citation_Abbreviation: AIRPHOTO

Process_Date: 19960102

Spatial_Data_Organization_Information:

Indirect_Spatial_Reference: UTM, WGS84 Bounding Coordinates

Lower Left $\quad 737428,3661649$

Upper Right $\quad 747428,3671199$

Direct Spatial Reference Method:

Raster

Raster_Object_Information:

Raster_Object_Type: Point

Row_Count: 1911

Column_Count: 2001

Spatial_Reference_Information:

Horizontal_Coordinate_System_Definition:

Planar:

Grid_Coordinate_System:

Grid_Coordinate_System_Name: Universal Transverse Mercator

Universal_Transverse_Mercator:

ŪTM_Zone_Number: 11

Transverse_Mercator:

Scale_Factor_at_Central_Meridian: 0.9996

Longitude_of_Central_Meridian: 117.0

Latitude_of_Projection_Origin: $\quad 0.0$

False_Easting:

False_Northing: $\quad 0.0$

Planar_Coordinate_Information:

Planar_Coordinate_Encoding_Method: row and column

Coordinate_Representation:

Abscissa_Resolution: $\quad 5.0$

Ordinate_Resolution: $\quad 5.0$

Geodetic_Model:

Planar_Distance_Ünits: meters

Horizontal_Datum_Name: WGS84

Ellipsoid_Name: WGS84

Semi-Major_Axis: $\quad 6378137$

Denominator_of_Flattening_Ratio: 298.257223563

Vertical_Coordinate_System_Definition: 
Altitude_System_Definition:

Altitude_Datum_Name:

Altitude_Resolution:

mean sea level

Altitude_Distance_Units:

1.0

Altitude_Encoding_Method:

meters

Implicit coordinate

Distribution_Information:

Distributor:

Contact_Information:

Contact_Organization_Primary: Contact_Organization:

Contact_Position:

Contact_Address:

Ms. Janice Johnson, Data Manager

Address_Type:

Address:

mailing and physical address

City: 7701 Telegraph Road

State_or_Province: Alexandria

Postal_Code:

Country:

VA

22315-3864

Contact_Voice_Telephone:

(703) 428-6851

Contact_Facsimile_Telephone:

(703) 428-8176

Contact_Electronic_Mail_Address: jjohnson@tec.army.mil

Hours_of_Service:

$0800-1700$ EST

Resource_Description:

Distribution_Liability:

Standard_Order_Process:

Yuma_5m_gridded_UTM_WGS84

Digital_Form:

distributor assumes no liability

Digital_Transfer_Information:

Format_Name: raw, row \& column data

Format_Information_Content:

BIL and HDR are standard format for most Geographic

Information System and Image Processing software packages

File_Decompression_Technique:

Transfer_Size:

Use standard UNIX [de]compression techniques

Digital_Transfer_Option:

Online_Option:

Computer_Contact_Information:

Network Äddress:

Network_Resource_Name:isc.tec.army.mil

Access_Instructions: contact POC's

Offline_Option:

Online_Computer_and_Operating_System: Solaris 2.4

Offline_Media:

8 \& $4 \mathrm{~mm}$ cartridge tape; 3-1/2 \& 5-1/4" floppy disk

Fees:

Recording_Format: UNIX tar \& standard cartridge format

The online copy of the data set (when available electronically)

may be accessed without charge. The offline fee is to be determined. 
APPENDIX E

Example Metadata File

Yuma Fieldwork 
Metadata File for Field Collected Visibility Data at Yuma Proving Ground

Identification_Information:

Citation:

Citation_Information:

Originator: U.S. Army Topographic Engineering Center

Publication_Date: 19960102

Title: Yuma_5m_vector_UTM_WGS84

Description:

Geospatial_Data_Presentation_Form: profile

Abstract:

High-accuracy hand-recorded field data describing "loss" and "gain" visibility information along profiles originating from six observation sites was converted to digital data spreadsheet using Excel 7.0.

Purpose:

To support positioning requirements for Global Positioning System (GPS) tests and evaluations.

Time_Period_of_Content:

Time Period Information:

Single_Date/Time:

Calendar_Date:

19960102

Currentness_Reference:

Date of Field Work

Status:

Progress:

Maintenance_and_Update_Frequency:

complete

none planned

Spatial_Domain:

Bounding_Coordinates:

West_Bounding_Coordinate:

East_Bounding_Coordinate:

$-114.446$

North_Bounding_Coordinate:

$-114.358$

South_Bounding_Coordinate:

33.083

Keywords:

Theme:

Theme_Keyword_Thesaurus:

none

Theme_Keyword:

Theme_Keyword:

Theme_Keyword:

Theme_Keyword:

Theme_Keyword:

Place:

Place_Keyword_Thesaurus:

Place_Keyword:

Place_Keyword:

Place_Keyword:

Place_Keyword:

Place_Keyword:

visibility

line-of-sight

LOS

field-work

survey

none

$\mathrm{AZ}$

Yuma Proving Ground

Fort Huachucha

Sierra Vista

Cibola Test Range

Access_Constraints:

None

Use_Constraints:

None

Point of Contact:

Contact_Information: 


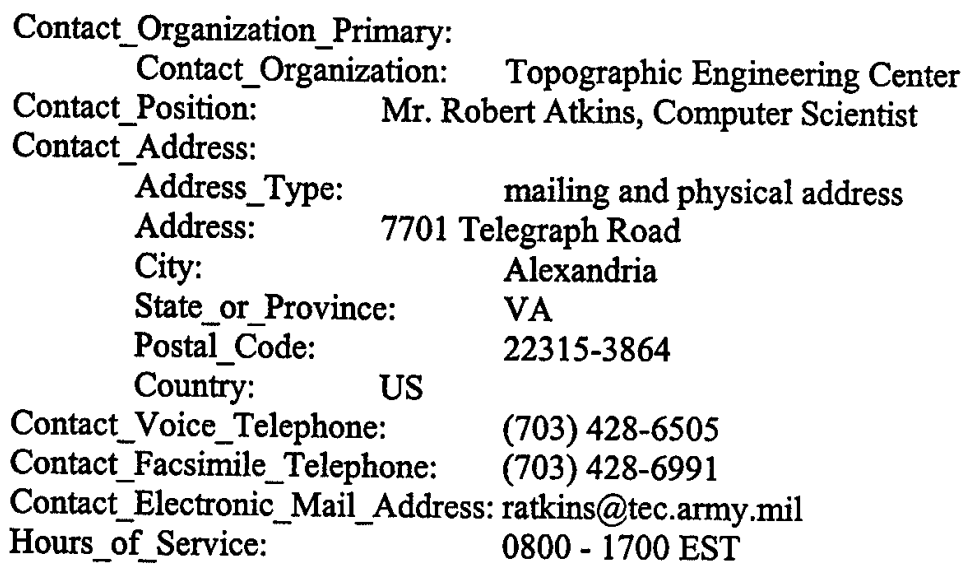

Data_Quality_Information:

Attribute_Accuracy:

Attribute_Accuracy_Report: See Lineage Process Description

Logical_Consistency_Report: No Logical Consistency information found in documentation.

Completeness_Report: No Completeness information found in documentation

Positional_Accuracy:

Horizontal_Positional_Accuracy:

Horizontal_Positional_Accuracy_Report:

Six origin points were established using classical static GPS

observations with 4000 SSE Trimble GPS geodetic receiver system

with post-processing software. Geodetic 3D position were obtained at each position relative to the Cibola Test Range Geodetic Control Network and were adjusted using Trimble GPS vector/terrestrial measurement network adjustment program. See also Lineage Process Description.

Quantitative_Horizontal_Positional_Accuracy_Assessment:

Horizontal_Positional_Accuracy_Value:

Vertical_Positional_Accuracy:

Horizontal_Positional_Accuracy_Explanation: System Accuracy

Vertical_Positional_Accuracy_Report:

See Lineage Process Description.

Lineage:

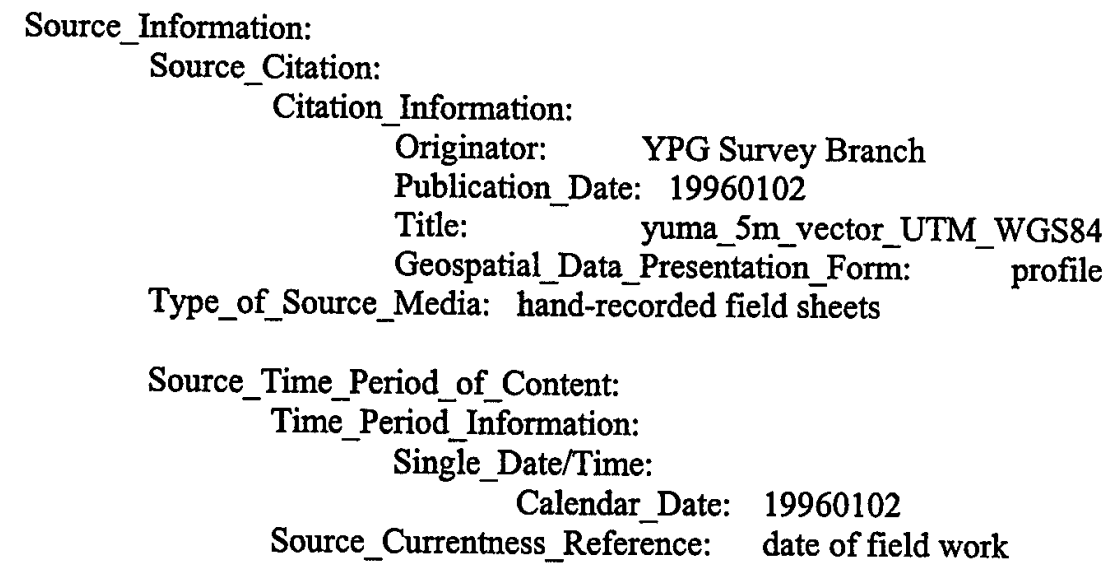


Source_Citation_Abbreviation: SURVEY

Source_Contribution: see Lineage Process Description

Process_Step:

Process_Description:

Yuma Proving Ground (YPG) contracted with Atlantic Technologies to create a digital elevation model (DEM) for an area approximately 10- x 9.55-kilometers over the training area. Yuma asked the Training and Doctrine Command (TRADOC) Analysis Center - White Sands Missile Range (TRAC-WSMR) and the Topographic Engineer Center (TEC) to conduct a LOS analysis of the YPG DEM in order to verify and validate the accuracy of the DEM.

Five sites were selected for the LOS analysis. Azimuths from these five sites were selected in order to cover the entire field of view and to exercise the data. A vehicle drove along each azimuth for $3.2 \mathrm{~km}$ (unless the edge of the DEM was exited or the azimuth crossed an impact area) and LOS gains and losses were recorded. The area covered by these sites cover over half of the DEM and nearly all of the area within the test site.

Geodetic and geoceiver surveys were performed by DMA (NIMA), and personnel at Yuma Proving Ground Arizona to support positioning requirements for Global Positioning System (GPS) tests and evaluation beginning in 1975. Upon completion of these surveys, computations were made to determine adjusted NAD-27 via the NGS Precise Geodimeter Traverse and WGS-72 geodetic coordinates at survey sites in the Cibola Test Range. Additional measurements and re-observations were made through 1996 for control network densification and the TECOM Joint Range Accuracy Improvement and Integration Program. These measurements included astronomic positions, gravity measurements and azimuth determination, EDM observations, measurements of horizontal directions, differential leveling, GPS receiver observations relative to WGS-84 stations and to a local NGS A-Order (VLBI/SLR/GPS) fiducial station. Selected control points in the Cibola and Kofa firing ranges were re-observed during the NGS B-Order HARN Network Projects for Arizona and California.

The geodetic survey performed at YPG and the subsequent adjustment yielded very precise geodetic coordinates for the Cibola Test Range at Yuma Proving Ground. These coordinates provided relative horizontal and vertical positions with accuracies that are representative of the state-of-the-art in geodetic positioning. The standard error of WGS-84 positions in this area with respect to the Earth's center of mass is estimated to be $5.0 \mathrm{~m}$ in each component. The LOS Field Analysis Project used six (6) control or origin points that were established using classical static GPS observations with 4000SSE Trimble GPS geodetic receiver systems with post-processing software. Geodetic 3D positions and orthometric heights, via differential leveling, were obtained at each position relative to the Cibola Test Range Geodetic Control network and were adjusted by least squares using Trimbles GPS vector/terrestrial measurement network adjustment program. The specified horizontal accuracy for the 4000 SSE is $+/-5 \mathrm{~mm}+1 \mathrm{ppm}$ and the specified vertical accuracy is $+/-10 \mathrm{~mm}=1 \mathrm{ppm}$.

The Geotronics Geodimeter 444 Total Station was used at each Control point as the primary instrument for collecting 3D positioning 
data for each loss or gain observed during either the departing or the approaching mission. The Geodimeter $\mathbf{4 4 4}$ total station specified standard distant measurement accuracy is $+/-5 \mathrm{~mm}+5 \mathrm{ppm}$ and in average measurement mode over 10 seconds is $+/-2 \mathrm{~mm}+3 \mathrm{ppm}$. The angle accuracy (DIN 18723) is 1 arc second. The total instrument setup error source at each origin point is estimated to be $1.0 \mathrm{~mm}$ vertically and $1.0 \mathrm{~mm}$ radially. As an example the expected observed horizontal positional accuracy of a measurement made under average atmospheric conditions out to $3200 \mathrm{~m}$ would be $+1-4.0 \mathrm{~cm}$. The expected observed vertical positional accuracy would be $+1-35.0 \mathrm{~cm}$. Note: Masked and unmasked sections of the azimuths of more than 5 meters were identified in the LOS field survey collections.

Source_Used_Citation_Abbreviation: SURVEY

Process_Date: $\quad 19960102$

Spatial_Data_Organization_Information:

Direct_Spatial_Reference_Method:

Vector

Spatial_Reference_Information:

Horizontal_Coordinate_System_Definition:

Planar:

Grid_Coordinate_System:

Grid_Coordinate_System_Name: Universal Transverse Mercator

Universal_Transverse Mercator:

UTTM_Zone_Number: 11

Transverse_Mercator:

Scale_Factor_at_Central_Meridian: 0.9996

Longitude_of_Central_Meridian: 117.0

Latitude_of_Projection_Origin: $\quad 0.0$

False_Easting:

False_Northing:

500000.0

Planar_Coordinate_Information:

0.0

Planar_Coordinate_Encoding_Method: distance and bearing

Distance_and_Bearing_Representation:

Distance_Resolution: 5

Bearing_Resolution: 1

Bearing_Units: Decimal degrees

Bearing_Reference_Direction: north

Bearing_Reference_Meridian: assumed

Geodetic_Model:

Planar_Distance_Units:

meters

Horizontal_Datum_Name: WGS84

Ellipsoid_Name:

WGS84

Semi-Major_Axis:

6378137

Denominator_of_Flattening_Ratio: 298.257223563

Distribution_Information:

Distributor:

Contact_Information:

Contact_Organization_Primary:

Contact_Organization: Topographic Engineering Center

Contact_Position:

Ms. Janice Johnson, Data Manager

Contact_Address:

Address_Type:

Address:

mailing and physical address

City:

7701 Telegraph Road

Alexandria 
Resource_Description:

Distribution_Liability:

Standard_Order_Process:

Digital_Form:

Digital_Transfer_Information:

Format_Name: $\quad \mathrm{CDF}$

Postal_Code: 22315-3864

Country: US

Contact_Voice_Telephone:

Contact_Facsimile_Telephone:

(703) 428-6851

(703) 428-8176

Contact_Electronic_Mail_Address: jjohnson@tec.army.mil

Hours of Service: 0800 - 1700 EST

yuma_5m_vector_UTM_WGS84

distributor assumes no liability

Format_Information_Content: Microsoft Excel Version 7.0

File_Decompression_Technique: none

Transfer_Size:

0.282

Digital_Transfer_Option:

Online_Option:

Computer Contact Information:

Network_Address:

Access_Instructions: contact POC's

Offline_Option:

Online_Computer_and_Operating_System: Solaris 2.4

Offline_Media:

8 \& $4 \mathrm{~mm}$ cartridge tape; 3-1/2 \& 5-1/4" floppy disk

Recording_Format: UNIX tar \& standard cartridge format

Fees:

The online copy of the data set (when available electronically)

may be accessed without charge. The offline fee is to be determined.

Metadata_Reference_Information:

Metadata_Date:

Metadata_Contact:

19970401

Contact_Information:

Contact_Organization_Primary:

Contact_Organization: Topographic Engineering Center

Contact_Position:

Ms. Joni Jarrett, Physical Scientist

Contact_Address:

Address_Type: mailing and physical address

Address:

7701 Telegraph Road

City:

Alexandria

State_or_Province: VA

Postal_Code:

22315-3864

Country:

US

Contact_Voice_Telephone:

(703) $428-6840$

Contact_Facsimile_Telephone:

(703) 428-8176

Contact_Electronic_Mail_Address: jarrett@tec.army.mil

Hours_of_Service: 0800 - 1700 EST

Metadata_Standard_Name: FGDC Content Standards for Digital Geospatial Metadata Metadata_Standard_Version: June 8, 1994 
APPENDIX $F$

Earth Curvature Error Analysis 

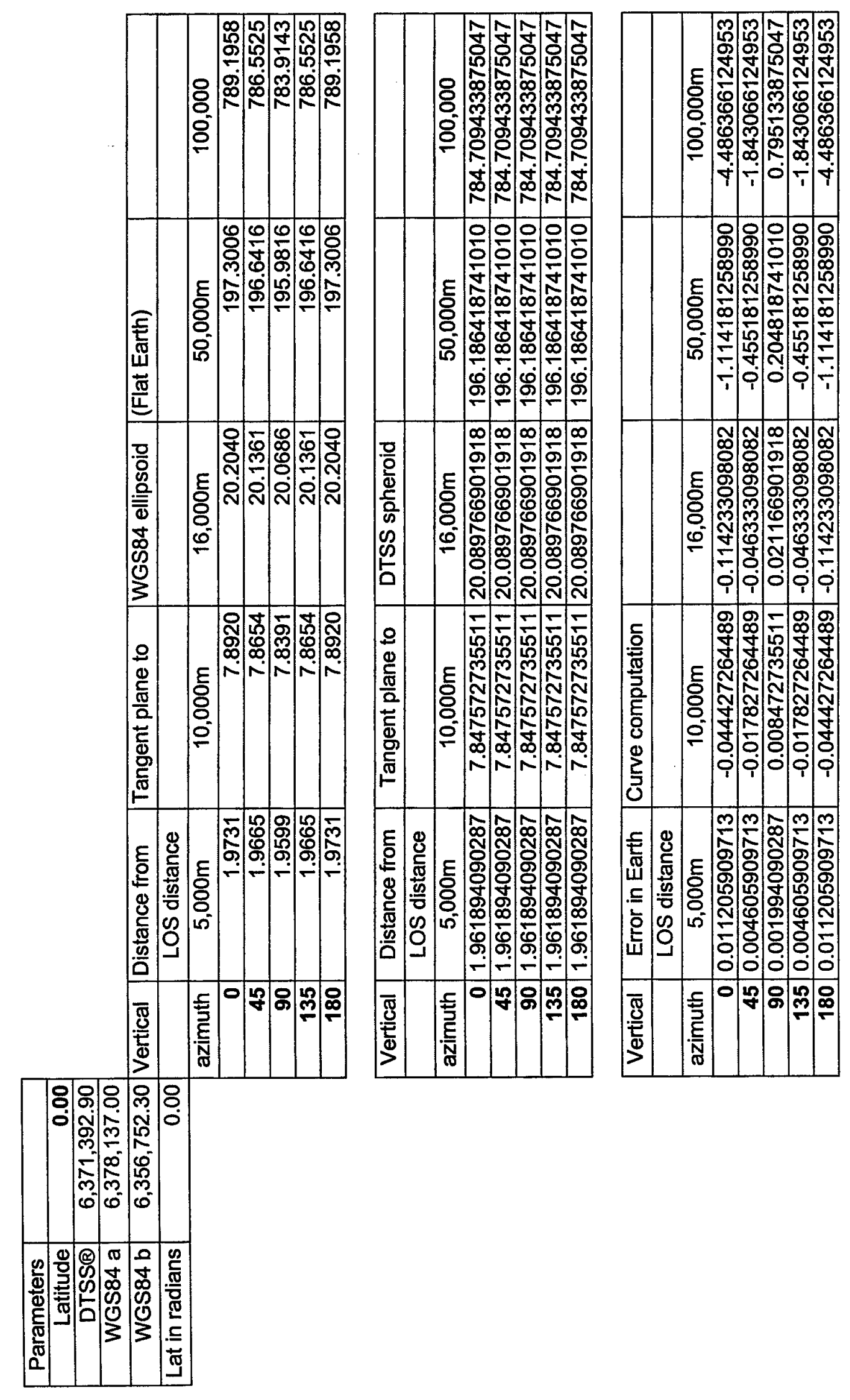

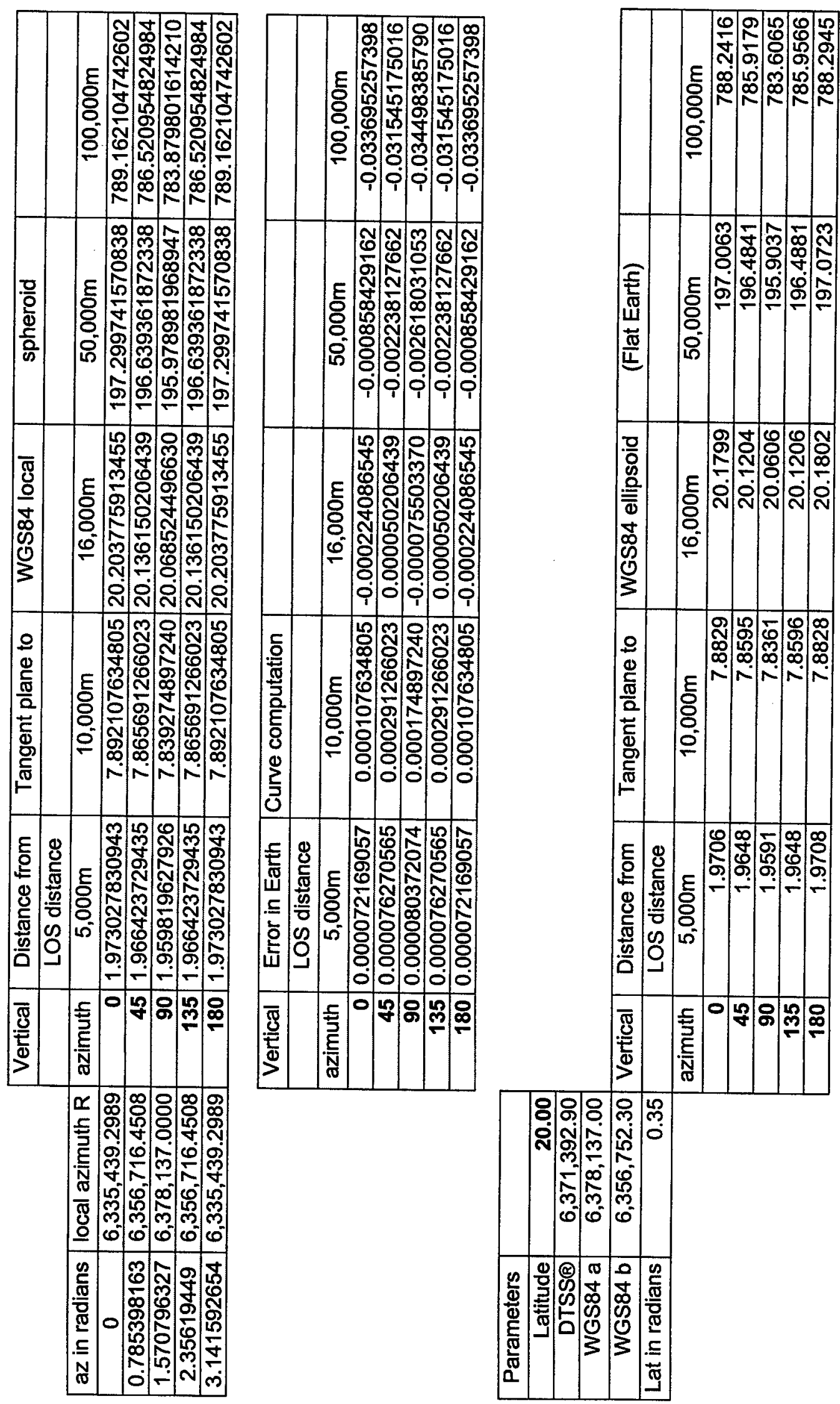

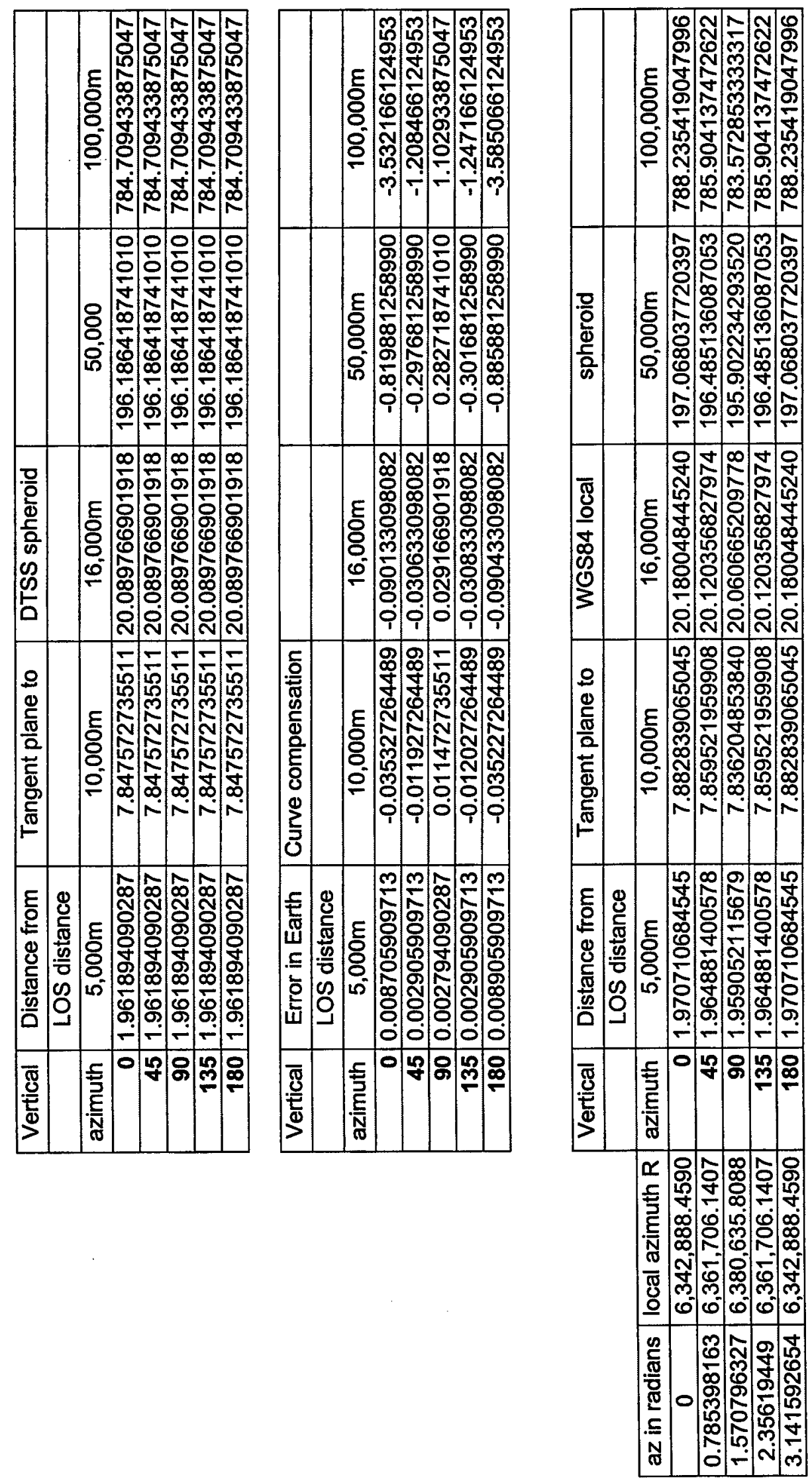

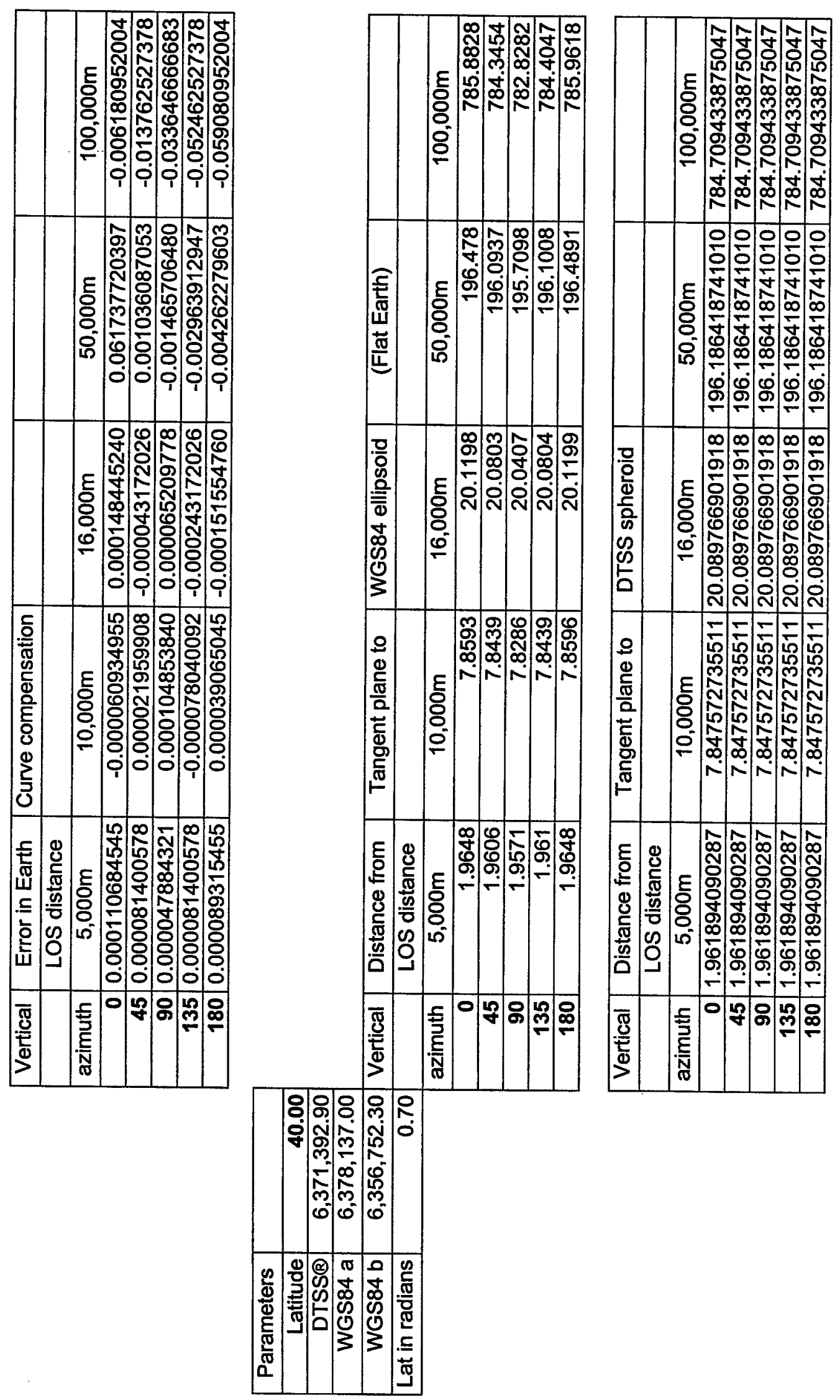

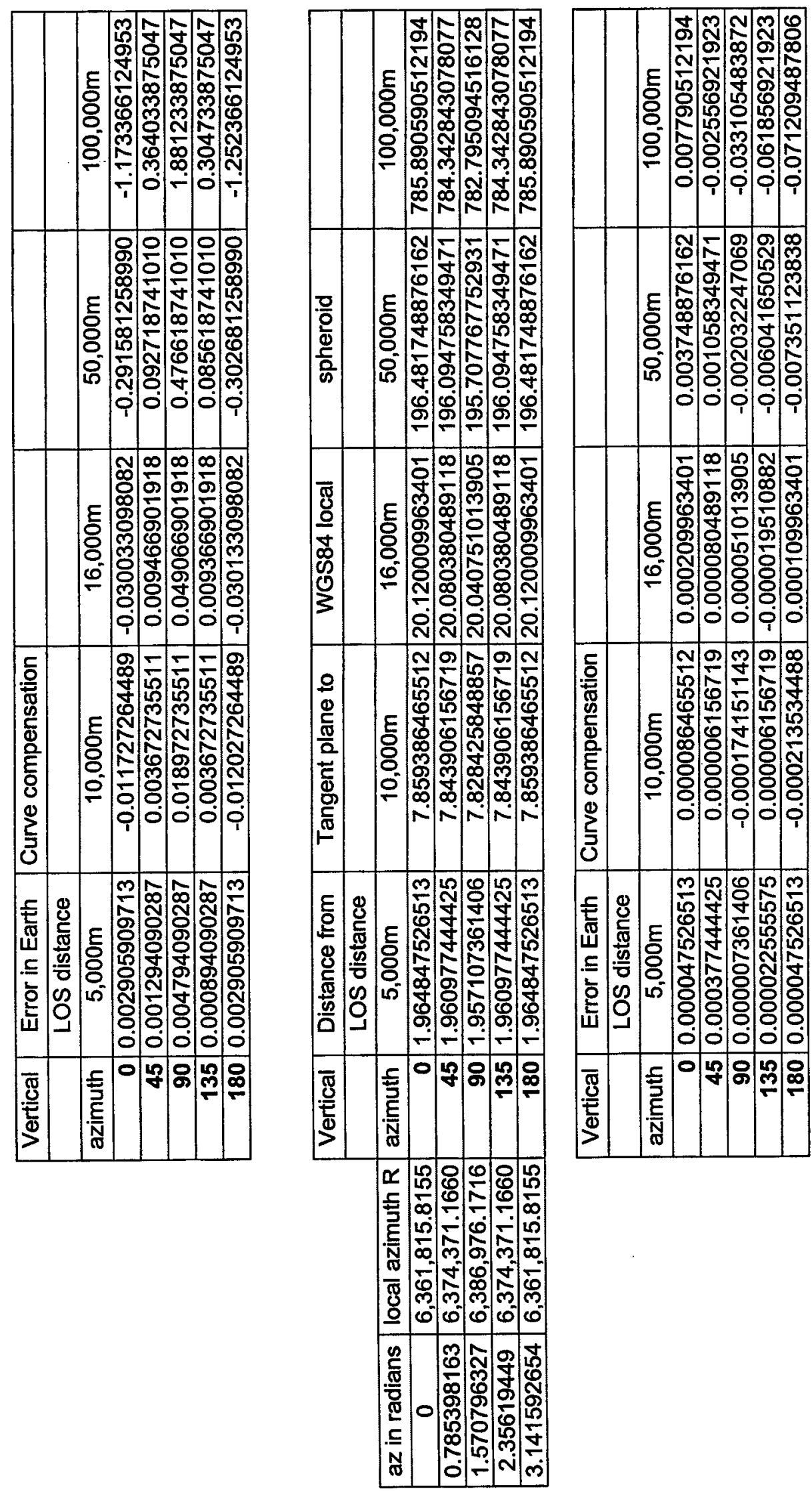


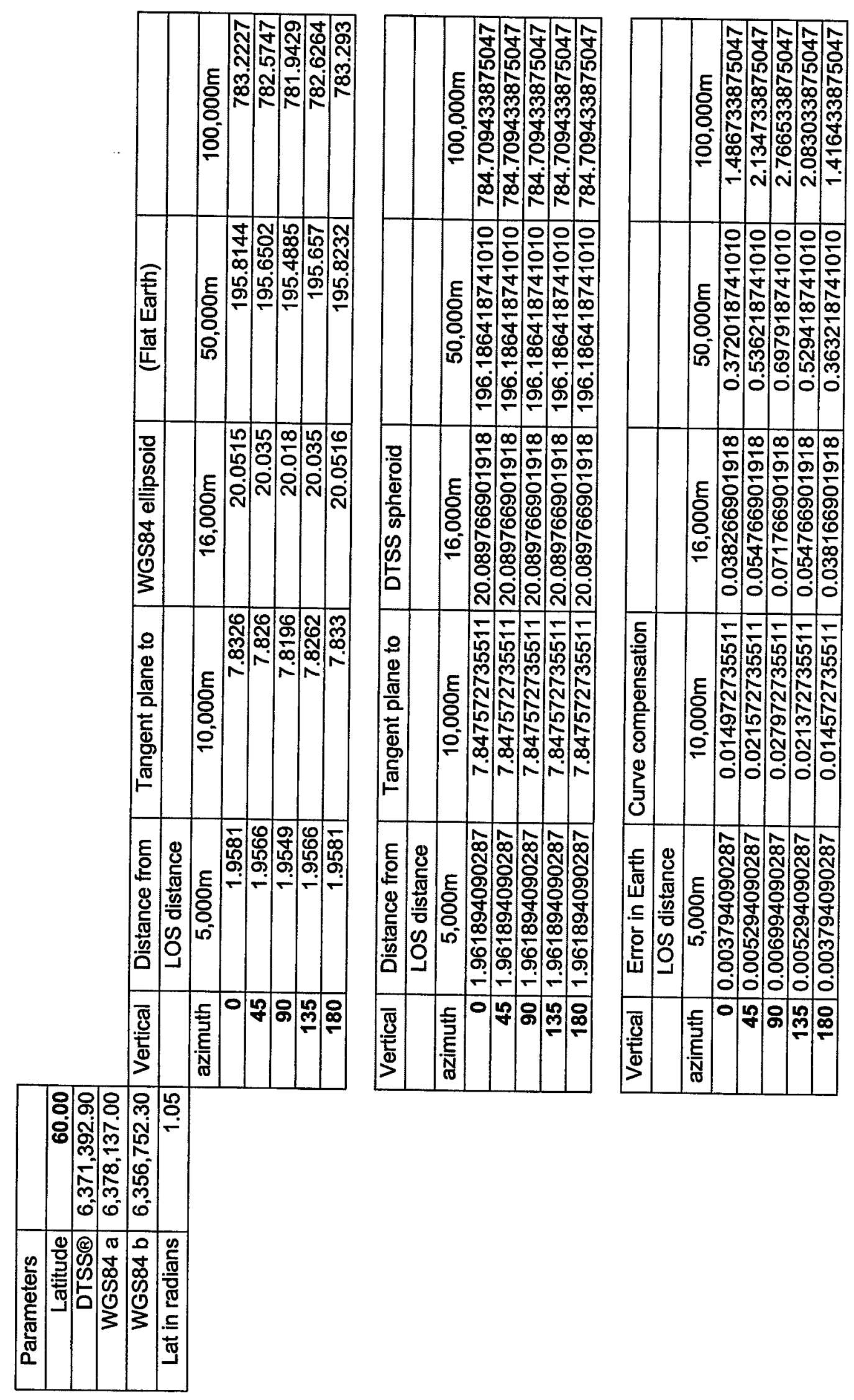



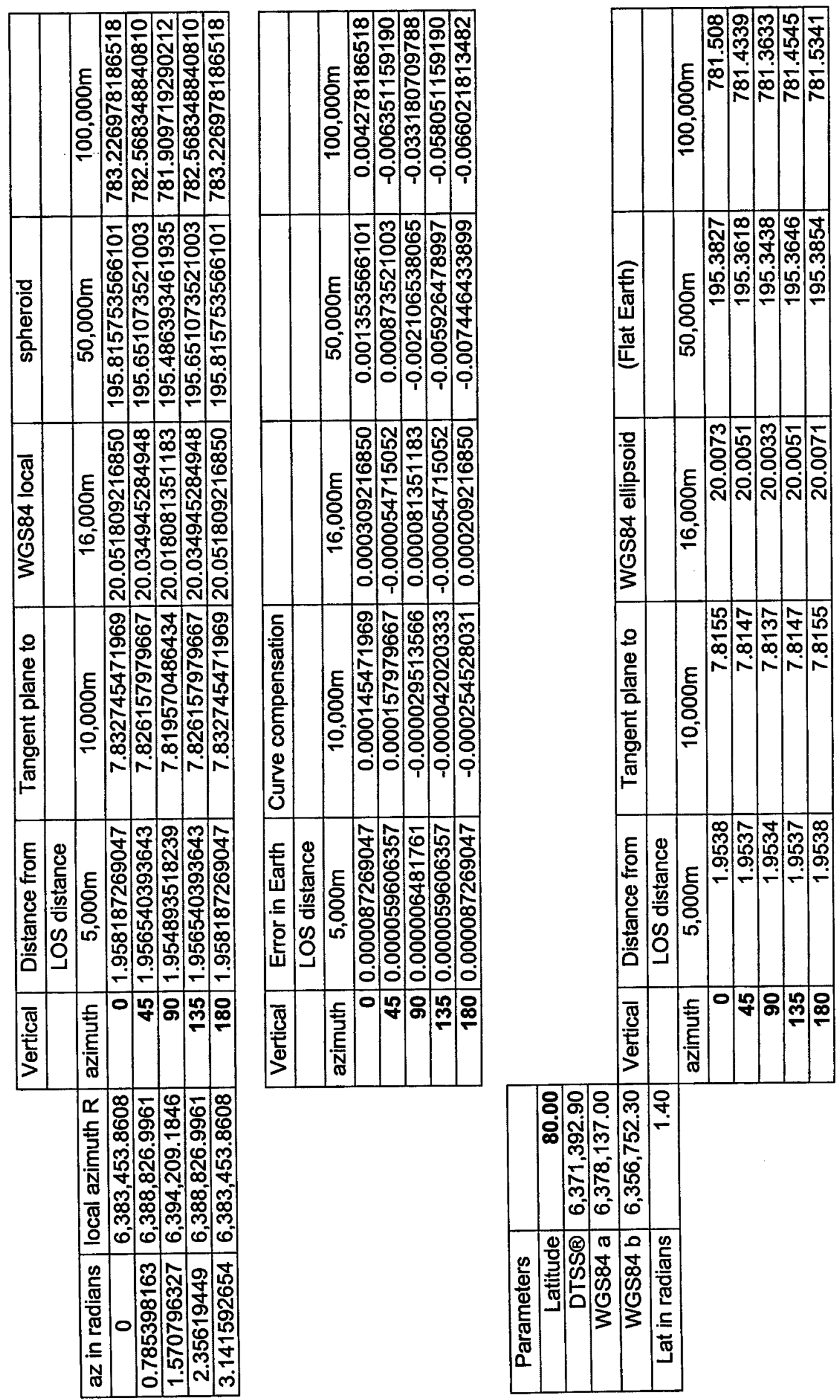

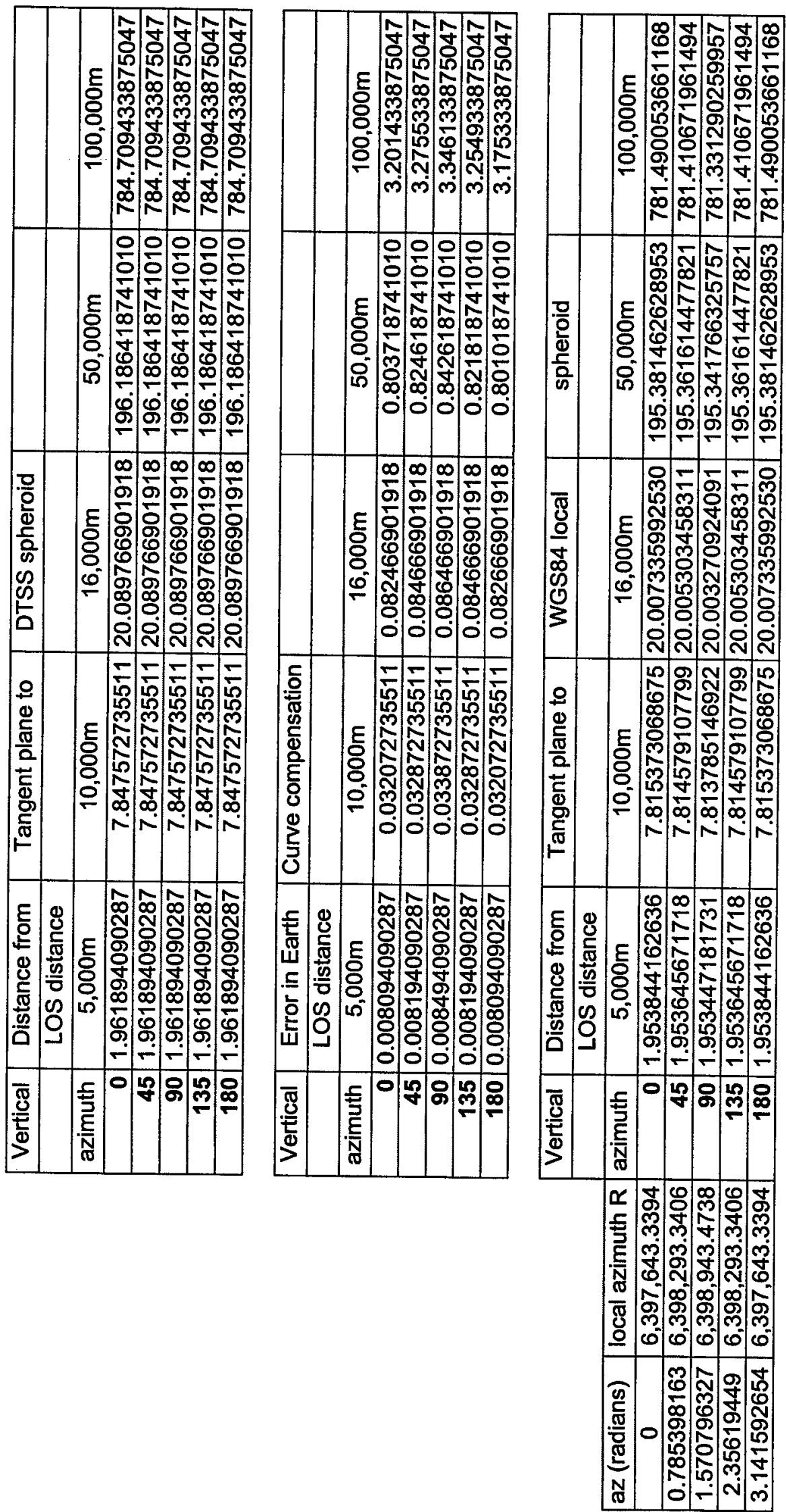


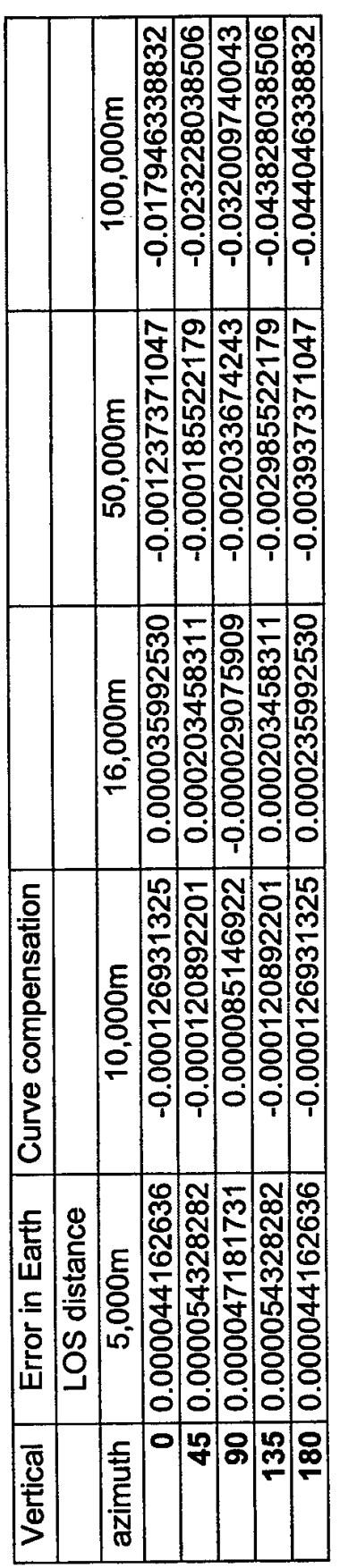


APPENDIX G

Sample Survey Form 
Site Location: (Real World)

Origin Point ID\#:

Site Name:

Site Coordinates: E/Long Site Coordinates: $N / L a t$

Azimuth (from 0 deg North):

Observer Height (m):

Target Height $(\mathrm{m})$ :
Date:

Equipment A (i.e., EDM, PLGR):

Horizontal Datum:

Vertical Datum:

Ellipsoid Name:

Maximum Range (m):

Departing/Approaching (circle one)

Observer slope away from profile azimuth:

Approx. slope at endpoint along azimuth:

Minimum sample size collected along profile:

\begin{tabular}{|c|}
\hline Distance \\
\hline (meters) \\
\hline \\
\hline \\
\hline \\
\hline \\
\hline \\
\hline \\
\hline \\
\hline \\
\hline \\
\hline \\
\hline \\
\hline \\
\hline \\
\hline \\
\hline \\
\hline \\
\hline
\end{tabular}
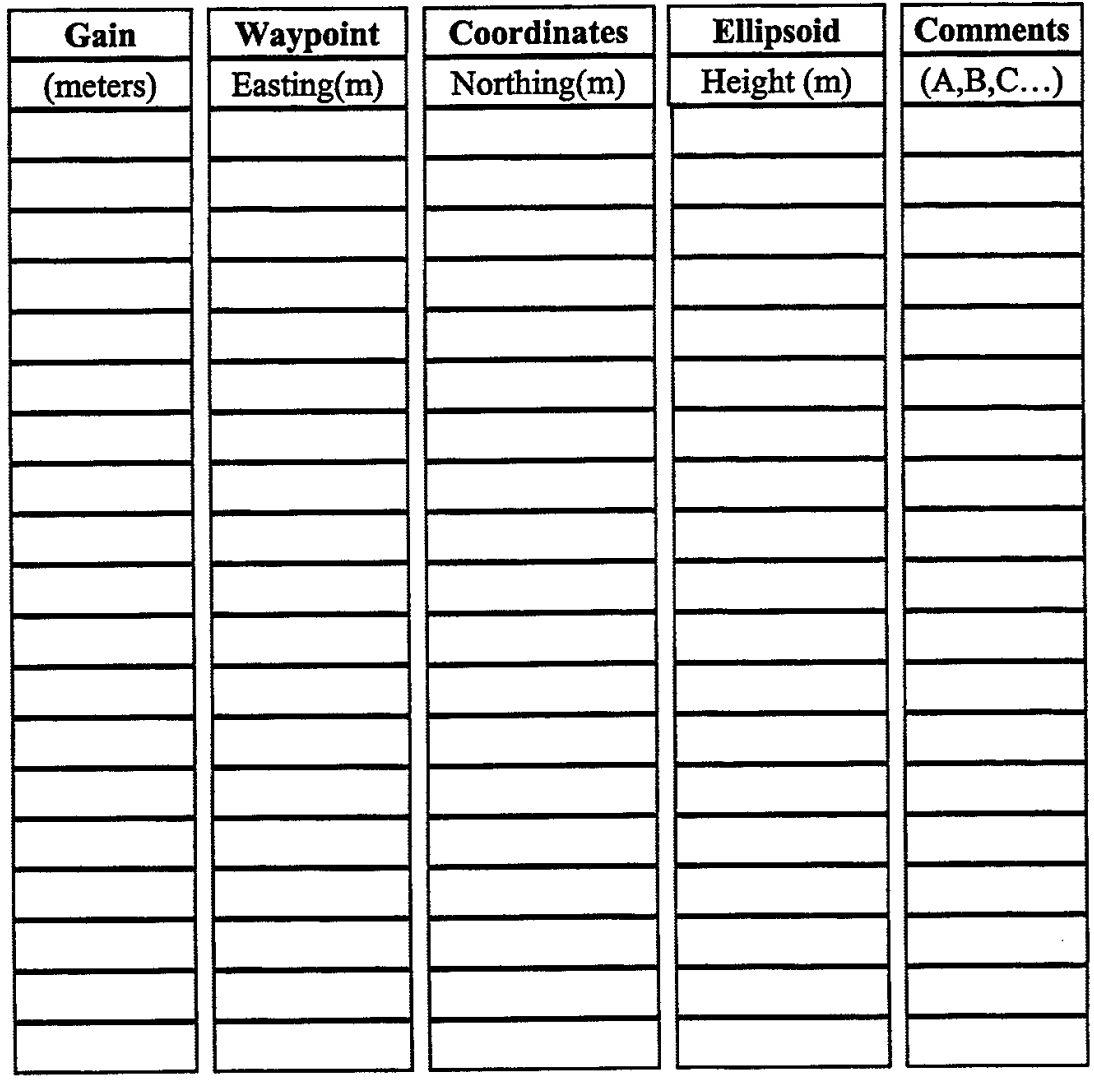


\section{Survey Form Definitions}

Site Location:

Date:

Origin Point ID:

Equipment:

Site Name:

Site Coordinates:

Horizontal Datum, Vertical Datum and Ellipsoid Name:

Azimuth:

Maximum Range:

Observers Height:

Target Height:

Departing/Approaching:
String describing unique spot on the globe.

Date of field collect. mm/dd/yyyy format

Alphanumeric description of a specific location at the site.

Simple descriptive statement of the equipment used, brand name, year, etc., to create metadata on the advantages and limitations of equipment.

Unique string describing the site.

UTM coordinate system or Lat/Long position. Precision must be equivalent to or better than, the data set being used in the computational runs.

Specific information on the Earth model being used to gather information in the field.

In decimal degrees, the angle of the profile from your true North location. Add additional information if True North location is not the 0 degree azimuth.

Maximum distance along profile that information will be collected.

In decimal meters the height of the equipment (eye level) at the origin point.

In decimal meters the height of the target above ground level.

Indication of how the data were collected along the profile. As target moves in toward observer or moves out from observer.

Observer slope away from profile azimuth: The approximate slope in decimal degrees away from observer (i.e., 180 degrees from profile azimuth) taken at least one sample distance away (i.e., DEM grid resolution).

Approx. slope at endpoint along azimuth: The approximate slope in decimal degrees further along the profile taken at least one sample distance away (i.e., DEM grid resolution).

Minimum sample size collected along profile: Indicate the accuracy of the data collected along the profile (e.g., all segments less than $5 \mathrm{~m}$ were discarded from the fieldwork).

Spread sheet information: Record information at each transition point along the azimuth. Distance value is the most critical value when trying to compare computer vs. real-world data. At least $2^{\text {nd }}$ order measurement should be collected, preferably $3^{\text {rd }}$ order, to obtain a good average for the distance. 